\title{
A Climatology of the Middle Atlantic Bight Shelfbreak Front
}

\author{
by \\ Christopher Anthony Linder \\ B.S. United States Naval Academy \\ (1994) \\ Submitted in partial fulfillment of the \\ requirements for the degree of

\section{MASTER OF SCIENCE} \\ at the
MASSACHUSETTS INSTITUTE OF TECHNOLOGY
and the

\section{WOODS HOLE OCEANOGRAPHIC INSTITUTION}

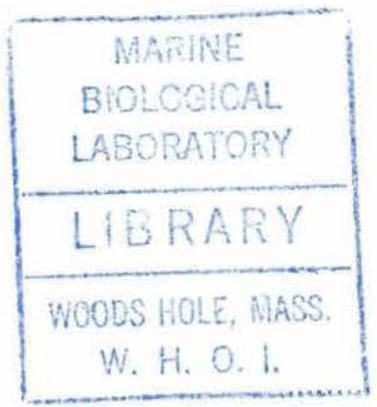

September 1996

C 1996 Christopher Anthony Linder. All rights reserved.

The author hereby grants to MIT and WHOI permission to reproduce and to distribute publicly paper and electronic copies of this thesis document in whole or in part.

Signature of Author.

MIT/WHOI Joint Program in Applied Ocean Science and Engineering

July 15, 1996

Certified by.
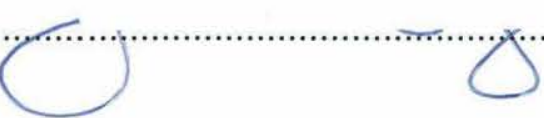

James F. Lynch

Associate Scientist

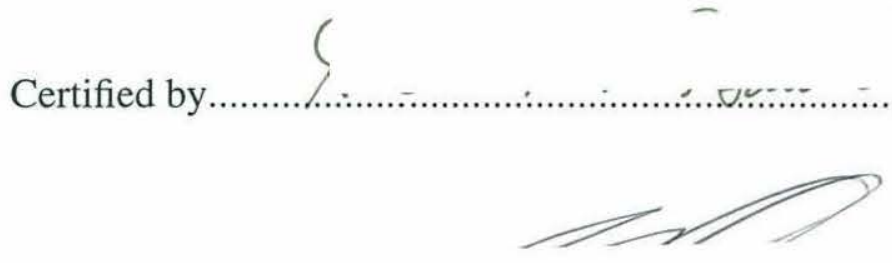

Thesis Supervisor

Accepted by

Henrik Schmidt Acting Chair, Joint Committtee for Applied Ocean Science and Engineering Massachusetts Institute of Technology Woods Hole Oceanographic Institution 


\title{
A Climatology of the Middle Atlantic Bight Shelfbreak Front
}

\author{
by \\ Christopher Anthony Linder \\ Submitted to the MIT/WHOI Joint Program in Applied Ocean Sci- \\ ence and Engineering on July 15, 1996 in partial fulfillment of the \\ requirements for the degree of Master of Science in Applied Ocean \\ Science and Engineering
}

\begin{abstract}
Description of the shelfbreak front in the Middle Atlantic Bight is hampered by the extreme variability of the front. In order to gain more insight into the mean frontal structure and associated baroclinic jet, historical data is used to produce two dimensional climatological fields of temperature and salinity for the region south of Nantucket shoals. Associated cross-shelf fields of density, geostrophic velocity, relative vorticity, and shallow water potential vorticity have also been computed. Historical data from a quality-controlled database (HydroBase) in the region $69-72{ }^{\circ} \mathrm{W}, 39.5-41^{\circ} \mathrm{N}$ is included. Cross-shelf sections are obtained by averaging the data in nine depth bins with an average cross-shelf spacing of $10 \mathrm{~km}$ but an increased resolution of $4 \mathrm{~km}$ near the shelfbreak. The vertical averaging interval was $10 \mathrm{~m}$ over the shelf and upper slope waters, increasing to $50 \mathrm{~m}$ in the deep slope waters. The data were averaged in bimonthly periods to study seasonal trends. For inter-regional comparison, similar analyses were performed for the south flank of Georges Bank and the shelf off New Jersey.
\end{abstract}

The climatological temperature and salinity are consistent with previous descriptions of the frontal hydrography (e.g. Wright [1976], Beardsley and Flagg [1976], and Flagg [1987]). Most importantly, features such as the "cold pool", the upper slope pycnostad, and the frontal boundary are well resolved when compared with synoptic sections. The temperature contrast across the front varies seasonally between $2-6{ }^{\circ} \mathrm{C}$ near the surface and at depths of $45-65 \mathrm{~m}$. The salinity contrast is 1.5-2 PSS, with little seasonal variation. The resulting cross-frontal near surface density gradients are strongest during the winter and weakest during the summer, when the seasonal thermocline is established. The crossfrontal density gradients are stronger near the bottom outcrop of the front, consistent with previous modeling studies [Gawarkiewicz and Chapman, 1992].

Despite the inherent smearing of frontal gradients incurred by averaging over large temporal and spatial scales, the geostrophic velocity field shows a strong $\left(20-30 \mathrm{~cm} \mathrm{~s}^{-1}\right)$ baroclinic jet associated with the cross-frontal density gradients. The core of the jet, having a width of $15-20 \mathrm{~km}$, is located between the $100-120 \mathrm{~m}$ isobaths. The core of the jet is well shoreward of the surface expression of the front, resulting from strong density gradients at the foot of the front. The horizontal velocity shear on the cyclonic, offshore edge of the 
front is roughly $0.2-0.4 * 10^{-4} \mathrm{~s}^{-1}$, with shears on the anticyclonic, offshore edge of the jet being half as large. The potential vorticity structure is drastically affected by the seasonal pycnocline during the summer but remains relatively uniform during the winter months.

Comparisons of the mean fields from Georges Bank, Nantucket Shoals, and New Jersey show that the foot of the front shoals as the flow progresses to the southwest. The seasonal migration of the frontal boundary experiences a phase shift consistent with an alongshelf propagation of minimum salinities to the southwest.

Finally, transport calculations for the flow over the outer shelf and slope give values in the range of $0.1-0.6 \mathrm{~Sv}$ to the west. This is comparable to the estimated transport shoreward of the $100 \mathrm{~m}$ isobath of $0.38 \mathrm{~Sv}$ [Beardsley et al., 1985], which suggests that the shelfbreak frontal jet may be an extremely important element in the alongshelf transport of fresh water in this region.

Thesis Supervisor: Dr. James F. Lynch

Title: Associate Scientist, Woods Hole Oceanographic Institution

Thesis Supervisor: Dr. Glen G. Gawarkiewicz

Title: Associate Scientist, Woods Hole Oceanographic Institution 


\section{Acknowledgements}

Special thanks are due to Glen Gawarkiewicz and Jim Lynch, my thesis advisers, for their guidance and support. Glen Gawarkiewicz's enthusiastic encouragement is particularly appreciated. I would also like to extend thanks to Dave Chapman and Bob Pickart for valuable discussions regarding this thesis and shelf circulation in general.

Many thanks are due to Rich Signell, who wrote the gridding program and supplied the coastline data used in this thesis. Art Newhall and Rich Pawlowicz also provided much direct and indirect help in producing the figures in this work. Steve Jayne was instrumental in helping with all manner of computer crises, in particular the formatting of this thesis. Lyn Harris's advice, suggestions, and matlab code have also been much appreciated.

Several people have also made this thesis possible through their much needed, but seldom recognized, support. They are: Steve Jayne, Ryan Frazier, Nicole Poulton, Rachel Adams, and my family, Peter, Louise, Ames, and Benny. 


\section{Contents}

$\begin{array}{ll}\text { Abstract } & 3\end{array}$

Acknowledgements $\quad 5$

1 Introduction 15

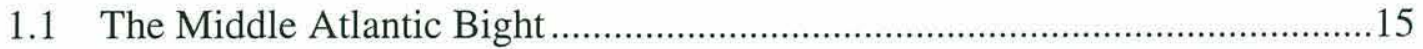

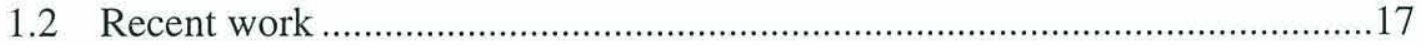

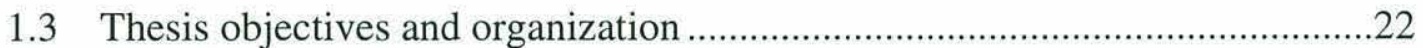

2 Data and Methods $\quad 25$

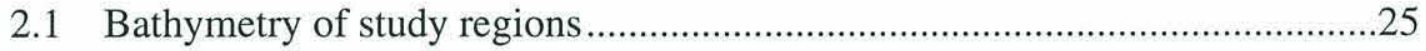

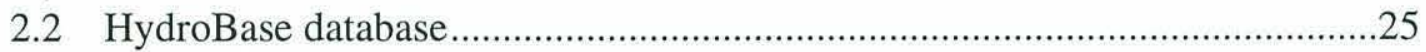

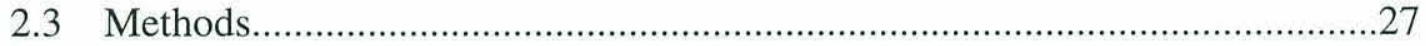

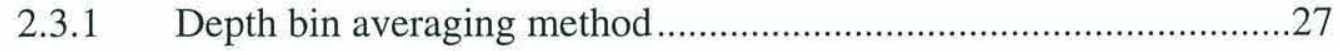

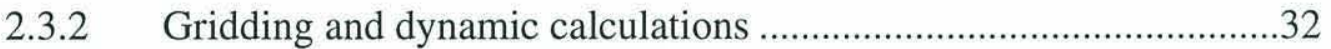

3 Climatological mean fields 35

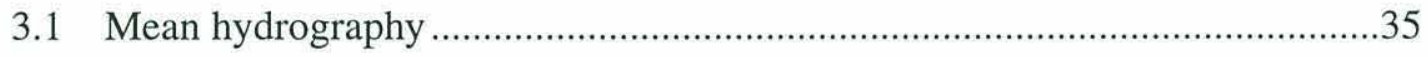

3.1.1 Qualitative thermohaline structure ..............................................35

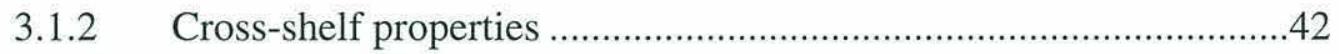

3.2 Mean frontal position and seasonal progression ...........................................50

3.3 Nantucket shoals salinity variability ...........................................................60

4 Dynamics of the mean fields $\quad 69$

4.1 Baroclinic jet temporal and spatial variability .........................................69

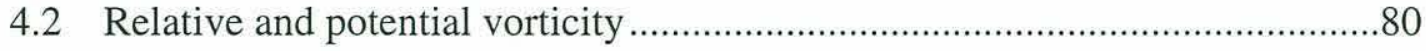

5 Conclusions $\quad 85$ 


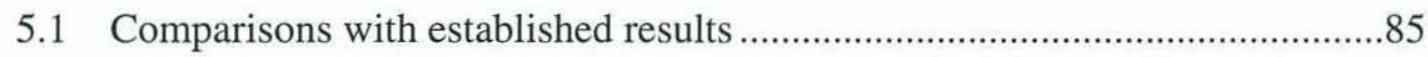

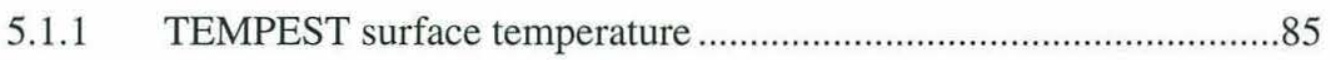

5.1.2 "Synoptic" SEEP thermohaline fields ..........................................86

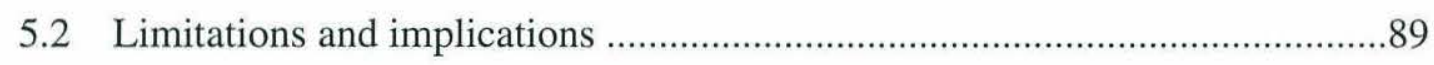

$\begin{array}{ll}\text { References } & 93\end{array}$ 


\section{List of Figures}

1.1: The Middle Atlantic Bight (from Beardsley and Boicourt, 1981) .........................16

1.2: Mean positions of the shelfbreak front and Gulf Stream.......................................17

1.3: Winter and summer hydrographic sections from SEEP-I....................................20

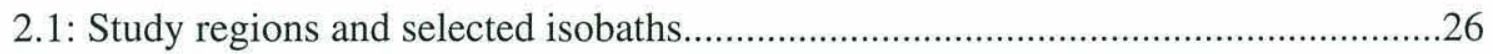

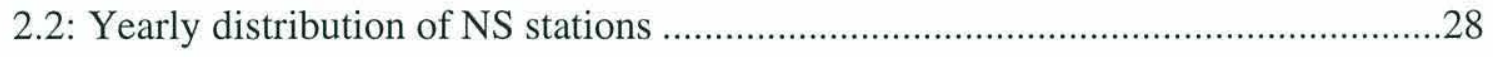

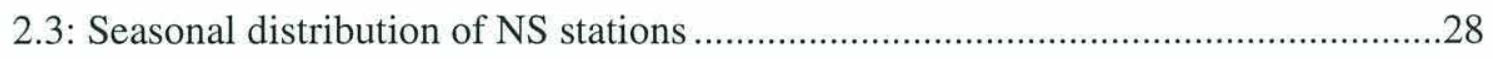

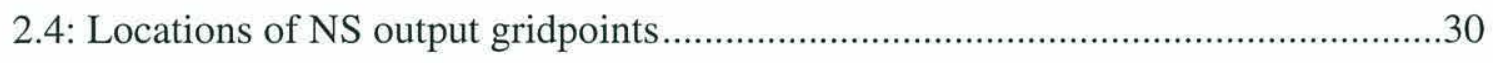

2.5: Cross-shelf and seasonal distribution of NS stations............................................. 31

2.6: NS temperature and salinity standard deviations...................................................31

2.7: NSFE [Beardsley et al., 1983] near-bottom velocities ...........................................34

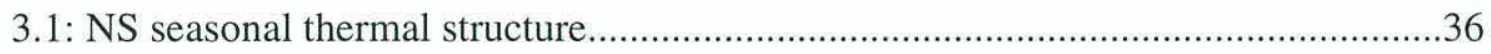

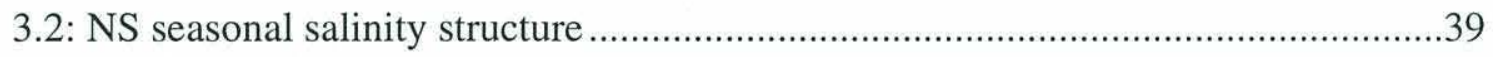

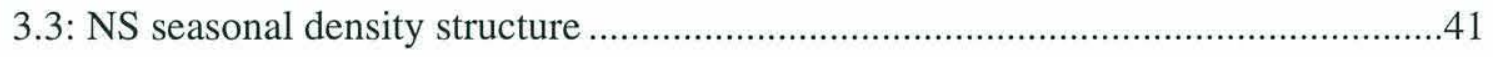

3.4: Depth averaged near surface and intermediate layer NS temperature......................43

3.5: Depth averaged near surface and intermediate layer NS salinity ............................46

3.6: Depth averaged near surface and intermediate layer NS density ............................47

3.7: NS depth averaged cross-shelf density difference ..................................................49

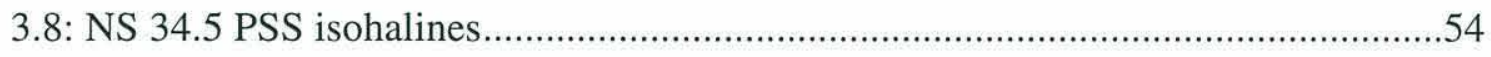

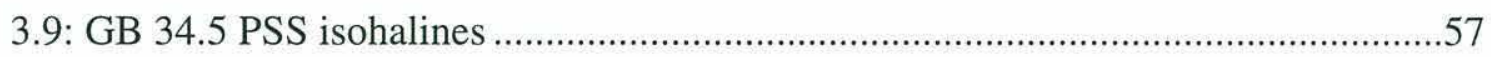

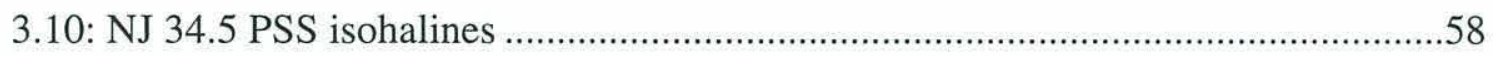

3.11: Inter-regional comparison of the depth of the frontal bottom outcrop ..................59

3.12: (a) Near surface (b) Intermediate layer NS shelf water salinity ...........................61 
3.13: (a) Near surface (b) Intermediate layer NS frontal water salinity

3.14: (a) Near surface (b) Intermediate layer NS slope water salinity.

3.15: Winter/spring NS cross-shelf near surface salinities .......................................65

3.16: Summer/fall NS cross-shelf near surface salinities ...........................................66

4.1: Winter and summer NS geostrophic velocity sections …................................. 71

4.2: Depth averaged near surface and intermediate layer NS geostrophic velocity .......72

4.3: NS geostrophic velocity contributions above the $113 \mathrm{~m}$ isobath.........................73

4.4: Peak surface velocity and location of shelfbreak jet core ....................................75

4.5: Shelfbreak jet width and depth, defined by $\mathrm{V}_{\max } / 2$ contour................................77

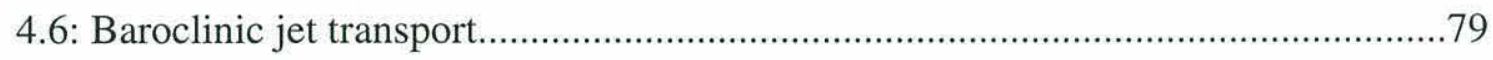

4.7: NS relative vorticity and potential vorticity structure ....................................... 81

4.8: Depth averaged near surface and intermediate layer NS relative vorticity ............82

4.9: Depth averaged near surface and intermediate layer NS potential vorticity ...........84

5.1: Comparison of NS and TEMPEST [Mountain, 1989] temperature.......................87

5.2: Comparison of NS and SEEP II winter temperature and salinity .........................8

5.3: Comparison of NS and SEEP II summer temperature and salinity .......................88 


\section{List of Tables}

3.1: Recent examples of frontal outcrop and slope measurements ..................................51 
For Dad 


\section{Chapter 1}

\section{Introduction}

\subsection{The Middle Atlantic Bight}

The shallow continental shelf region off the eastern United States known as the Middle Atlantic Bight (MAB), shown in Figure 1.1, extends from the Great South Channel in the north to Cape Hatteras in the south. The MAB is a dynamically complex region where fresh, cool continental shelf water interacts with warmer, more saline continental slope water. The sharp transition in both temperature and salinity, which occurs near the shelfbreak, is known as the shelfbreak front. Figure 1.2 shows the average location of the surface expression of the shelfbreak front based on mean satellite sea surface temperature measurements [Drinkwater et al., 1994]. Due to enhanced primary production in the frontal region [Marra et al., 1990], the area is critical to the fishing industry [Manning, 1991]. Also, the MAB's close proximity to major East Coast cities has sparked an interest in the dispersion of pollutants in the MAB and their effect on marine resources. The role of the shelfbreak front in inhibiting or promoting the passage of outflow pipe waste to the deep ocean has provided additional motivation for studying the dynamics of the front [Wright, 1976 and Manning, 1991]. The concern of fishermen, environmentalists, and oceanographers has made the MAB one of the most heavily sampled regions in the world. Beardsley and Boicourt [1981] provide a comprehensive historical description of research efforts in the MAB. 


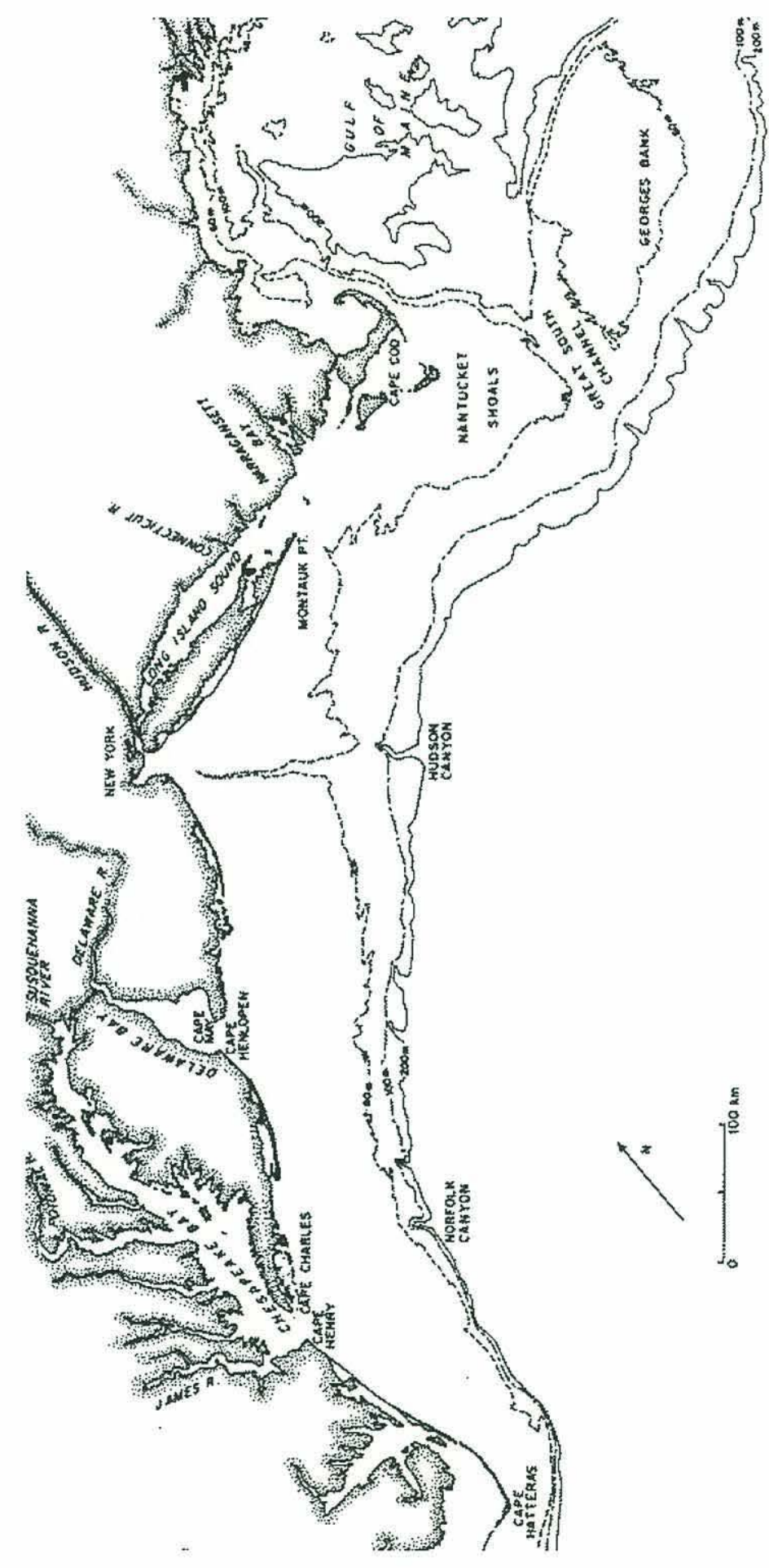

Figure 1.1: The Middle Atlantic Bight (from Beardsley and Boicourt, 1981) 


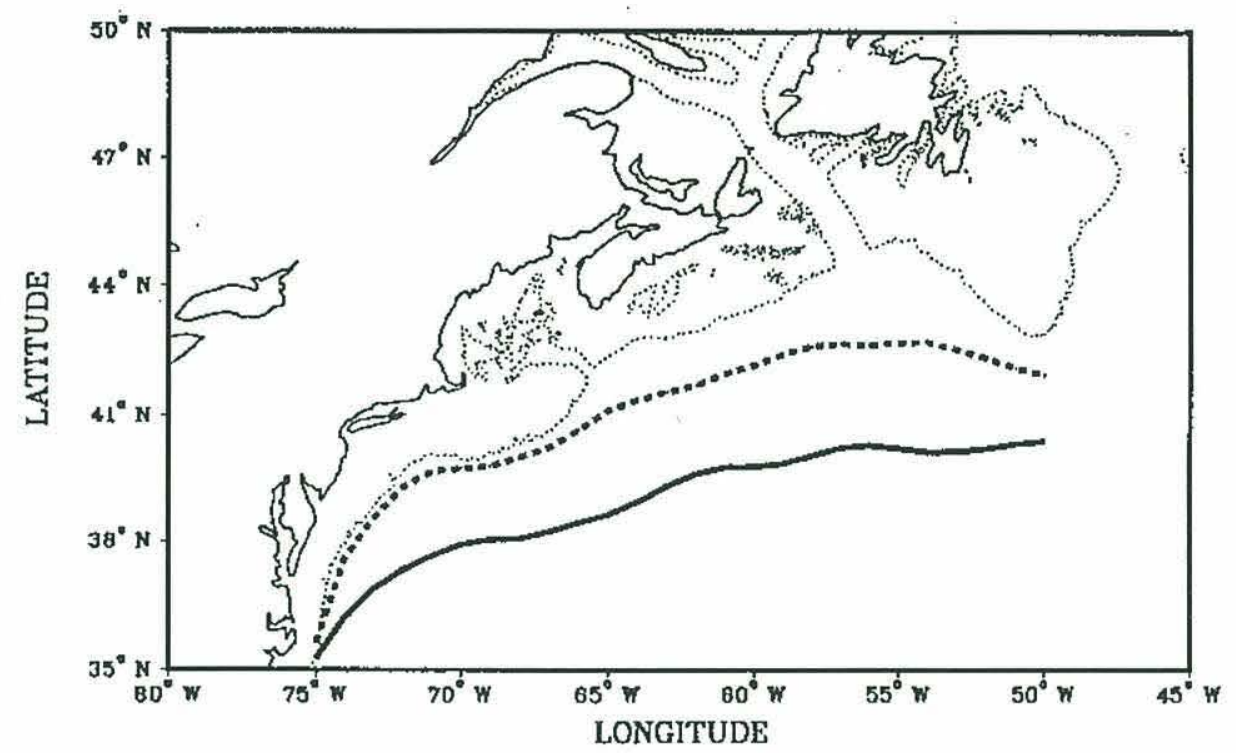

Figure 1.2: Mean positions of the shelfbreak front (dashed) and northern extent of Gulf Stream (solid) (from Drinkwater et al., 1994)

\subsection{Recent work}

By the early 1900s, the transition in temperature from a well-mixed "winter" case to the vertically stratified "summer" case had been observed in the MAB [Bigelow, 1933]. Since then, the major focus of studies in the MAB frontal region has been to characterize this seasonal variability of the hydrography and current structure. In the past few decades, an incredible volume of publications about the MAB has been written. A few key recent observational contributions include: Beardsley and Flagg [1976], Beardsley et al. [1985], Burrage and Garvine [1988], and Houghton et al. [1988]. In addition, Wright [1976] has used a large dataset to examine climatological issues.

Beardsley and Flagg [1976] conducted a field experiment on the New England continental shelf to study the variability of the winter hydrography and currents. They 
analyzed data from a moored current meter array, four hydrographic transects, and meteorological and coastal tide stations. They observed that the water column was nearly vertically homogenized in temperature and salinity during late February and March. The temperature and salinity fronts were collocated during the study, and contributed to a density increase of $0.5 \mathrm{~kg} \mathrm{~m}^{-3}$ moving offshore across the front. They predicted that this density difference, combined with the mean frontal slope of $2.0 \times 10^{-3}$, should have produced a baroclinic shear of $10.0 \mathrm{~cm} \mathrm{~s}^{-1}$ across the front. Although direct current measurements showed a mean westward flow of shelf water parallel to the local topography, the lateral shear of the along-shelf velocity was not well resolved. They also discussed the seasonal progression of the hydrography, showing how the formation of the summer thermocline changes the hydrographic structure.

The Nantucket Shoals Flux Experiment (NSFE79) [Beardsley et al., 1985] was a year long field experiment conducted on the continental shelf south of Nantucket. Six moored current meter arrays were used, spaced between $16-23 \mathrm{~km}$ apart. The goals of the experiment were to study the alongshelf flux of heat, mass, salt, and nutrients over an entire annual cycle and to measure the vertical and cross-shelf current and temperature structure. Beardsley et al. [1985] found that the mean currents over the shelf during both summer and winter were a maximum of $8-12 \mathrm{~cm} \mathrm{~s}^{-1}$ at the surface, oriented westward along the isobaths. The mean westward volume flux over the shelf and shelfbreak (40-120 $\mathrm{m}$ isobaths) was $0.383 \pm 0.069 \mathrm{~Sv}$.

Burrage and Garvine [1988] have studied the summertime hydrography of the MAB shelfbreak front off New Jersey through a series of detailed transects. They discovered that near surface cross-frontal density gradients above the pycnocline were extremely 
weak compared to the foot of the front. Due to measurement aliasing, they concluded that geostrophic calculations for the summertime front were unreliable, and attributed the majority of the alongshelf transport (80\%) to the barotropic component. Surface velocity measurements from drifters revealed shelf surface velocities ranging in strength from 20 $40 \mathrm{~cm} \mathrm{~s}^{-1}$ and slope surface velocities of $10 \mathrm{~cm} \mathrm{~s}^{-1}$. The maximum surface velocity was centered on the 90 and $120 \mathrm{~m}$ isobaths for two different drifter deployments.

A detailed study of the temperature and currents in the New England shelfbreak frontal region was Shelf Edge Exchange Processes I (SEEP-I). The hydrographic observations are summarized by Houghton et al. [1988] and the current meter observations by Aikman et al. [1988]. The primary goals of SEEP-I were to study the motion of the shelfbreak front and the cross-shelf exchange of carbon. Figure 1.3 shows "typical" winter and summer hydrographic sections through the shelfbreak front, taken from two SEEP cruises. It is important to note the sharp seasonal contrast in the temperature and density distributions. In the winter, the shelf and slope regions are vertically well mixed and the density front extends to the surface. In the summer, however, increased solar radiation causes a thermocline to form in the upper 10-30 m of the water column. Beneath the thermocline lies the "cold pool", a remnant of winter water colder than $10{ }^{\circ} \mathrm{C}$, shown clearly in the summer temperature plot in Figure 1.3. Based on the variation of temperature at the foot of the front, Houghton et al. [1988] found that in the winter the front experienced 10-20 $\mathrm{km}$ oscillations about its mean location near the $100 \mathrm{~m}$ isobath. In the summer, the wind stress and frontal oscillations decreased. In addition, the formation of the seasonal pycnocline created an isopycnal connection between the shelf and slope waters which facilitated cross-shelf water parcel exchange. Aikman et al. [1988] concentrated their discussion on the current meter observations. They made several important observations about the mean 
current structure: seasonal changes were minimal, currents were intensified at the surface, and surface currents were greatest above the shelfbreak. All current meters revealed westward flow, generally along the isobaths.

A climatological analysis of the temperature structure of the New England front has been described by Wright [1976]. Wright [1976] analyzed bathythermogram and oceanographic station data in the region $39-41^{\circ} \mathrm{N}, 69-72{ }^{\circ} \mathrm{W}$ from $1941-1972$. Wright [1976] characterized the frontal boundary by the $10{ }^{\circ} \mathrm{C}$ isotherm. He found that the front

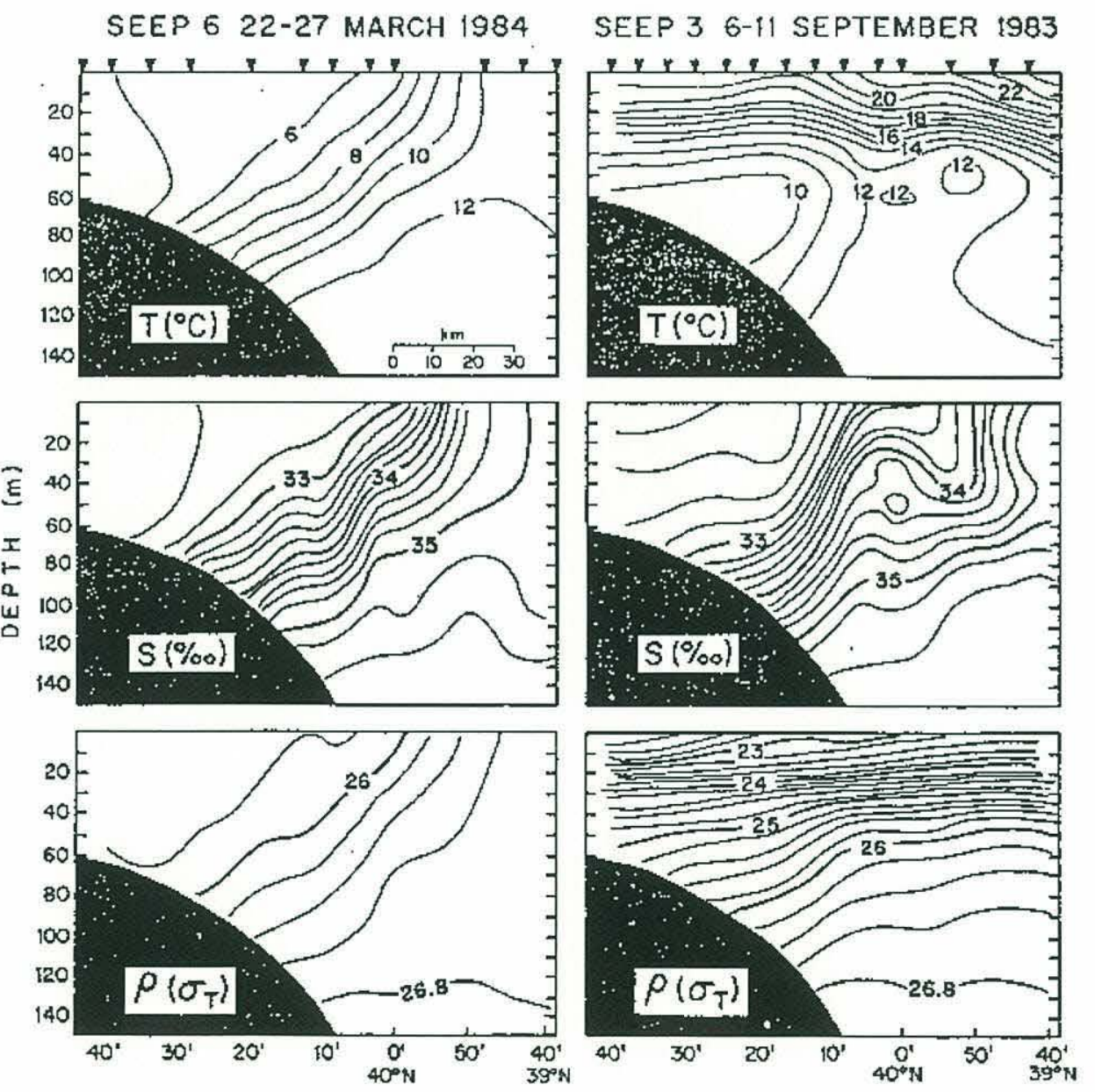

Figure 1.3: Winter (left) and summer (right) hydrographic sections from SEEP-I (courtesy C. Flagg and T. Hopkins, from Houghton et al., 1988) 
intersected the bottom within $16 \mathrm{~km}$ of the $100 \mathrm{~m}$ isobath $80 \%$ of the time. He also observed a northward progression in frontal position during the spring and summer months.

Modelers [Ou, 1983 and 1984, Wang, 1984, and Condie, 1993] have characterized a strong baroclinic jet resulting from the sloping isopycnals in the frontal zone. However, researchers have seldom directly observed this feature [Aikman et al., 1988 and Burrage and Garvine, 1988]. Gawarkiewicz et al. [in press] provides shipboard ADCP measurements of a strong $\left(51 \mathrm{~cm} \mathrm{~s}^{-1}\right)$, narrow (10 km wide) surface jet located above the shelfbreak off New Jersey. Geostrophic velocity calculations from the density field yielded a 55 $\mathrm{cm} \mathrm{s}^{-1}$ jet, indicating the strong baroclinicity of the jet feature. Its small lateral scale explains why it has seldom been well resolved in the past. The transport associated with the jet was calculated to be $0.38 \mathrm{~Sv}$, comparable to the amount calculated by Beardsley et al. [1985] for the shelf shoreward of the $100 \mathrm{~m}$ isobath. This indicates that the jet may be a critical component in the transport of shelf water in the MAB.

Ou [1983 and 1984] studied frontal dynamics through a two dimensional, two layer model. He predicted the formation of two baroclinic jets: one intensified at the surface and the other intensified at the bottom in a region of initially sloping isopycnals. The jets were oriented in opposite directions. The vertical velocity shear tended to diminish in magnitude towards the interior, corresponding to a mid-depth flattening of the isopycnals.

Using a two dimensional prognostic model of a density front, Wang [1984] also found an alongshelf baroclinic jet. The model had a flat bottom (depth of $50 \mathrm{~m}$ ) and a 0.5 $\mathrm{kg} \mathrm{m}^{-3}$ density increase across the front. With these parameters the model produced a steady baroclinic jet with a maximum amplitude of $10 \mathrm{~cm} \mathrm{~s}^{-1}$ occurring at the surface. The 
jet was aligned with lighter water on the right-hand side (looking downstream). This corresponds to a westward jet for the New England shelf region. When a two slope bottom is introduced to simulate the shelfbreak bathymetry, the density field tends to lean out over the slope, with the baroclinic jet located directly above the shelfbreak. The inclusion of bottom friction eliminated the second bottom-trapped jet predicted by $\mathrm{Ou}$ [1984]. These modeling results indicate that the baroclinic jet may contribute a significant portion of the southwestward flow of water through the MAB.

More recently, Condie [1993] has used an analytical, inviscid two dimensional model similar to Ou's [1983] to study the shelfbreak front formation and stability. Condie [1993] assumes that the upper layer fluid originates on the shelf and that a density difference exists between the shelf and slope water. Other assumptions include: negligibly small lower layer velocities and uniform potential vorticity distributions over the shelf and slope. Cross-shelf sections of shallow water potential vorticity computed from the mean fields will show that this assumption may not always be valid. Also, Condie [1993] shows the results of some idealized laboratory experiments. He argued that the mechanisms of potential vorticity conservation and geostrophy were responsible for anchoring the front near the shelfbreak.

\subsection{Thesis objectives and organization}

Climatological analyses are useful in quantifying the first order, "typical" frontal structure. Wright [1976] has produced the most comprehensive climatological picture of the front to date. However, Wright's [1976] data collection was limited to a 31 year period, and was dominated by temperature measurements. The climatology presented in this thesis compiles over 80 years of National Oceanographic Data Center (NODC) hydrographic 
station temperature and salinity data in the New England MAB using a depth bin averaging method. This climatological analysis has been repeated for two other regions, the south flank of Georges Bank and the region offshore of New Jersey, for inter-regional comparisons. Detailed fields of temperature, salinity, and density clearly show the mean cross-shelf seasonal structure of the shelfbreak front hydrography.

Salinity, being a better property than temperature in distinguishing shelf and slope water [Wright and Parker, 1976], is used to trace the seasonal migration of the front in the three regions. A comprehensive salinity analysis is also presented for the Nantucket Shoals subset. Specifically, the monthly mean salinity and standard error of shelf, frontal, and slope waters are shown. The water types have been subdivided based on station echosounder depth (shelf: $40-80 \mathrm{~m}$, frontal: $80-300 \mathrm{~m}$, and slope: $300-2500 \mathrm{~m}$ ). Also, the bimonthly near surface salinity distributions, plotted as a function of cross-shelf distance, are discussed.

The structure of the baroclinic jet at the shelfbreak has been poorly defined due to the coarse horizontal resolution of moored current meter arrays to date and the limited temporal nature of synoptic surveys. This work will define the dimensions, location, and structure of the jet. The narrowness of the jet makes direct observations difficult. The seasonal evolution of the jet and its significance to the mean alongshelf transport through the three MAB regional subsets is also presented. 


\section{Chapter 2}

\section{Data and Methods}

\subsection{Bathymetry of study regions}

The focus of this climatological study is the New England continental shelf south of Nantucket Shoals $\left(39-41^{\circ} \mathrm{N}, 69-72^{\circ} \mathrm{W}\right.$, hereafter referred to as "NS"). The region is convenient for a climatological study because there are few major bathymetric features, the station density is relatively high, and it encompasses almost a quarter of the area of the MAB [Wright, 1976]. The nearly parallel alignment of the isobaths to the lines of latitude also simplified the process of computing an average bathymetric profile. To illustrate inter-regional comparisons, climatological mean fields have also been computed for the south flank of Georges Bank (39.5-41.5 ${ }^{\circ} \mathrm{N}, 65.5-68.5^{\circ} \mathrm{W}$, “GB”) and a section of the MAB east of New Jersey (37-39.5 ${ }^{\circ} \mathrm{N}, 72.5-75.5^{\circ} \mathrm{W}$, “NJ"). These regions and selected isobaths are shown in Figure 2.1.

\subsection{HydroBase database}

Curry's [1996] HydroBase database is the data source for this climatology. HydroBase is a database of hydrographic profiles obtained from the National Oceanographic Data Center (NODC) collected from the early 1900s to April 1990. Currently, 131,635 stations in the Atlantic $\left(0-75^{\circ} \mathrm{N}, 85^{\circ} \mathrm{W}-20^{\circ} \mathrm{E}\right)$ are included in HydroBase. Deep water stations (200 m or greater water depth) were subjected to a vigorous quality control process in which realizations with temperature and salinity characteristics more than 2.3 standard deviations away from the mean were discarded [Curry, 1996]. The extreme variability of coastal hydrography precluded quality control based on standard deviations in shallow 


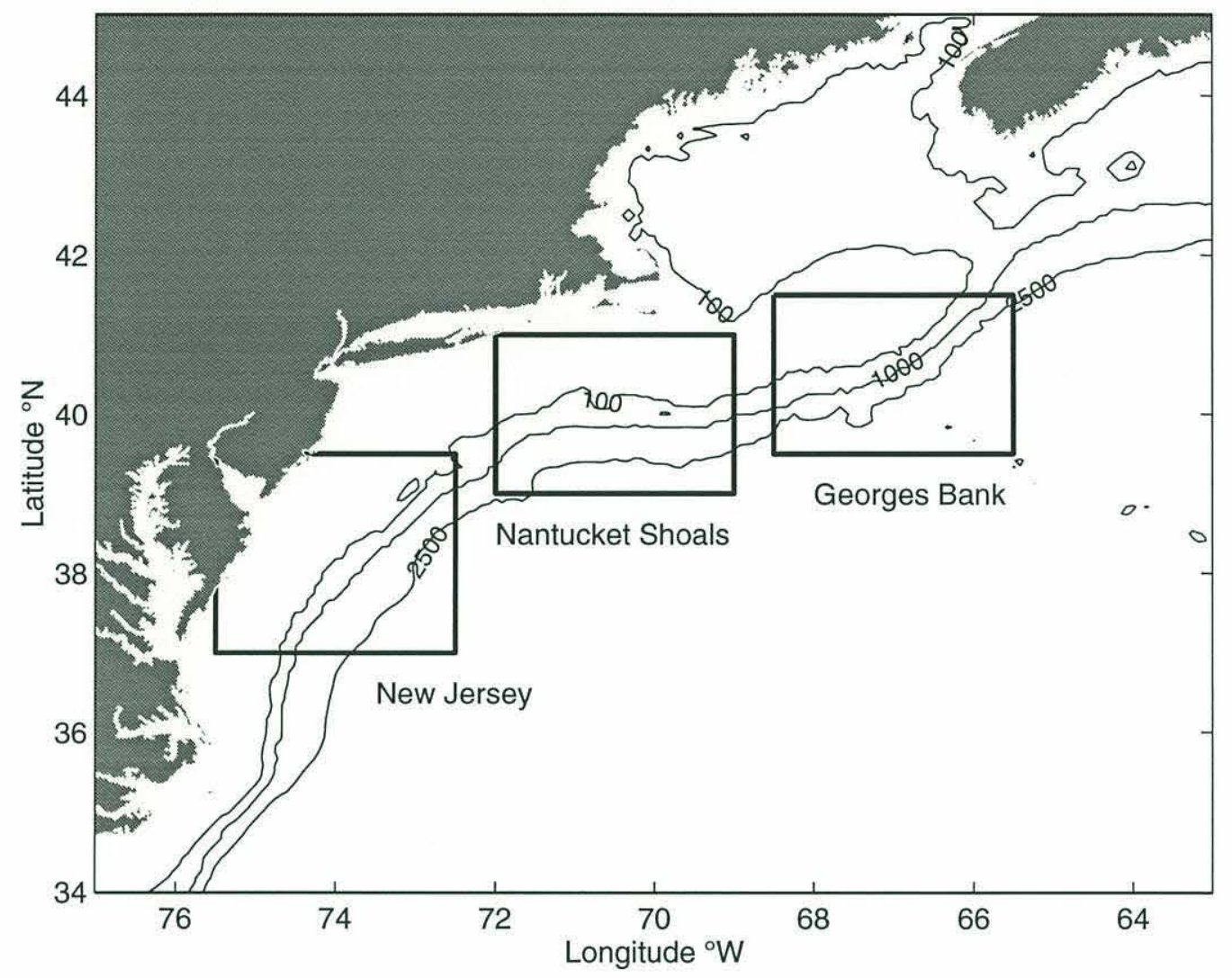

Figure 2.1: Study regions and selected isobaths

( $<200 \mathrm{~m}$ depth) regions. The HydroBase software package, modeled after the GMT-SYSTEM [Wessel and Smith, 1991], also enables the user to extract data from specified regions and perform 3-D gridding and smoothing subject to a wide variety of controls.

Figure 2.2 shows the histogram of HydroBase stations in the NS region plotted by year. A total of 3,240 stations were extracted for NS. This is more than double the hydrographic stations used in the Wright [1976] climatology, although he also included 19,000 bathythermograms measuring only temperature. A significant peak in sampling occurred in 1957, corresponding to the International Geophysical Year (IGY). Since IGY stations 
only represent $\sim 8 \%$ of the total, this year is not expected to bias the climatology. Figure 2.3 shows the seasonal distribution of NS stations. The histogram shows that more NS stations (820) were collected during Aug/Sep, no time period contains less than 400 stations. The station distributions for GB and NJ were both seasonally similar to NS, although smaller in magnitude (2,150 total stations for GB and 2,765 for NJ).

\subsection{Methods}

\subsubsection{Depth bin averaging method}

The HydroBase GRID3D function was initially used [Curry, 1996] to compute three dimensional isopycnally and spatially averaged (see Lozier et al., 1994 for description) fields of temperature and salinity for a variety of grid resolutions. On the shelf, isopycnal averaging is complicated by the presence of the surface mixed layer. Over the slope water, where the number of realizations was low, the fields appeared particularly biased by the presence of a few warm core rings. Spatial averaging was corrupted by the presence of bathymetric irregularities near some grid points, which resulted in shallow (shelf) water stations being averaged with deep (slope) water stations. This created unrealistic smoothing in the frontal region. Therefore, for the small scales and shallow water of the region of interest here, both three dimensional isopycnal averaging and spatial averaging were insufficient for creating a statistically significant mean field.

To maximize the number of contributions to the mean and to avoid averaging water masses with different properties, a depth bin averaging method was implemented. A similar method was used by Pickart [1992] to compare 12 hydrographic sections through the Gulf Stream. Pickart [1992] converted each of the sections to a height above bottom versus bottom depth coordinate system to allow for comparison of sections from different 


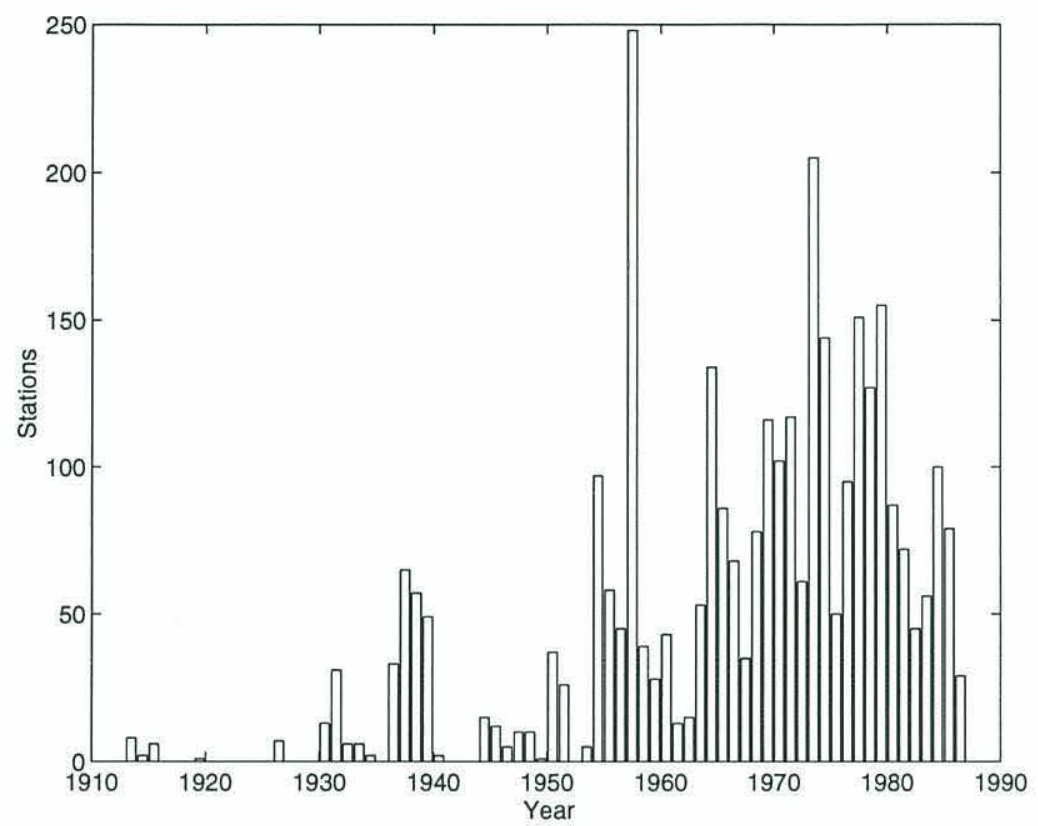

Figure 2.2: Yearly distribution of NS stations

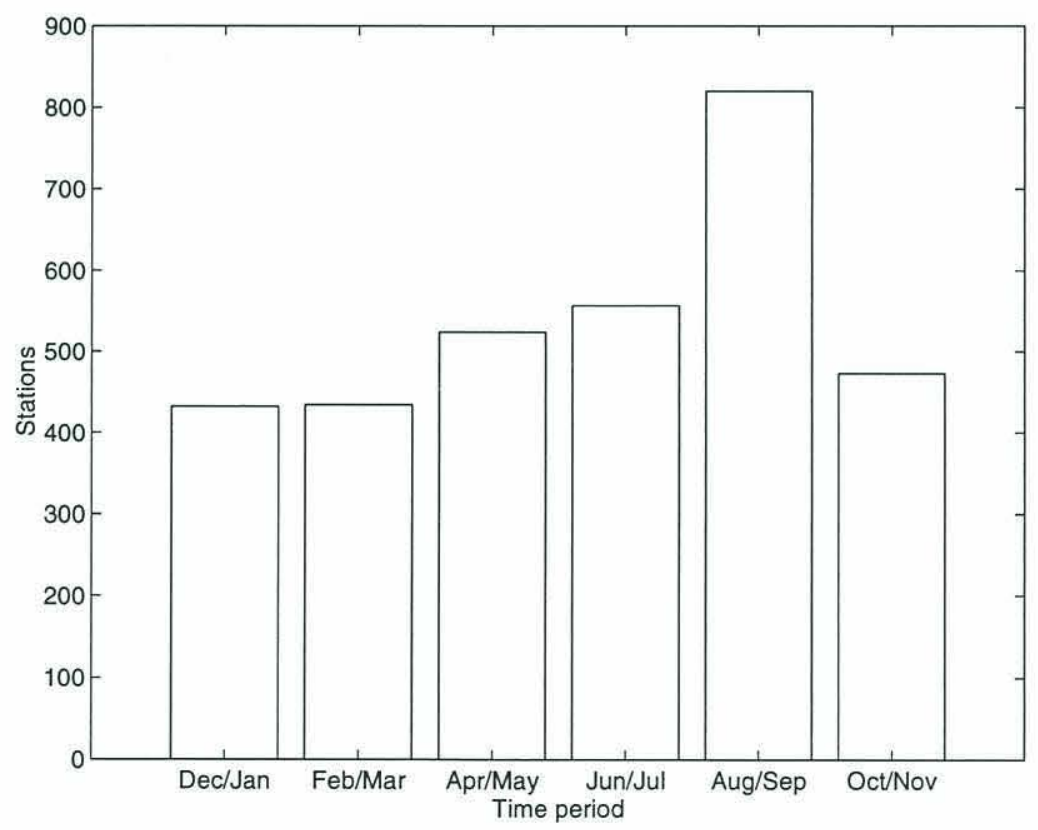

Figure 2.3: Seasonal distribution of NS stations 
hydrographic regions. He then regridded each of the sections onto a regular grid, facilitating easy comparison of the sections from each region. Finally, he computed a mean field by averaging the 12 gridded sections.

Depth bin averaging, using a simple procedure, created a single two dimensional cross-shelf transect of properties based on hydrocasts from a three dimensional ocean volume. First, the NODC data were extracted from HydroBase for the study region using the EXTRACT routine [Curry, 1996]. To include the maximum amount of points while preserving seasonal variations, data were extracted in bimonthly periods beginning with Dec/ Jan, etc. Next, an average bathymetric profile aligned perpendicular to the local isobaths was computed for the region based on ETOPO5 bathymetry data. Then, a set of depth bins in which to segregate the casts was selected. The number and size of the bins were chosen based on the total number of casts per bin and the cross-shelf spacing of the bins. This resulted in a small number of widely spaced bins over the shelf and a concentration of bins near the shelfbreak. This selection allowed for peak cross-shelf resolution near the shelfbreak, where the most interesting dynamic effects typically occur. After selecting the bins, the data were sorted into the bins based on their echosounder depth values. Casts without echosounder depths (roughly 16\% for NS) were discarded. The cross-shelf bins were then segregated further into vertical bins, ranging in size from $10 \mathrm{~m}$ over the shelf and upper slope to $50 \mathrm{~m}$ in the deep slope waters. An arithmetic mean of each vertical bin was then computed. Finally, the mean data were transformed to a cross-shelf distance versus depth profile by assigning a cross-shelf distance to each depth bin. The cross-shelf distances in this climatology were found by linearly interpolating the average bathymetric profile and are all measured in kilometers from the $100 \mathrm{~m}$ isobath, with positive distance denoting the offshore direction. Figure 2.4 shows the location of the averaged points for NS, clearly 
illustrating the concentration of bins near the shelfbreak (4 cross-shelf grid points within $20 \mathrm{~km}$ ). Figure 2.5 shows the cross-shelf distribution of stations for each seasonal period and echosounder depth bin, revealing the high number of stations in the shelfbreak bins. The station density is relatively constant seasonally and spatially, although sampling increased slightly during the summer months. The depth bin method allows a large number of data points to be included (across $3^{\circ}$ longitude for NS) while preserving water mass integrity.

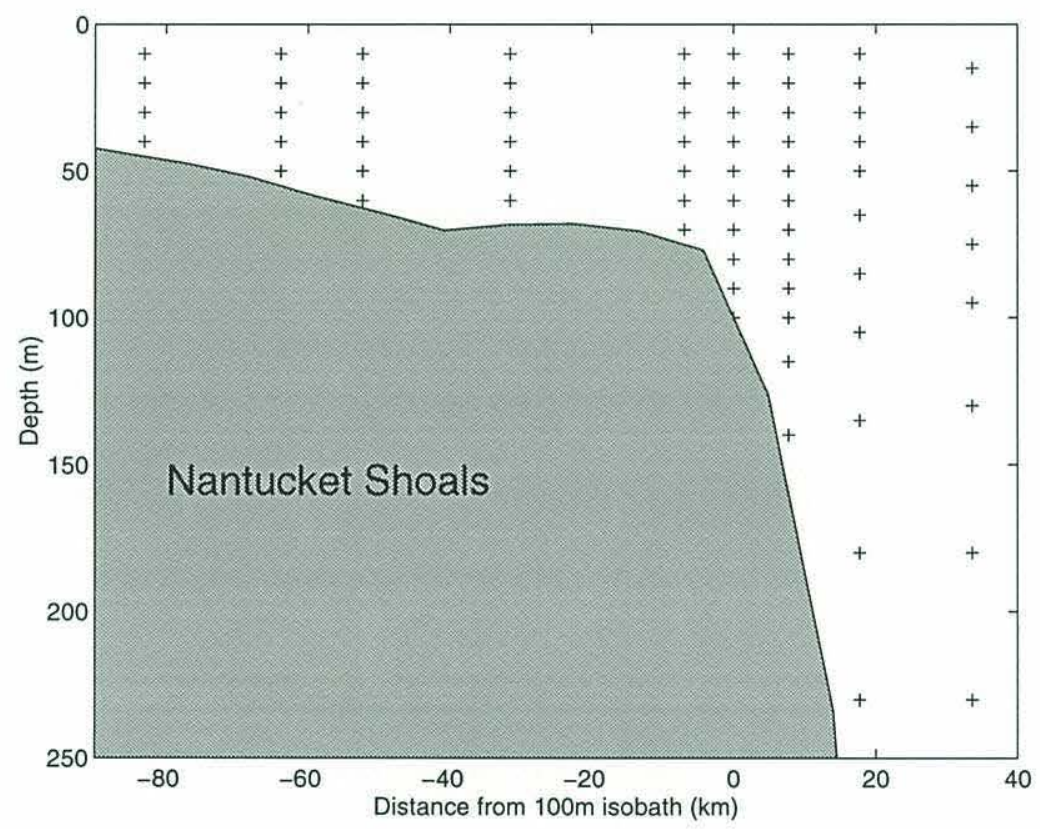

Figure 2.4: Locations of NS output gridpoints

The statistics of the depth bin averaging method, including the standard deviations and standard errors for every grid point, have been computed for GB, NS, and NJ. Figure 2.6 shows the gridded standard deviation for both temperature and salinity for the typical "winter" time period, Feb/Mar, and the typical "summer" time period, Aug/Sep. As expected, temperature is much (more than three times) more variable than salinity. The standard deviations tended to increase offshore, showing the high variability caused by 


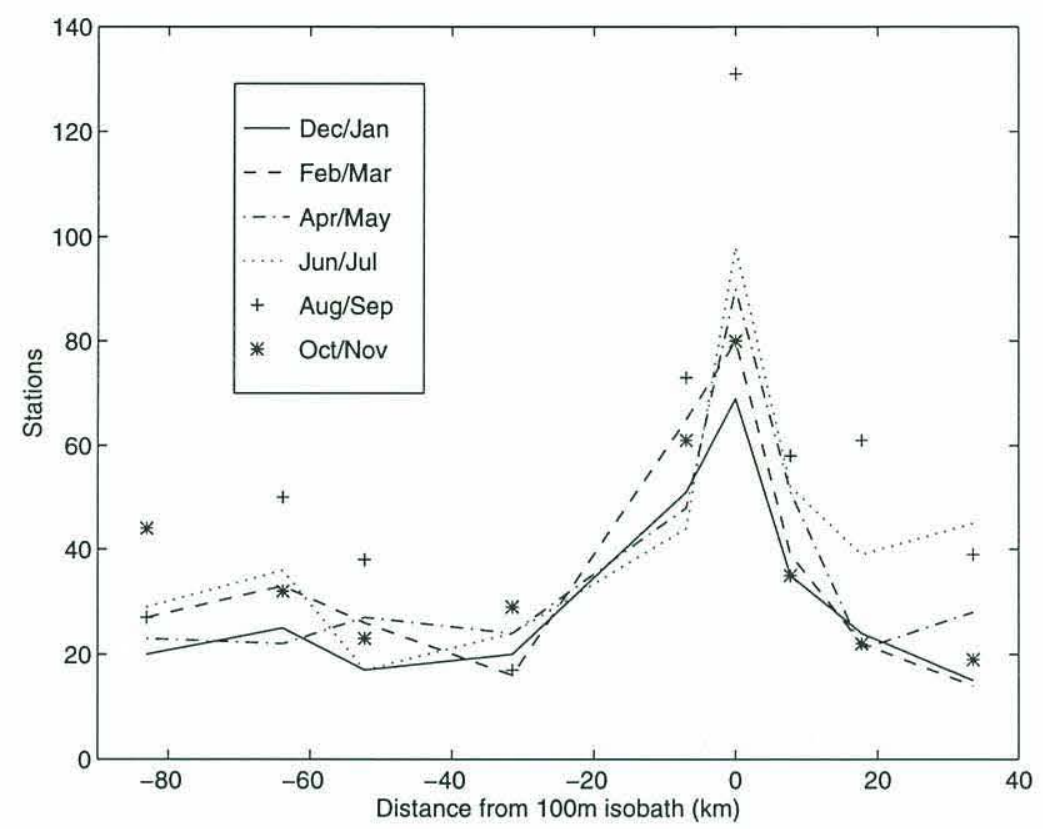

Figure 2.5: Cross-shelf and seasonal distribution of NS stations
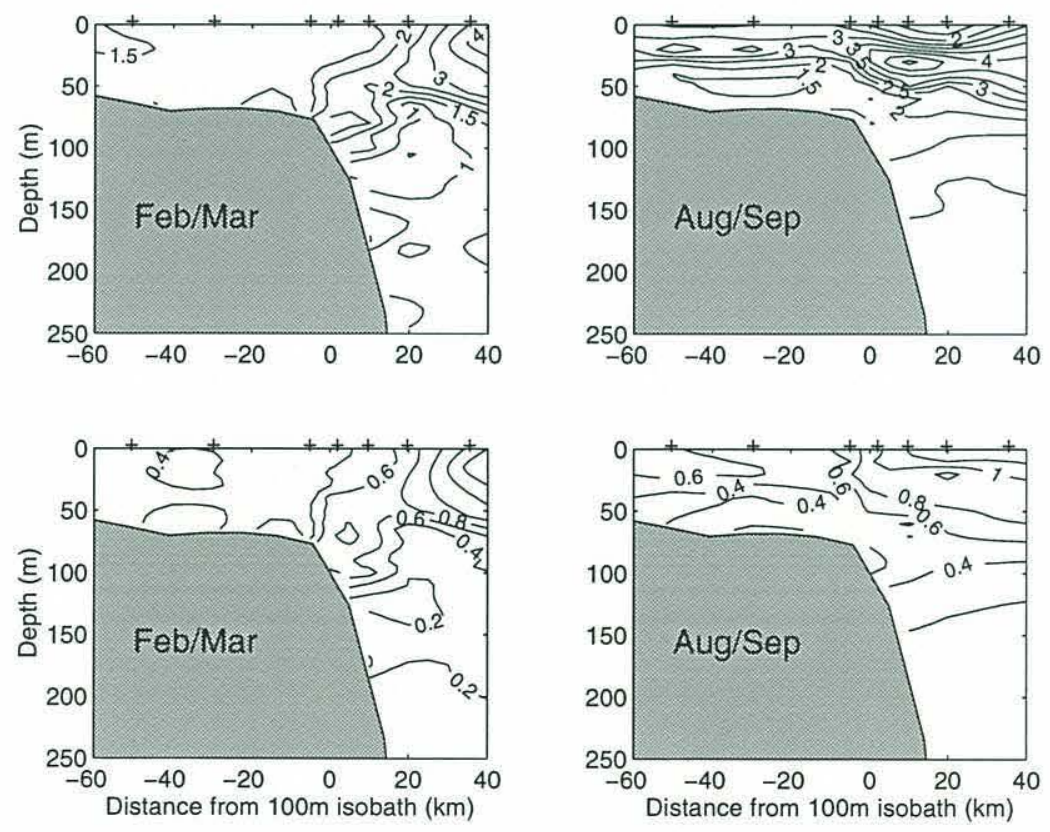

Figure 2.6: NS temperature (upper panels) and salinity (lower panels) standard deviations 
slope water interactions with warm core rings and Gulf Stream streamers. Interpretation of binned data offshore of the shelfbreak front should thus be tempered with caution. The summer temperature standard deviation (upper right panel) shows the high variability of the near surface temperature over the two month averaging interval. Burrage and Garvine [1988] have produced a similar plot of the temperature standard deviation for 12 collocated hydrographic sections taken off New Jersey over 6 days in September. Remarkably, they observed standard deviations as high as $4{ }^{\circ} \mathrm{C}$ in the center of the thermocline over the shelf. This climatology, which synthesizes over 90 years of hydrographic data and combines measurements in two month periods, yields qualitatively and quantitatively similar standard deviations. The peak in NS summer temperature standard deviation, $\sim 5{ }^{\circ} \mathrm{C}$, occurs in the thermocline frontal zone. Burrage and Garvine [1988] found that all frequency ranges (supertidal, tidal, and subtidal) contributed to the high variability in temperature. They linked the subtidal variations to the alongshelf advection of alongshelf property gradients.

\subsubsection{Gridding and dynamic calculations}

The binning method produces a two dimensional field of irregularly spaced data. The grid point locations were previously shown in Figure 2.4. Regularly spaced fields are much easier to manipulate for derivative calculations and plotting. The Fortran 77 program GRIDGEN has been used to interpolate this data onto a regularly spaced grid with 5 $\mathrm{km}$ horizontal and $5 \mathrm{~m}$ vertical resolution. GRIDGEN uses a combination of Lagrangian and spline interpolation methods.

The dynamic calculations presented have been computed from dynamically stable $\sigma_{\mathrm{t}}$ fields. The fields were calculated using the Unesco 1983 polynomial [Fofonoff and 
Millard, 1983]. In the cases where hydrostatic instabilities existed in the raw $\sigma_{\mathrm{t}}$, the two vertical data points were replaced by the mean of the two points, weighted by the volume of the vertical bin. Multiple iterations were performed until the fields achieved stability. Usually no more than two iterations were required

The alongshelf geostrophic velocities, $v$, were computed by integrating upwards from a value of zero at the bottom using the thermal wind relation:

$$
\frac{\partial v}{\partial z}=\frac{-g}{\rho_{o f}} \frac{\partial p}{\partial x}
$$

where $\mathrm{x}$ denotes the cross-shelf coordinate and $\mathrm{z}$ the vertical. A near bottom barotropic current was used instead of the default zero bottom velocity for the Feb/Mar (winter) and Aug/Sep (summer) NS fields. Figure 2.7 shows the averaged near bottom current meter values taken from the NSFE experiment for summer and winter [Beardsley et al., 1983]. It is important to note that the barotropic current is only significant over the shelf, ranging from $0-10 \mathrm{~cm} \mathrm{~s}^{-1}$ to the west. The relative vorticity:

$$
\zeta=\frac{\partial v}{\partial x}
$$

is computed directly from the regularly spaced alongshelf geostrophic velocity field using a finite difference method. The inviscid shallow water potential vorticity is also computed using a finite difference scheme applied to the following equation:

$$
q=\frac{-1}{\rho_{0}}\left[\left\langle f-\frac{\partial v}{\partial x}\right\rangle \frac{\partial \rho}{\partial z}+\frac{\partial v \partial \rho}{\partial z \partial x}\right]
$$




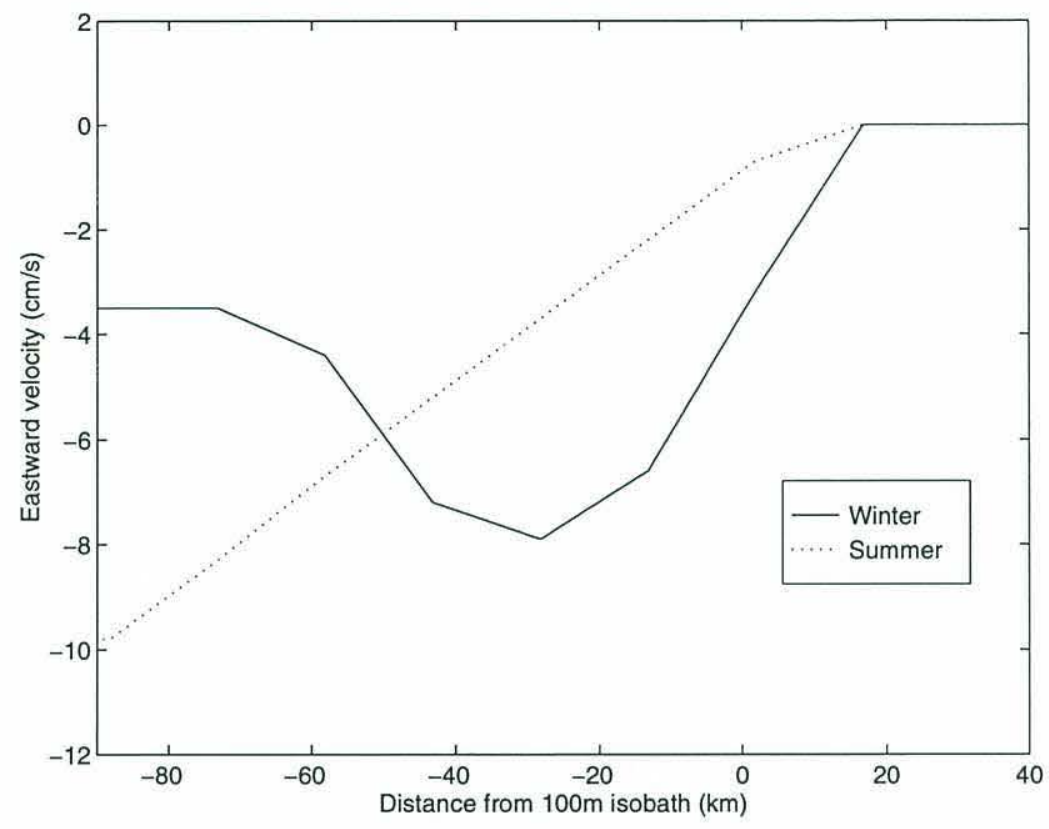

Figure 2.7: NSFE [Beardsley et al., 1983] near-bottom velocities 


\section{Chapter 3}

\section{Climatological mean fields}

\subsection{Mean hydrography}

\subsubsection{Qualitative thermohaline structure}

Figures 3.1, 3.2, and 3.3 show the seasonal evolution of the climatological NS temperature, salinity, and density fields, respectively. Bold contours indicate the nominal frontal boundary chosen in previous works: the $10{ }^{\circ} \mathrm{C}$ isotherm [Wright, 1976], the 34.5 Practical Salinity Scale (PSS) isohaline [Beardsley and Flagg, 1976], and the $26.5 \mathrm{~kg} \mathrm{~m}^{-3}$ isopycnal.

The temperature fields exhibit the greatest seasonal variability because the shallow shelf waters are strongly affected by the seasonal cycle of insolation. During the winter months, the temperature over the shelf becomes nearly homogeneous presumably due to enhanced vertical mixing caused by storm activity and convective overturning at the surface [Beardsley and Flagg, 1976]. Figure 3.1 shows that this homogenization is most complete during Feb/Mar. The shelf waters, from the surface to the bottom and over 50 $\mathrm{km}$ of cross-shelf distance, are between $4-6^{\circ} \mathrm{C}$. This is comparable to shelf temperatures ranging from $4-5{ }^{\circ} \mathrm{C}$ observed by Beardsley and Flagg [1976]. They also observed that, seaward of the $80 \mathrm{~m}$ isobath, the temperature increased more than $5{ }^{\circ} \mathrm{C}$ over $5-25 \mathrm{~km}$ in the horizontal and 5-30 $\mathrm{m}$ in the vertical. The climatological temperature front is also particularly narrow and strong during this time period, increasing from 6 to $12{ }^{\circ} \mathrm{C}$ over 20 $\mathrm{km}$. Considering the large spatial and temporal scales over which the climatology was computed, this agreement is remarkable. Wright and Parker [1976] have observed a 100 

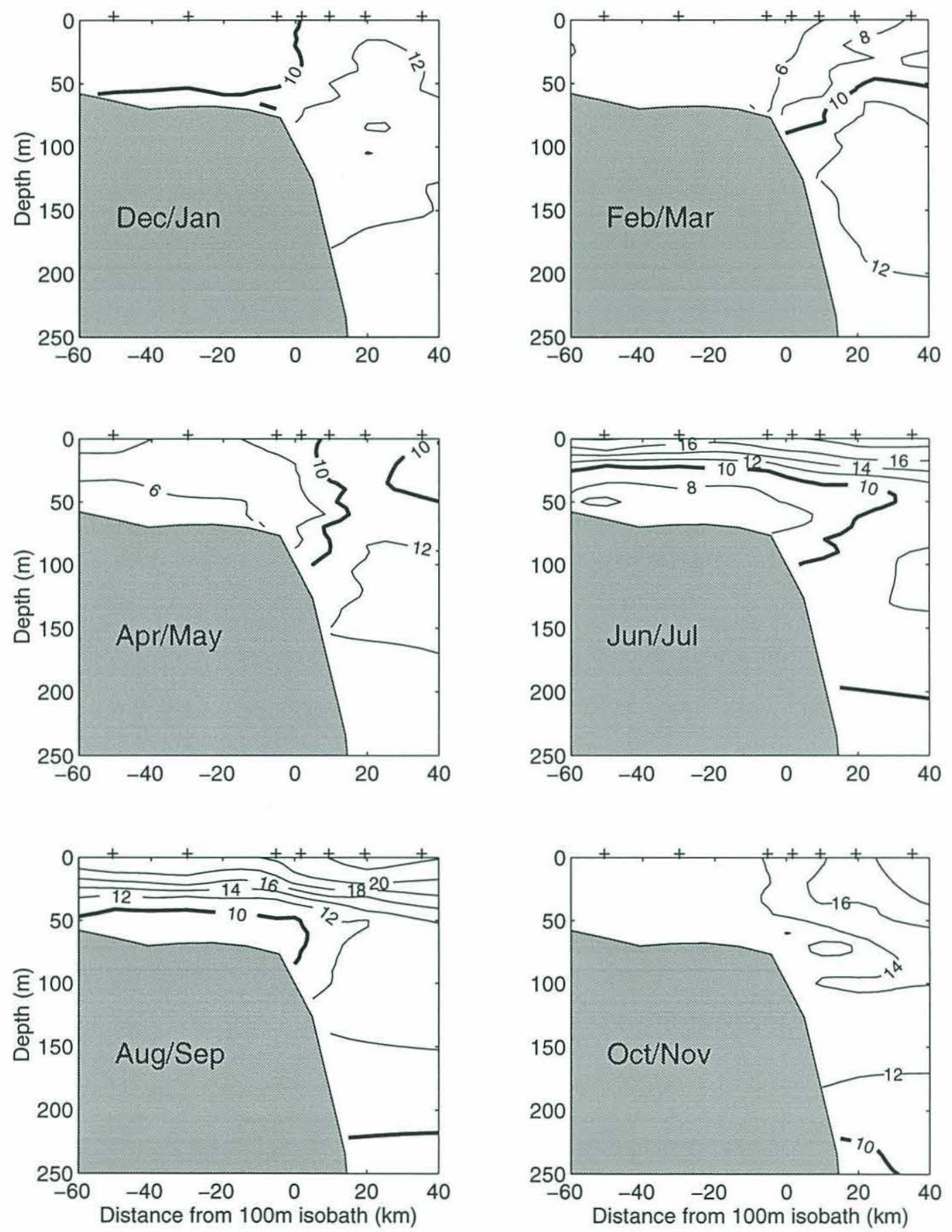

Figure 3.1: NS seasonal thermal structure 
$\mathrm{m}$ thick slope water mass, termed the "upper slope water pycnostad" $\left(10-13{ }^{\circ} \mathrm{C}, 35-35.6\right.$ PSS), centered between $100-120 \mathrm{~m}$. This feature is clearly shown in the climatology, outlined by the $12{ }^{\circ} \mathrm{C}$ isotherm and evident during every time period except Oct/Nov. It appears most clearly during Feb/Mar, where it is slightly thicker $(\sim 150 \mathrm{~m})$ and is centered slightly deeper ( 150 m) than Wright and Parker's [1976] observations.

The Apr/May fields show the initiation of surface stratification, associated with decreasing storm activity and increasing insolation. The frontal boundary defined by the $10{ }^{\circ} \mathrm{C}$ isotherm now intersects the surface about $10 \mathrm{~km}$ seaward of the shelf break. Beardsley and Flagg [1976] have observed that by June the "summer" temperature structure is fully developed. This is confirmed in the climatology. A stratified layer, approximately 25 $\mathrm{m}$ deep, has formed over the winter remnant of shelf water, also known as the "cold pool" [Beardsley and Flagg, 1976 and Houghton et al., 1982]. Houghton et al. [1982] have studied the structure of the cold pool throughout the MAB. They observed that the cold pool, centered over the middle and outer shelf, extends from Georges Bank in the north to near Cape Hatteras in the south. During Jun/Jul, the cold pool, defined by the $10{ }^{\circ} \mathrm{C}$ isotherm, extends over the shelf and terminates close to the $90 \mathrm{~m}$ isobath, close to the shelfbreak. As summer progresses (Aug/Sep), the thermocline deepens to almost $40 \mathrm{~m}$. This is comparable to Flagg's [1987] observation of a maximum thermocline depth of 30-40 m in September over the south flank of Georges Bank. The cold pool gradually erodes through the summer. By Aug/Sep the volume of water $<10^{\circ} \mathrm{C}$ has decreased in size significantly. The cold pool is about $20 \mathrm{~m}$ thick over the shelf, and extends only to about the $80 \mathrm{~m}$ isobath in the cross-shelf direction. Convective overturning in late fall (Oct/Nov) acts to return the shelf to a homogenized state. It is important to note that the shelf waters in Oct/Nov are all warmer than $10{ }^{\circ} \mathrm{C}$. The lack of a $10{ }^{\circ} \mathrm{C}$ isotherm in the frontal region during this time 
period indicates that using temperature to trace the movement of the frontal boundary may not be desirable.

Figure 3.2 shows the seasonal evolution of the NS salinity structure. The qualitative salinity field characteristics remain relatively constant throughout the year despite variations in the local seasonal fresh water input cycle [Bue, 1970]. Beardsley and Flagg [1976] have observed that the salinity front, centered on the 34.5 PSS isohaline, coincides with the temperature front during the winter. Figures 3.1 and 3.2 confirm this observation, especially during Feb/Mar. They also found that the salinity difference across the front was roughly 1-2 PSS over $10-40 \mathrm{~km}$ in the horizontal and $20-35 \mathrm{~m}$ in the vertical. The climatological salinity gradient is comparable: roughly 1 PSS over $20 \mathrm{~km}$ in the horizontal and $40 \mathrm{~m}$ in the vertical. Beardsley and Flagg [1976] found that the slope water reached a salinity maximum between 100-200 $\mathrm{m}$ in depth, below which it decreased. Evidence of this can be seen in the Dec/Jan, Feb/Mar, Apr/May, and Aug/Sep time periods as a penetration of $>35.5$ PSS water centered between 100-150 m depth. The salinity front has been observed to move offshore during the summer months [Beardsley and Flagg, 1976, Flagg et al., 1982]. The field then exhibits little variability until it begins moving onshore again in late fall. The variations in the salinity structure over the mid and outer shelf depend at least in part upon the signal received from far to the north [Chapman and Beardsley, 1989]. Chapman and Beardsley [1989], using a limited set of $\mathrm{O}^{18}$ data, showed that the freshwater input from glacial melt and river runoff near southern Greenland may be the driving force in determining MAB water properties. Manning [1991], however, postulated that large interannual fluctuations in shelf water salinity were caused mainly $(70 \%)$ by local meteorological effects such as local river runoff and precipitation. The seasonal migration of the frontal boundary will be discussed in depth in Section 3.3. 

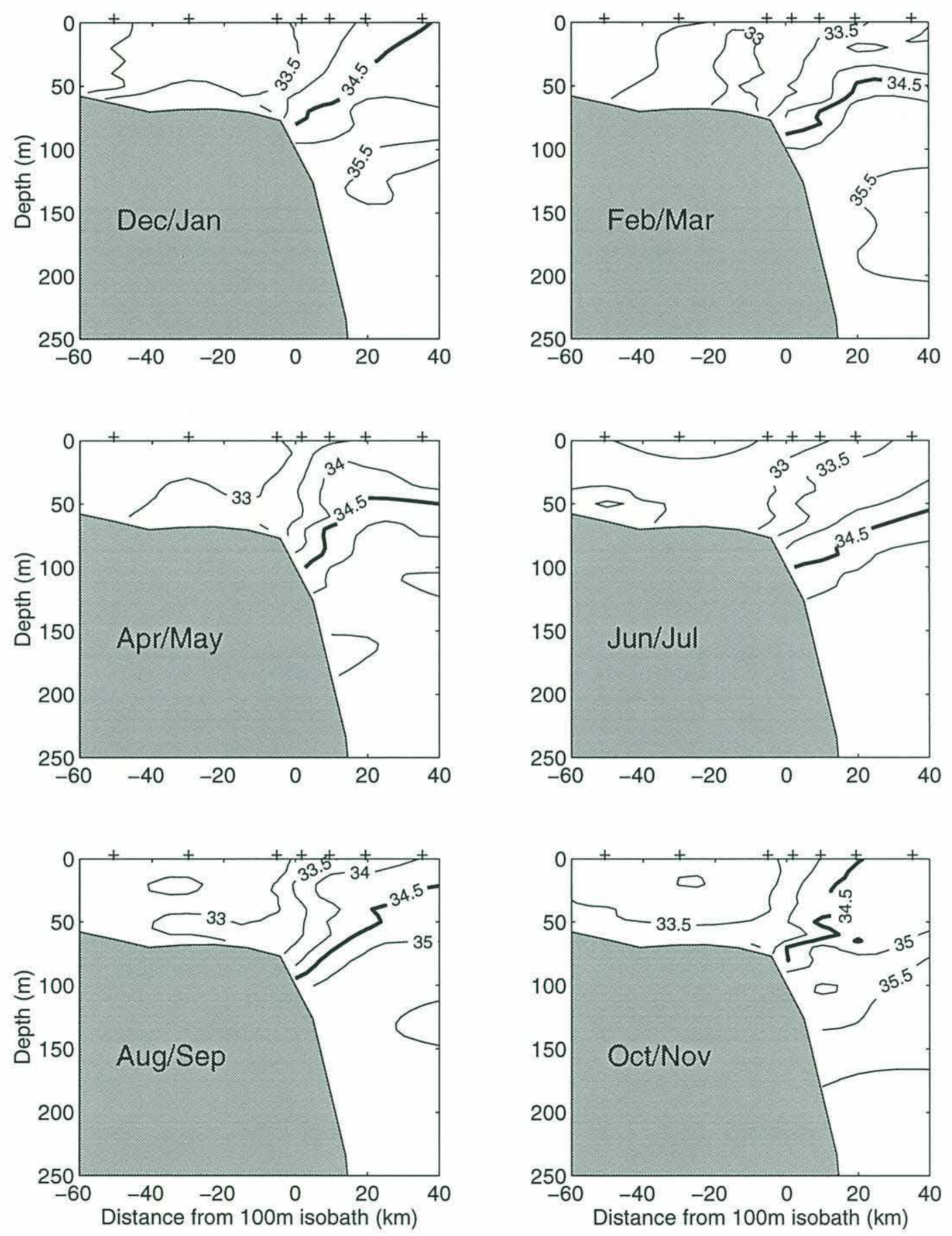

Figure 3.2: NS seasonal salinity structure 
The density fields, computed using the Unesco 1983 polynomial [Fofonoff and Millard, 1983], are shown in Figure 3.3. Since the salinity fields change little seasonally, the density fields tend to be qualitatively similar to the temperature fields. Beardsley et al. [1985] observed that during the winter months the density front has well defined surface and bottom outcrops due to the homogeneity of the water masses. This is reflected in the Dec/Jan climatological density field and is somewhat evident in Feb/Mar. The low winter temperatures create a dense shelf water mass $\left(\sigma_{\mathrm{t}}>26 \mathrm{~kg} \mathrm{~m}^{-3}\right)$. However, the high salinity of the slope waters contributes to create an even more dense slope water mass $\left(\sigma_{t}>26.5\right.$ $\left.\mathrm{kg} \mathrm{m}^{-3}\right)$. Beardsley and Flagg [1976] observed comparable densities over the shelf $\left(\sigma_{\mathrm{t}} \sim\right.$ $\left.25.9 \mathrm{~kg} \mathrm{~m}^{-3}\right)$ and slope $\left(\sigma_{\mathrm{t}} \sim 26.7 \mathrm{~kg} \mathrm{~m}^{-3}\right)$. The net increase in density moving offshore across the front is due to the cross-shelf increase in salinity, which is great enough to overcome the temperature-induced density decrease. Since the temperature and salinity gradients have opposite effects on the density field, the front is said to be density compensated [Marra et al., 1990]. Beardsley and Flagg [1976] observed a $0.5 \mathrm{~kg} \mathrm{~m}^{-3}$ cross-frontal density increase during March 1974. The climatology shows similar gradients. The depth averaged cross-shelf density difference will be studied further in Section 3.2.2. The development of the upper stratified layer is evident as early as Apr/May, where surface densities have already decreased below $26 \mathrm{~kg} \mathrm{~m}^{-3}$. By Jun/Jul, the upper pycnocline is fully developed, with a vertical density difference of over $2 \mathrm{~kg} \mathrm{~m}^{-3}$ in $\left.25 \mathrm{~m}_{\left(\mathrm{N}^{2}\right.} \sim 0.76 \times 10^{-3} \mathrm{~s}^{-2}\right)$. In the upper pycnocline, the slope of the front, defined by the $26.5 \mathrm{~kg} \mathrm{~m}^{-3}$ isopycnal, has decreased significantly. Now a common density surface connects the shelf and slope waters, facilitating the cross-frontal exchange of water parcels [Aikman, 1984]. This summer isopycnal flattening has also been commented on by Houghton et al. [1988]. The Aug/Sep period shows a "typical" summer density field; it is very similar to the Houghton 

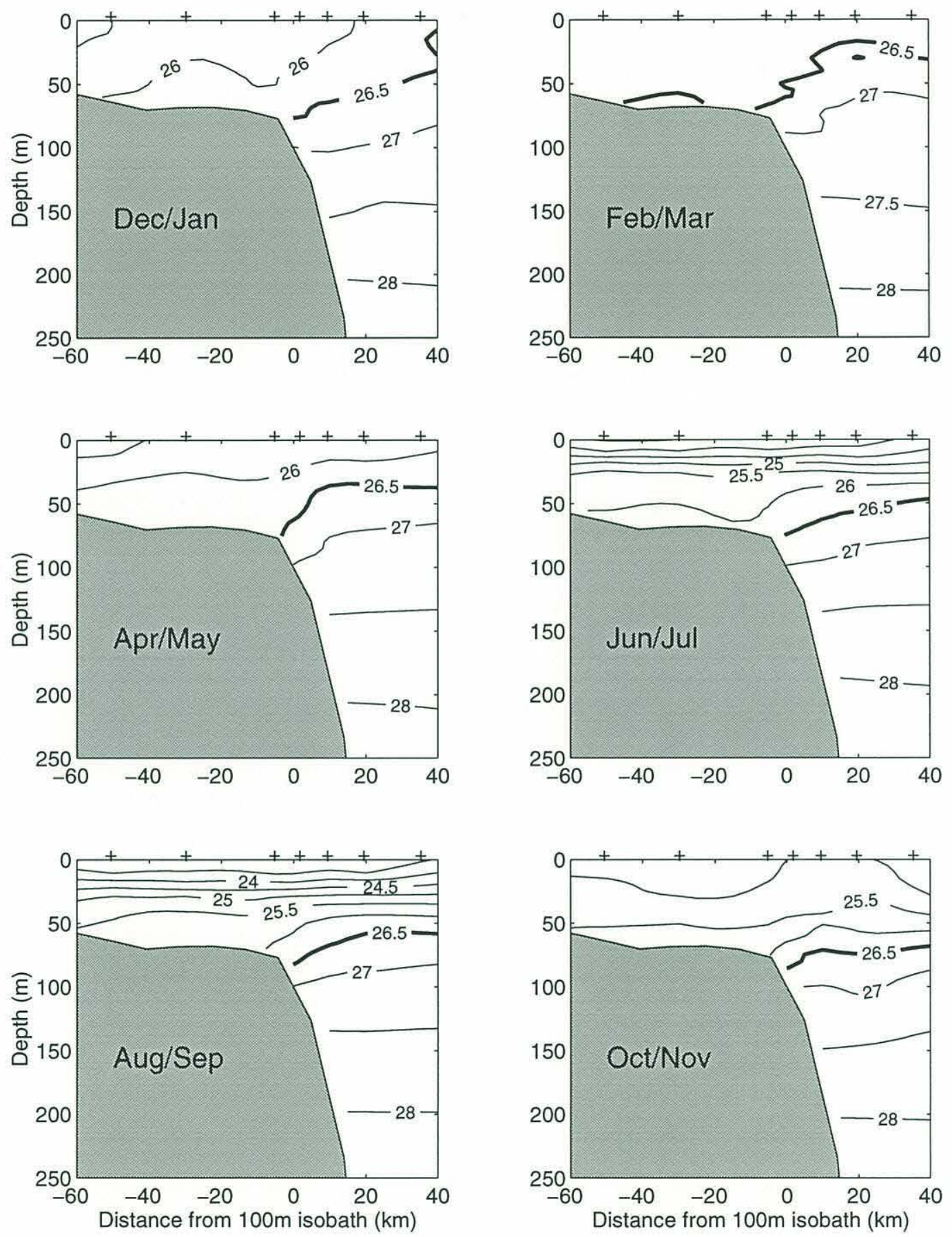

Figure 3.3: NS seasonal density structure 
et al. [1988] SEEP $\sigma_{\mathrm{t}}$ section shown in Figure 1.3. The vertical stratification in the surface pycnocline has now strengthened to a vertical density difference of $3 \mathrm{~kg} \mathrm{~m}^{-3}\left(\mathrm{~N}^{2} \sim 1.1 \mathrm{x}\right.$ $10^{-3} \mathrm{~s}^{-2}$ ), which is within the range of $3.0-4.0 \mathrm{~kg} \mathrm{~m}^{-3}$ observed by Beardsley and Flagg [1976]. Surface cooling initiates in late Autumn (Oct/Nov), leading to convective overturning. Winter storms also begin to vertically mix the shelf and slope waters. These processes weaken the pycnocline, giving the field a similar structure to that computed for the spring months (Apr/May). It is important to observe that although the upper level thermocline causes the isopycnals in the frontal region to flatten, they retain a positive slope near the shelfbreak throughout the year. The baroclinic shear associated with these sloping isopycnals will be discussed in depth in Chapter 4.

\subsubsection{Cross-shelf properties}

To further illustrate the cross-frontal and seasonal changes, the temperature, salinity, and density have been plotted from the regularly gridded NS fields. Two layers are shown for each property: a near surface layer averaged over 5-25 $\mathrm{m}$ in depth and an intermediate layer, corresponding to the depth of the cold pool, averaged over 45-65 m.

The upper panel of Figure 3.4 shows the clear seasonal progression of the near surface temperature. The coldest seasonal temperatures, from $\sim 4^{\circ} \mathrm{C}$ on the shelf to $\sim 8{ }^{\circ} \mathrm{C}$ over the slope, occur in Feb/Mar. This period can thus be denoted the typical "winter" case. The Apr/May and Dec/Jan temperatures are both $\sim 2-3{ }^{\circ} \mathrm{C}$ warmer than the Feb/Mar case. Peak temperatures occur in Aug/Sep, the typical "summer" case, with the shelf waters reaching about $15^{\circ} \mathrm{C}$ and the slope waters over $20^{\circ} \mathrm{C}$. The Oct/Nov and Jun/Jul periods are quantitatively similar to each other, being colder than Aug/Sep by $\sim 2{ }^{\circ} \mathrm{C}$, on the average. All time periods show a cross-frontal temperature increase between $3-6{ }^{\circ} \mathrm{C}$. 
This increase is a gradual transition beginning $10 \mathrm{~km}$ shoreward of the shelfbreak and extending 20-30 km seaward of the shelfbreak.

The deep (45-65 m) temperature plot (lower panel of Figure 3.4) illustrates the seasonal evolution of the cold pool and the contrast between the highly variable shelf waters and the relatively invariable upper slope pycnostad. The seasonal evolution of the
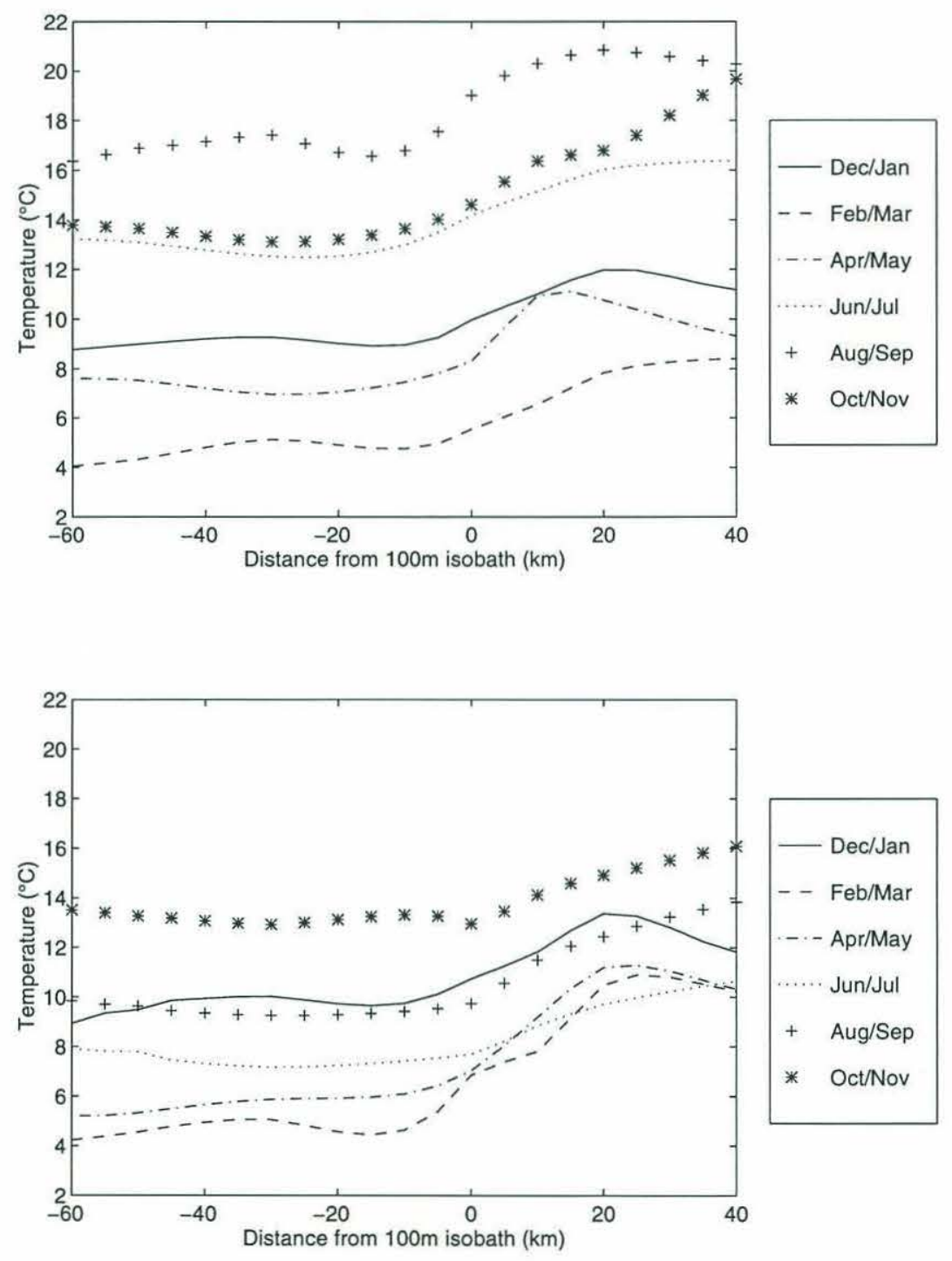

Figure 3.4: Depth averaged near surface (5-25 m, upper panel) and intermediate layer (45-65 m, lower panel) NS temperature 
cold pool is clearly illustrated. It reaches a minimum temperature, like the surface layer, during Feb/Mar, when the shelf water is well-mixed. The temperature rises by about $1{ }^{\circ} \mathrm{C}$ during Apr/May due to increased insolation. The cold pool temperature rises to about $7{ }^{\circ} \mathrm{C}$ during Jun/Jul, and increases further to $9-10{ }^{\circ} \mathrm{C}$ during Aug/Sep due to slow, diffusive mixing with the surrounding waters. It is interesting to note that while the surface layer heats in phase with the insolation, reaching a maximum in Aug/Sep, the cold pool waters lag the insolation by one bimonthly time period. The cold pool reaches its maximum temperature of $13{ }^{\circ} \mathrm{C}$ in Oct/Nov, when the warm surface thermocline waters are finally mixed downward. During Dec/Jan, when winter storms fully homogenize the shelf waters, bringing cold surface water downward, the cold pool temperature drops drastically to $9-10{ }^{\circ} \mathrm{C}$. Houghton et al. [1982] have plotted the New England shelf cold pool minimum temperature evolution from February to October. Their observed annual minimum temperature ( 2-3 $\left.{ }^{\circ} \mathrm{C}\right)$ occurred in February, while the maximum $\left(\sim 11^{\circ} \mathrm{C}\right)$ occurred in October, showing very close agreement with the climatology.

The climatology shows that the cold pool temperature ranges from about $4-13{ }^{\circ} \mathrm{C}$ throughout the year. In contrast, the maximum seasonal temperature range of the upper slope pycnostad is from $10{ }^{\circ} \mathrm{C}$ from Feb-Jul, to $16^{\circ} \mathrm{C}$ in Oct/Nov. The shelf cold pool water mass therefore has about twice the seasonal temperature range as the pycnostad. The cross-frontal temperature rise occurs over a cross-shelf distance of about $30 \mathrm{~km}$. The frontal transition is sharper than near the surface due to the sharp transition from cold pool to pycnostad waters. At the surface, the formation of the summer thermocline tends to diffuse the cross-frontal temperature gradient. This smearing of the surface thermal frontal boundary indicates that satellite sea surface measurements taken during the summer may be of questionable value. Burrage and Garvine [1988] reached similar conclusions based 
on a mean temperature field incorporating 12 detailed hydrographic transects taken off New Jersey during September 1982.

The near surface salinity, shown in the upper panel of Figure 3.5, exhibits much less seasonal variability than temperature, as expected. The least saline time period, from 32.5 PSS on the shelf to 33.7 PSS over the slope, is Jun/Jul. Manning [1991] has shown that minimum MAB salinities are typically found in early summer. The highest shelf salinities occur in Dec/Jan. Manning [1991] also observed a maximum in shelf water salinity in the beginning of the year.

The deep layer salinity appears to be broken into two distinct seasonal bands over the shelf. From February to September, the shelf waters are roughly 0.5 PSS fresher than the early winter time period (October to January) shelf waters. Over the slope, the salinity converges to about 34.7 PSS, except for the slightly fresher Jun/Jul time period $(\sim 34.5$ PSS). Wright and Parker [1976] observed upper slope pycnostad salinities of between 3535.6 PSS. The offset between this range and that shown by the climatology is most likely due to the difference in layer depths. The climatology, showing a cross-shelf mean for 45 $65 \mathrm{~m}$ in depth, is slightly shallower (and thus presumably slightly fresher) than Wright and Parker's [1976] 50-170 m deep pycnostad layer. A gradient region is clearly evident throughout the year, and is much less diffuse than the temperature gradient, especially in the surface layer. The gradient region is concentrated from between $10 \mathrm{~km}$ shoreward to $15-20 \mathrm{~km}$ seaward of the $100 \mathrm{~m}$ isobath.

Due to the relative lack of seasonal variability of the salinity (also observed by Manning, 1991), the depth-averaged density, shown in Figure 3.6, again follows the same trends as the temperature. The surface layer depth-averaged $\sigma_{t}$ (Figure 3.6, upper panel) 

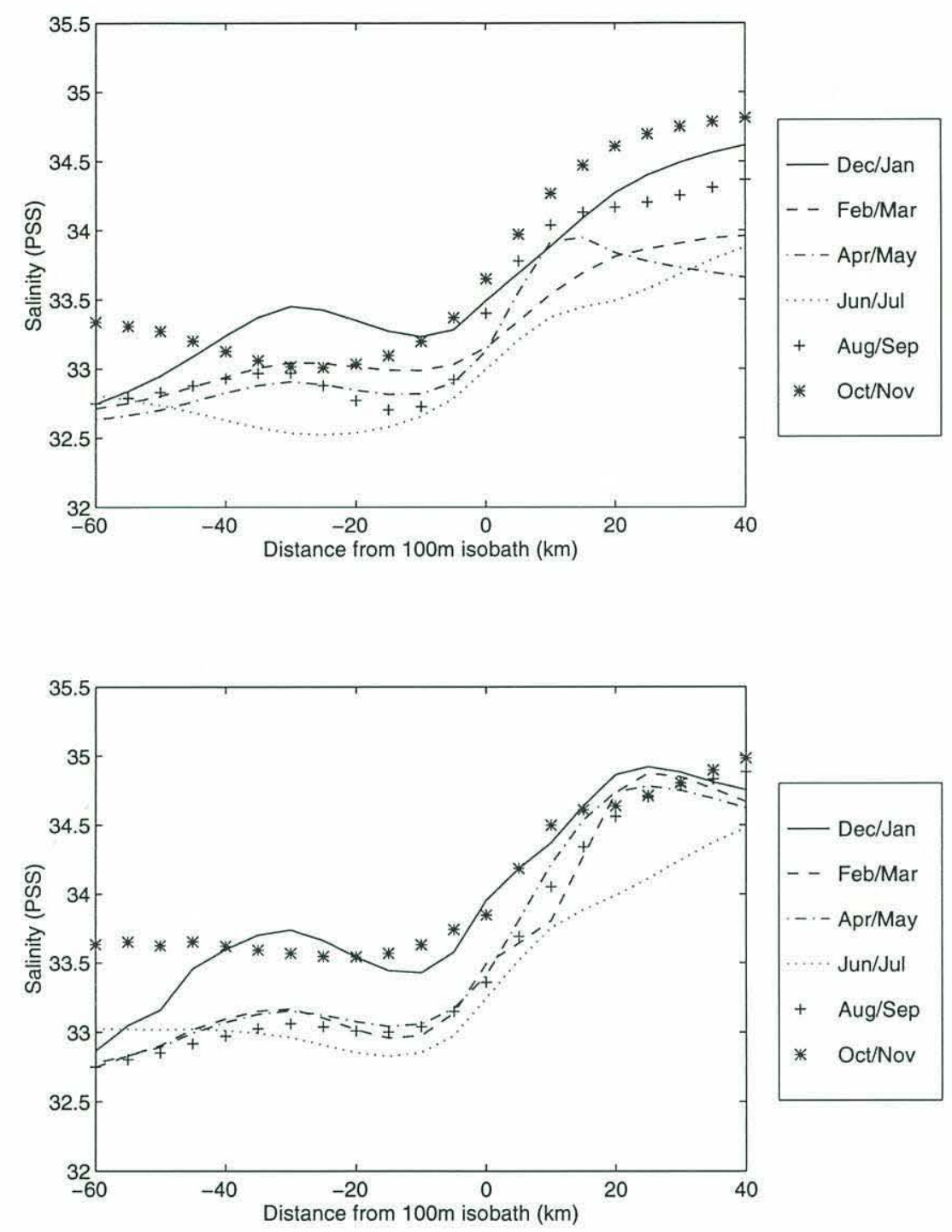

Figure 3.5: Depth averaged near surface (5-25 m, upper panel) and intermediate layer (45-65 m, lower panel) NS salinity

shows interesting seasonal variations. The densest waters are found in Feb/Mar, ranging from $26.1 \mathrm{~kg} \mathrm{~m}^{-3}$ over the shelf to $26.4 \mathrm{~kg} \mathrm{~m}^{-3}$ over the slope. The Dec/Jan and Apr/May time periods are both slightly less dense than Feb/Mar, corresponding to their slightly warmer temperatures. As expected, the Aug/Sep density is the lowest, corresponding to 

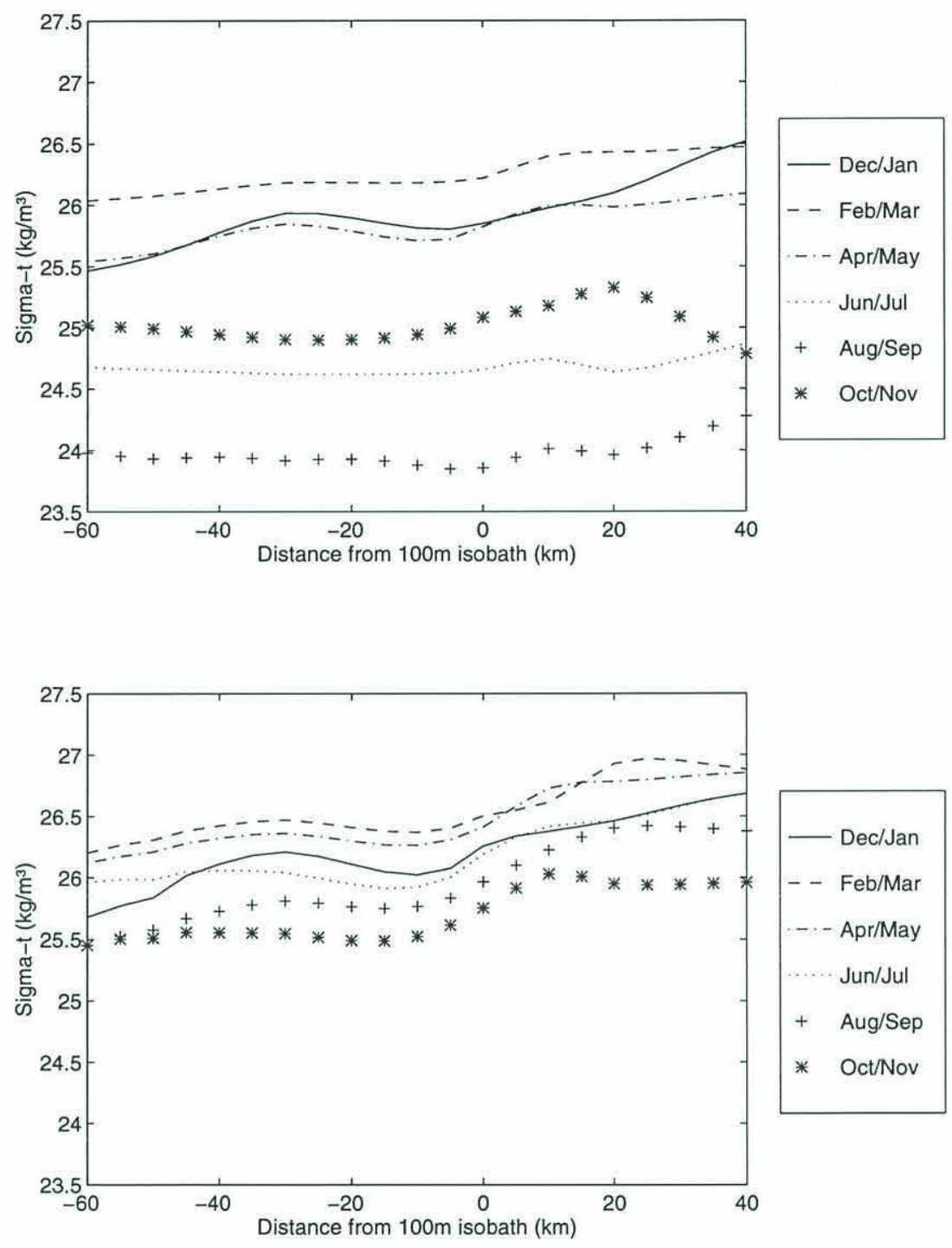

Figure 3.6: Depth averaged near surface (5-25 m, upper panel) and intermediate layer (45-65 m, lower panel) NS density

the highest temperatures. The isopycnal flattening effect of the seasonal pycnocline is clearly evident. The surface density only slightly increases across the front in this near surface layer throughout the year. The Jun/Jul and Oct/Nov densities are about $1.5 \mathrm{~kg} \mathrm{~m}^{-3}$ more dense than the Aug/Sep minimum density case. 
The density between 45-65 m (Figure 3.6, lower panel) also follows the temperature trends. The lightest water occurs during the warmest cold pool time period, Oct/Nov, while the densest water occurs during Feb/Mar. The seasonal range of $\sigma_{\mathrm{t}}$ is from 25.5 to $26.6 \mathrm{~kg} \mathrm{~m}^{-3}$, which is about half the upper layer range of 24 to $26.4 \mathrm{~kg} \mathrm{~m}-3$. The increased seasonal range of the surface layer density reflects the strong influence of the summer pycnocline.

The cross-shelf density contrast is useful in quantifying the strength of the front and the associated baroclinic current shear. Beardsley and Flagg [1976] found that for March, 1974, the "average" cross-frontal density contrast was $0.5 \mathrm{~kg} \mathrm{~m}^{-3}$. They did not specify the horizontal or vertical extents over which the densities were averaged. To better quantify this cross-shelf density difference, the onshore density (averaged over a $10 \mathrm{~km}$ interval from 30 to $20 \mathrm{~km}$ shoreward of the $100 \mathrm{~m}$ isobath) has been subtracted from the offshore density (averaged over a $10 \mathrm{~km}$ horizontal interval from 20 to $30 \mathrm{~km}$ seaward of the $100 \mathrm{~m}$ isobath) using the regularly gridded field. This has been repeated for three different depth intervals: 5-15 m, 25-35 m, and 45-55 m, to illustrate the depth dependence. Figure 3.7 shows the results of these calculations for the NS subset, plotted as a function of time. During Dec/Jan, the $\Delta \sigma_{\mathrm{t}}$ is $\sim 0.3 \mathrm{~kg} \mathrm{~m}^{-3}$ and is nearly uniform in depth, reflecting the well mixed shelf and slope waters. This vertical homogeneity has broken down by Feb/Mar. The surface $\Delta \sigma_{\mathrm{t}}$ has dropped to $0.23 \mathrm{~kg} \mathrm{~m}^{-3}$, while the deep (45-55 m) $\Delta \sigma_{\mathrm{t}}$ has increased to $0.47 \mathrm{~kg} \mathrm{~m}^{-3}$. As the spring progresses into summer, the three depth curves diverge further. The maximum range in $\Delta \sigma_{t}$ occurs in Aug/Sep, corresponding to the period of most intense stratification. During this time period, the extremes in $\Delta \sigma_{\mathrm{t}}$ are: $\sim 0$ $\mathrm{kg} \mathrm{m}^{-3}$ in the surface waters $(5-15 \mathrm{~m})$ and $\sim 0.5 \mathrm{~kg} \mathrm{~m}^{-3}$ for the deep (45-55 $\left.\mathrm{m}\right)$ waters. This extremely low $\Delta \sigma_{t}$ in the surface waters has been found by Aikman [1984] using a one 
dimensional, two layer bulk-mixing model. He observed the cross-shelf density gradients becoming negative at intermediate depths, leading to a slope water intrusion, known as the pycnocline salinity maximum [Aikman, 1984]. Although these calculations have revealed no negative gradients, the low summer $\Delta \sigma_{t}$ values suggest this phenomenon could easily occur. This cross-frontal isopycnal connection (when the $\Delta \sigma_{t}$ is zero or negative) facilitates the exchange of shelf and slope water, which has been a subject of study in many projects [Wright, 1976, Aikman, 1984, Houghton et al., 1988]. It is also important to note that horizontal density gradients at the surface are expected to be smoother in the climatology because of the high variability of the surface expression of the front [Wright, 1976]. By Oct/Nov the gradients have already begun to converge again. Surface cooling has contributed to the increased density of the surface layer, while increased mixing of the deep waters with warmer surface water has decreased their density.

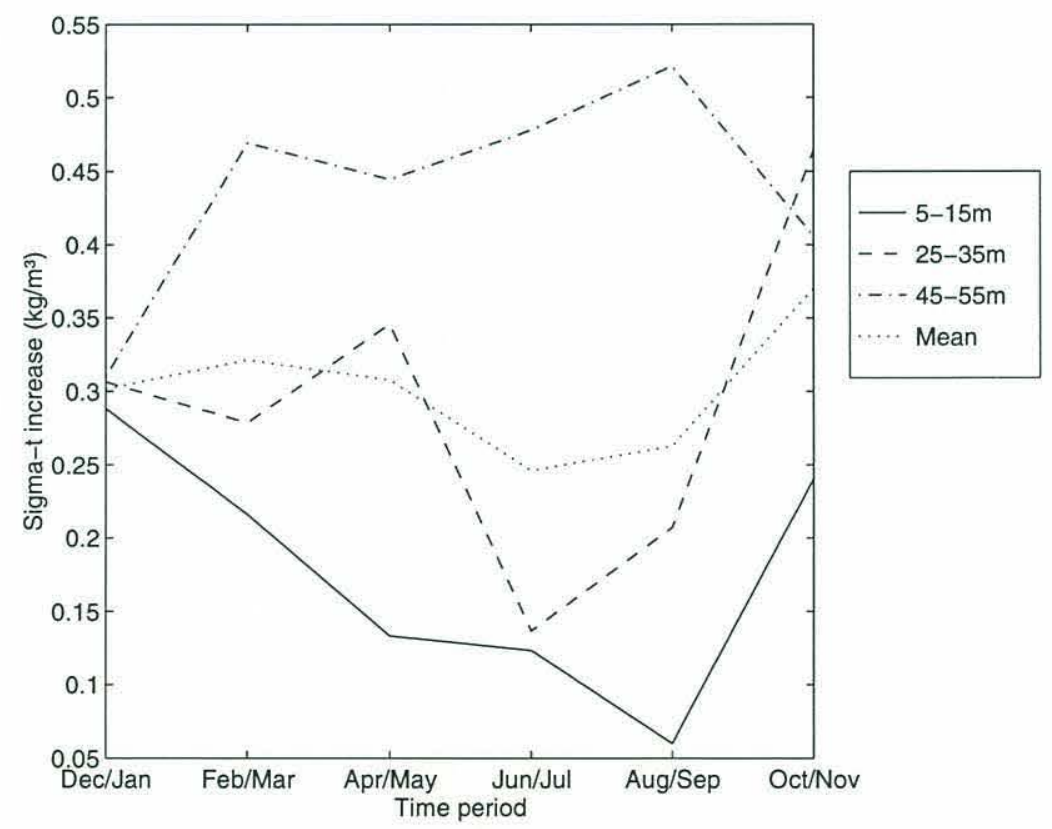

Figure 3.7: NS depth averaged cross-shelf density difference 
Figure 3.7 also shows where and when the most intense vertical baroclinic current shears occur. During the winter months, this current shear is relatively independent of depth. However, in the summer, the geostrophic current shear will be concentrated in the deep waters (45-55 m), with almost no shear occurring in the upper $20 \mathrm{~m}$ of the water column. Despite these differences in vertical position of the maximum shear, the relatively

constant mean density increase $\left(\sim 0.3 \mathrm{~kg} \mathrm{~m}^{-3}\right)$ indicates that the total velocity shear $(\sim 6$ $\mathrm{cm} \mathrm{s}^{-1}$ ) will be relatively unchanged seasonally. The relatively low average cross-shelf density increase, compared to the Beardsley and Flagg [1976] observation of $0.5 \mathrm{~kg} \mathrm{~m}^{-3}$, can be attributed to the smearing of gradients resulting from the averaging process. By this reasoning, the estimated climatological baroclinic jet feature, to be discussed in Chapter 4, is expected to be correspondingly weaker than "synoptic" measurements. Figure 3.7 clearly shows that information would be lost if $\Delta \sigma_{\mathrm{t}}$ were vertically averaged. Only during the winter months, when the water properties are vertically homogeneous, is this procedure sensible.

\subsection{Mean frontal position and seasonal progression}

The mean position and seasonal progression of the shelfbreak front have been previously studied based on advanced very high resolution radiometer (AVHRR) satellite measurements of the sea surface temperature (SST) [Halliwell and Mooers, 1979 and Drinkwater et al., 1994] and on mean fields of the hydrography [Wright, 1976 and Flagg et al., 1982]. A summary of mean frontal position and slope estimates is given in Table 1 for selected authors.

Halliwell and Mooers [1979] have studied the spatial and temporal variability of the surface temperature expression of the shelfbreak front based on satellite imagery. They 


\begin{tabular}{|c|c|c|c|c|c|}
\hline $\begin{array}{c}\text { Authors } \\
\text { [year] }\end{array}$ & $\begin{array}{l}\text { Region / } \\
\text { season }\end{array}$ & Method & $\begin{array}{c}\text { Surface }(\mathbf{s}) / \\
\text { bottom }(\mathbf{b}) \\
\text { frontal } \\
\text { position }\end{array}$ & $\begin{array}{l}\text { Mean } \\
\text { frontal } \\
\text { slope }\end{array}$ & Miscellaneous \\
\hline $\begin{array}{l}\text { Beardsleyand } \\
\text { Flagg [1976] }\end{array}$ & $\begin{array}{l}\text { New England } \\
\text { shelf, winter }\end{array}$ & Field experiment & $\begin{array}{l}80 \mathrm{~m} \text { isobath } \\
\text { (b) }\end{array}$ & $2 \times 10^{-3}$ & $\begin{array}{l}\text { Westward currents } \\
\text { observed over } \\
\text { shelf }\end{array}$ \\
\hline $\begin{array}{l}\text { Voorhis et al. } \\
\text { [1976] }\end{array}$ & $\begin{array}{l}\text { New England } \\
\text { shelf, late } \\
\text { spring }\end{array}$ & Field experiment & $\begin{array}{l}100 \mathrm{~m} \text { isobath } \\
\text { (b) }\end{array}$ & Not given & $\begin{array}{l}0.7 \mathrm{~Sv} \text { transport in } \\
\text { baroclinic jet }\end{array}$ \\
\hline Wright [1976] & $\begin{array}{l}\text { New England } \\
\text { shelf, all sea- } \\
\text { sons }\end{array}$ & $\begin{array}{l}\text { Climatological, } \\
\text { 1941-1972 }\end{array}$ & $\begin{array}{l}100 \mathrm{~m} \text { isobath } \\
\text { (b) }\end{array}$ & Not given & $\begin{array}{l}\text { Analyzed mostly } \\
\text { thermograms }\end{array}$ \\
\hline $\begin{array}{l}\text { Halliwell and } \\
\text { Mooers } \\
{[1979]}\end{array}$ & $\begin{array}{l}\text { Entire MAB, } \\
\text { all seasons }\end{array}$ & $\begin{array}{l}\text { Climatological, } \\
\text { based on satellite } \\
\text { SST }\end{array}$ & $\begin{array}{l}80 \mathrm{~km} \text { sea- } \\
\text { ward of shelf- } \\
\text { break (s) }\end{array}$ & Not given & $\begin{array}{l}\text { Based on surface } \\
\text { temperature }\end{array}$ \\
\hline $\begin{array}{l}\text { Flagg et al. } \\
\text { [1982] }\end{array}$ & $\begin{array}{l}\text { Georges } \\
\text { Bank, all sea- } \\
\text { sons }\end{array}$ & $\begin{array}{l}\text { Climatological, } \\
1975-1979\end{array}$ & $\begin{array}{l}100 \mathrm{~m} \text { isobath } \\
\text { (b) }\end{array}$ & $2.8 \times 10^{-3}$ & $\begin{array}{l}2 \mathrm{~km} / \text { month sum- } \\
\text { mer frontal migra- } \\
\text { tion }\end{array}$ \\
\hline $\begin{array}{l}\text { Burrage and } \\
\text { Garvine } \\
{[1988]}\end{array}$ & $\begin{array}{l}\text { New Jersey } \\
\text { shelf, summer }\end{array}$ & $\begin{array}{l}\text { Synthesis of } 12 \\
\text { transects }\end{array}$ & $\begin{array}{l}\sim 80 \mathrm{~m} \text { iso- } \\
\text { bath (est. } \\
\text { from plot) }\end{array}$ & Not given & $\begin{array}{l}\text { Computed stan- } \\
\text { dard deviation of } \\
\mathrm{T} \text { structure }\end{array}$ \\
\hline $\begin{array}{l}\text { Houghton et } \\
\text { al. [1988] }\end{array}$ & $\begin{array}{l}\text { New England } \\
\text { shelf, full } \\
\text { year }\end{array}$ & Field experiment & $\begin{array}{l}100 \mathrm{~m} \text { isobath } \\
\text { (b) }\end{array}$ & $\begin{array}{l}2.2 \times 10^{-3} \\
\text { (winter) } \\
1.3 \times 10^{-3} \\
\text { (summer) }\end{array}$ & $\begin{array}{l}\text { Focused on cross- } \\
\text { shelf exchange }\end{array}$ \\
\hline $\begin{array}{l}\text { Drinkwater } \\
\text { et al. [1994] }\end{array}$ & $\begin{array}{l}\text { Entire MAB, } \\
\text { all seasons }\end{array}$ & $\begin{array}{l}\text { Climatological, } \\
\text { based on satellite } \\
\text { SST, 1972-1994 }\end{array}$ & $\begin{array}{l}\sim 40 \mathrm{~km} \text { sea- } \\
\text { ward of shelf- } \\
\text { break at } 70 \\
{ }^{\circ} \mathrm{W}(\mathrm{s})\end{array}$ & Not given & $\begin{array}{l}\text { Also found } \pm 20 \\
\mathrm{~km} \text { interannual } \\
\text { deviation }\end{array}$ \\
\hline
\end{tabular}

Table 3.1: Recent examples of frontal outcrop and slope measurements

observed that the shelfbreak front near Georges Bank frequently underwent seaward migrations, often corresponding to nearby offshore eddies. They calculated the average surface position of the front to be $80 \pm 30 \mathrm{~km}$ seaward of the shelfbreak. However, the portion of the front between Cape Charles and the Great South Channel remained "tightly bound" to the shelfbreak in comparison (mean displacement was $20 \pm 30 \mathrm{~km}$ seaward of 
the shelfbreak). On rare occasions, the Gulf Stream itself meandered close to the shelfbreak front and forced it onshore. Halliwell and Mooers [1979] did not, however, discuss any seasonal frontal migrations.

Drinkwater et al. [1994] have similarly compiled statistical information on the surface expression of the shelfbreak front, encompassing the entire MAB. They used over twenty years of SST data from the National Oceanic and Atmospheric Administration (NOAA) TIROS satellites to estimate the monthly mean position of the shelfbreak front. They produced monthly average frontal positions for every degree of longitude from 50$75^{\circ} \mathrm{W}$. They found that the shelfbreak front migrates up to $40 \mathrm{~km}$ across the shelf, being farthest onshore in August through October and farthest offshore during the winter months.

Flagg et al. [1982], using a five year climatological average of data from the south flank of Georges Bank, showed that the front gradually moved onshore from spring to fall ( $2 \mathrm{~km} / \mathrm{month}$ ), and then suddenly moved offshore in late fall. They also approximated the bottom intersection of the front to be at the $100 \mathrm{~m}$ isobath and slope of the front to be $2.8 \mathrm{x}$ $10^{-3}$, with no large seasonal differences. Flagg et al. 's [1982] cross-shelf horizontal averaging resolution was 5 stations for $150 \mathrm{~km}$.

Wright [1976] analyzed 19,000 bathythermograms and 1,600 oceanographic stations collected from $1941-1972$ within the region $39-41^{\circ} \mathrm{N}, 69-72^{\circ} \mathrm{W}$ to study changes in the shelfbreak front. He estimated the frontal bottom outcrop, defined by the $10{ }^{\circ} \mathrm{C}$ isotherm, to be within $16 \mathrm{~km}$ of the $100 \mathrm{~m}$ isobath $80 \%$ of the time. He also noted that the mean position foot of the front moved from south to north (onshore) through the spring, summer, and fall. However, Wright [1976] found the frontal surface expression experi- 
enced an opposite migration, reaching an offshore extreme during July and an onshore extreme during the winter, in contradiction to Drinkwater et al.'s [1994] findings. The surface expression of the front was 2-3 times more variable than the bottom expression.

Figure 3.1 clearly shows the problems accompanying a classification of the frontal boundary based on the temperature. The large seasonal variations in temperature preclude selection of a single isotherm to represent the front. For example, although the $10{ }^{\circ} \mathrm{C}$ isotherm has been a popular choice for the frontal boundary [Wright, 1976], the NS climatological temperature fields (Figure 3.1) show that during Oct/Nov, the temperature has become greater than $10^{\circ} \mathrm{C}$ over the entire shelf. Also, the surface temperature expression of the front may become ambiguous in the summer due to formation of the thermocline [Burrage and Garvine, 1988]. The 34.5 PSS isohaline has thus been chosen to represent the mean position of the shelfbreak front in this study. This isohaline has also been used by Beardsley and Flagg [1976] and Burrage and Garvine [1988].

Figure 3.8 shows each bimonthly position of the NS 34.5 PSS isohaline. The 34.5 PSS mean isohaline, representing the mean frontal boundary, intersects the bottom near the shelfbreak between the 85 and $105 \mathrm{~m}$ isobaths during the entire year. This range of isobaths corresponds to a cross-shelf distance of about $10 \mathrm{~km}$. The isohaline generally slopes upward and offshore from the shelfbreak. The curves show a distinct seasonal transition. During Oct/Nov, the period when vertical homogenization initiates, the mean frontal slope is a maximum, and intersects the surface only $\sim 20 \mathrm{~km}$ away from the bottom outcrop (giving a slope of $\left.\sim 5 \times 10^{-3}\right)$. However, this slope decreases to roughly half $\left(2-3 \times 10^{-3}\right)$ during Dec/Jan, as the surface position of the front moves offshore. The bottom outcrop has not changed significantly. The 34.5 PSS isohaline does not intersect the surface 
(within the cross-shelf extent of the climatology, out to $40 \mathrm{~km}$ seaward of the shelfbreak) during any other time period. While all of the 34.5 PSS isohalines have roughly the same slope near the shelfbreak, the February through September cases tend to become horizontal in the upper water column. Thus, the front may be characterized by a two slope model consisting of a near-bottom slope and a mid-depth to surface slope. The only significant changes in frontal slope occur in the intermediate to surface layers, as shown in Figure 3.8. This plot also shows the large volume of fresh water present seaward of the $1500 \mathrm{~m}$ isobath (maximum extent of the last depth bin). Shelf and slope water migrations will be discussed further in Section 3.3.

Although the slope of the front near the shelfbreak remains relatively constant, the mean position of the frontal bottom outcrop exhibits a slight seasonal migration. During

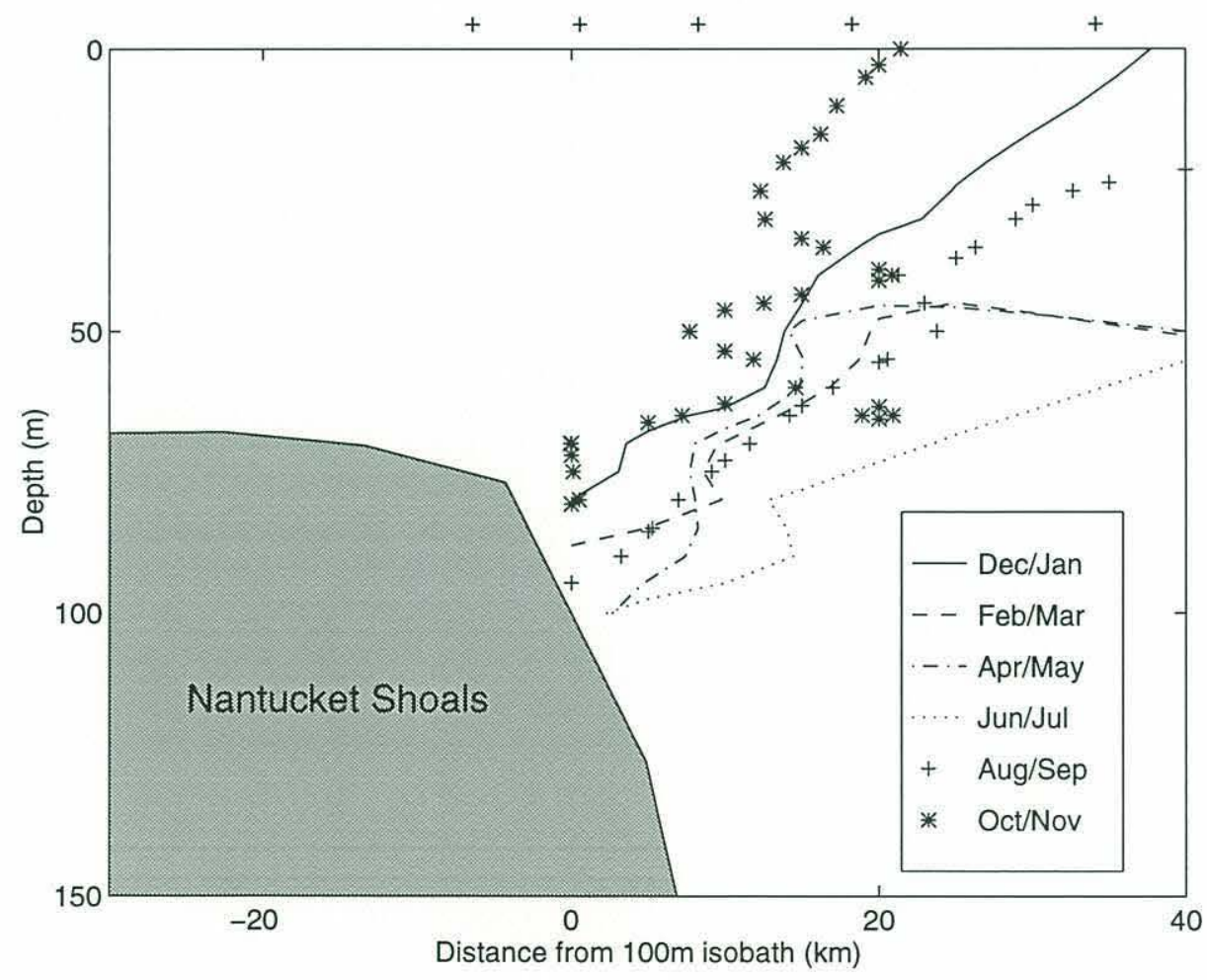

Figure 3.8: NS 34.5 PSS isohalines 
Oct/Nov and Dec/Jan the front is at its extreme onshore position. During Feb/Mar, the bottom outcrop shifts noticeably offshore by $1-2 \mathrm{~km}$ and deepens by $5 \mathrm{~m}$. This trend continues at roughly the same rate through Apr/May. The front reaches its maximum offshore position in Jun/Jul. The Aug/Sep bottom outcrop is displaced significantly shoreward (3-4 $\mathrm{km}$ horizontally or 10-15 m vertically). This onshore retreat continues through the winter, when the front reaches its most shoreward position. This corresponds well with both the previous observation of freshest depth averaged shelf water during Jun/Jul (Figure 3.5) and Manning's [1991] observations. Manning [1991] analyzed the salinity of MAB shelf waters from 28 National Marine Fisheries Service's (NMFS) Marine Resources, Monitoring, Assessment, and Prediction (MARMAP) hydrographic surveys. He computed a mean salinity profile for each season (Winter, Spring, Summer, and Fall) for the New York Bight and Great South Channel regions. For the New York Bight region, the 34.5 PSS isohaline reached an onshore extreme during the fall and winter, intersecting the bottom at about the $80 \mathrm{~m}$ isobath. His spring and summer contour plots reveal a roughly $10 \mathrm{~km}$ horizontal (10$15 \mathrm{~m}$ vertical) offshore summertime migration of the frontal boundary, again showing close agreement with the NS climatology. During the summer time period, the isohalines exhibit a mid-depth $(20-40 \mathrm{~m})$ bend, qualitatively matching the NS climatological data shown in Figures 3.2 and 3.8. Some contradictions can be found between the climatology and Wright's [1976] conclusions. Wright [1976] estimated the mean position of the foot of the front to be at its extreme offshore location during the winter. However, Wright's [1976] plot of the surface expression agrees well with the climatology, showing the front to be most offshore during July and most onshore during the winter. The climatology also shows mixed agreement with Drinkwater et al. [1994]. They claim that the surface outcrop is most offshore during the winter, in contradiction with Figure 3.8. However, they 
also state that the front is at its most onshore location from August to October, which agrees well with the extreme onshore position of the Oct/Nov isohaline shown in Figure 3.8. The average location of the bottom outcrop of the 34.5 PSS isohaline for NS is roughly the $95 \mathrm{~m}$ isobath, located about $4-5 \mathrm{~km}$ shoreward of the $100 \mathrm{~m}$ isobath.

To illustrate inter-regional comparisons, this analysis has been repeated for GB and NJ. The GB isohalines, shown in Figure 3.9, are different in several ways from the NS positions. An obvious difference between GB and NS is the relatively shallower slope of the GB isohalines in the region near the shelfbreak (roughly $2 \times 10^{-3}$ ). No isohalines physically intersect the surface for this cross-shelf range. Also, the point where the isohaline slopes incline toward the horizontal occurs higher in the water column (between 40-50 m). The bottom outcrop occurs at a minimum depth of $110 \mathrm{~m}$ from Oct/Nov through Dec/Jan. The maximum depth of the outcrop, at about $130 \mathrm{~m}$ depth, occurs during the spring months, Feb/Mar and Apr/May. During the summer months the front moves onshore to roughly the $110 \mathrm{~m}$ isobath again. Flagg et al. [1982] also showed an onshore frontal migration during the summer. However, while the climatology shows an offshore adjustment during the winter (Feb/Mar), Flagg et al. [1982] observed this movement in late fall. The seasonal cycle is much less clearly defined compared to NS, and the average bottom outcrop isobath, $120 \mathrm{~m}$, is deeper, most likely corresponding to the deeper average shelfbreak depth in this region. Manning's [1991] Great South Channel mean salinity profiles show a slightly shallower frontal bottom outcrop ( 100 $\mathrm{m}$ isobath). They also show very little seasonal variability, as is shown for GB in Figure 3.9. He found that the front reached its most shoreward position during the Fall, although the annual seasonal migration was very small. 


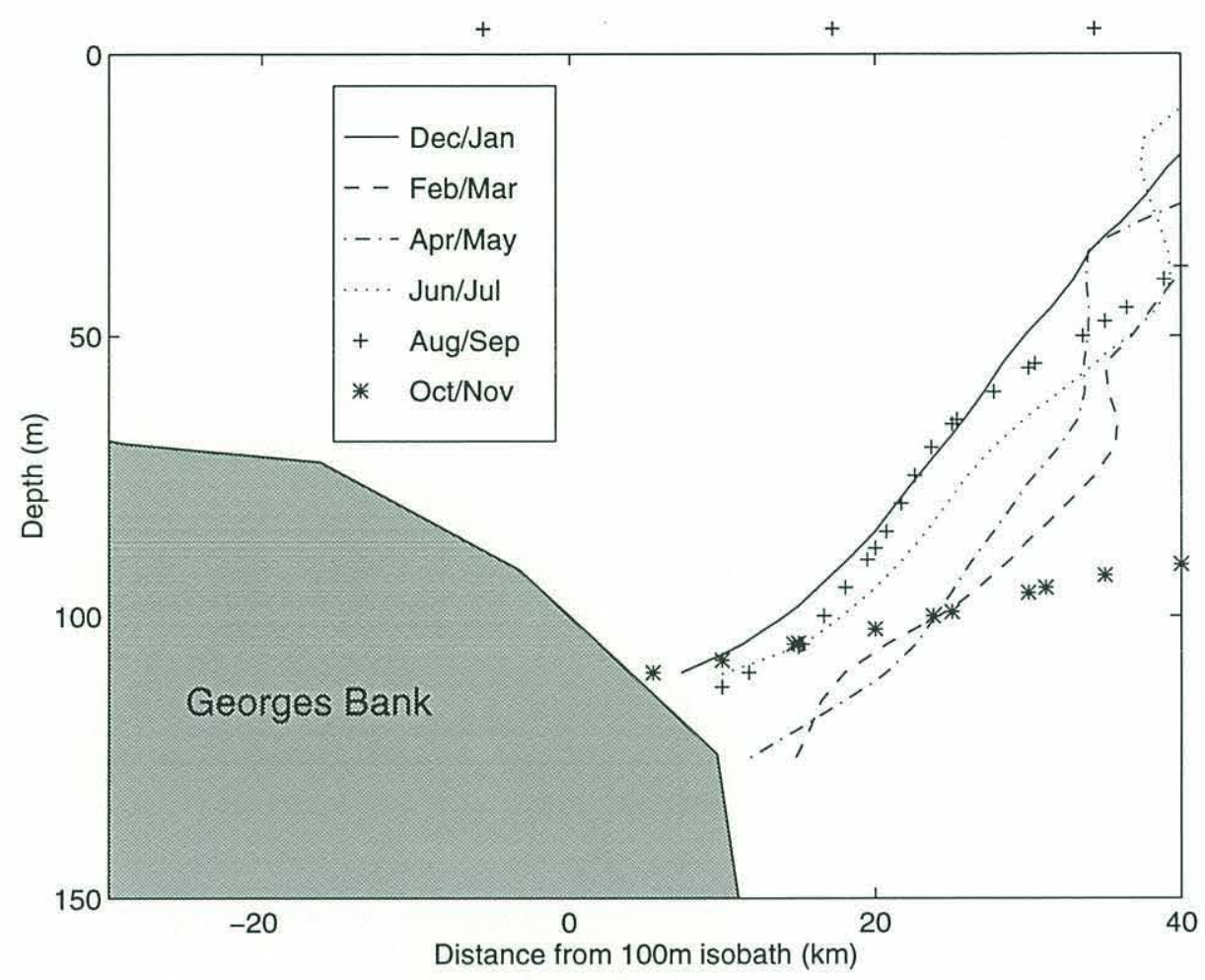

Figure 3.9: GB 34.5 PSS isohalines

In contrast to both GB and NS, the NJ isohalines, shown in Figure 3.10, exhibit a surface expression for this given cross-shelf range in every time period except Jun/Jul and Aug/Sep. The Dec/Jan curve is anomalous because it is almost $20 \mathrm{~km}$ shoreward of every other bimonthly curve. This may be due to the increased coarseness of the cross-shelf bin spacing (compared to NS), a result of data scarcity in the NJ regional subset. From February through November, though, the frontal bottom outcrop is tightly bound near the shelfbreak. Also, the slope of the isohalines near the shelfbreak is steeper than either of the other two regions $\left(>3 \times 10^{-3}\right)$. The seasonal cycle is easily observed in the position of the surface outcrop of the front, since it shows much more seasonal variability than the bottom outcrop. The increased surface variability was also observed by Wright [1976]. The 
frontal bottom outcrop progresses offshore further by about 2-3 km/month from February through April. Then, during Jun/Jul, there is as a flattening of the frontal isohaline at $30 \mathrm{~m}$ depth. By August, however, the front is already moving back onshore, by $1-2 \mathrm{~km}$. This trend continues through Oct/Nov, and the front makes a large onshore movement during Dec/Jan, the period of most vigorous vertical mixing. The average position of the bottom outcrop, the shallowest of the three regions, is roughly the $75 \mathrm{~m}$ isobath. Figure $3.11 \mathrm{sum}-$ marizes the frontal bottom outcrop migrations for each of the three regions. Clearly, the foot of the front is shoaling as the flow progresses to the southwest. It is important to note that although the annual mean position of the bottom outcrop varies substantially by region, the bathymetry also varies substantially. The overriding trend is for the shelfbreak front, marked by the 34.5 PSS isohaline, to manifest itself on or near the shelfbreak. Wang

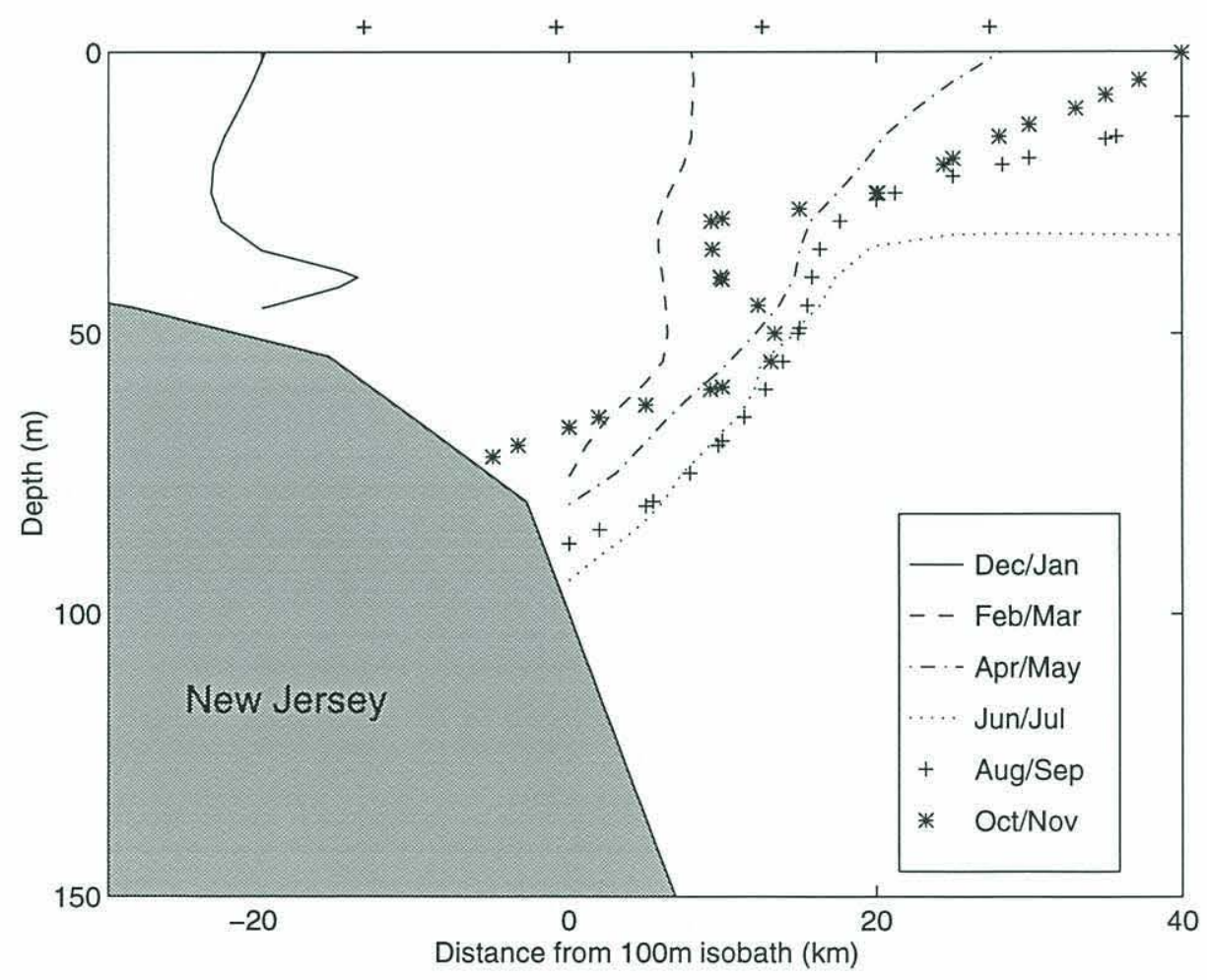

Figure 3.10: NJ 34.5 PSS isohalines 
[1984], Gawarkiewicz and Chapman [1992], and Condie [1993] have also studied this characteristic through different models. Their conclusions support the climatological results. Another prominent feature is the mid-depth flattening of the 34.5 PSS isohalines, indicating an extensive offshore presence of shelf water ( $<34$ PSS) during some time periods.

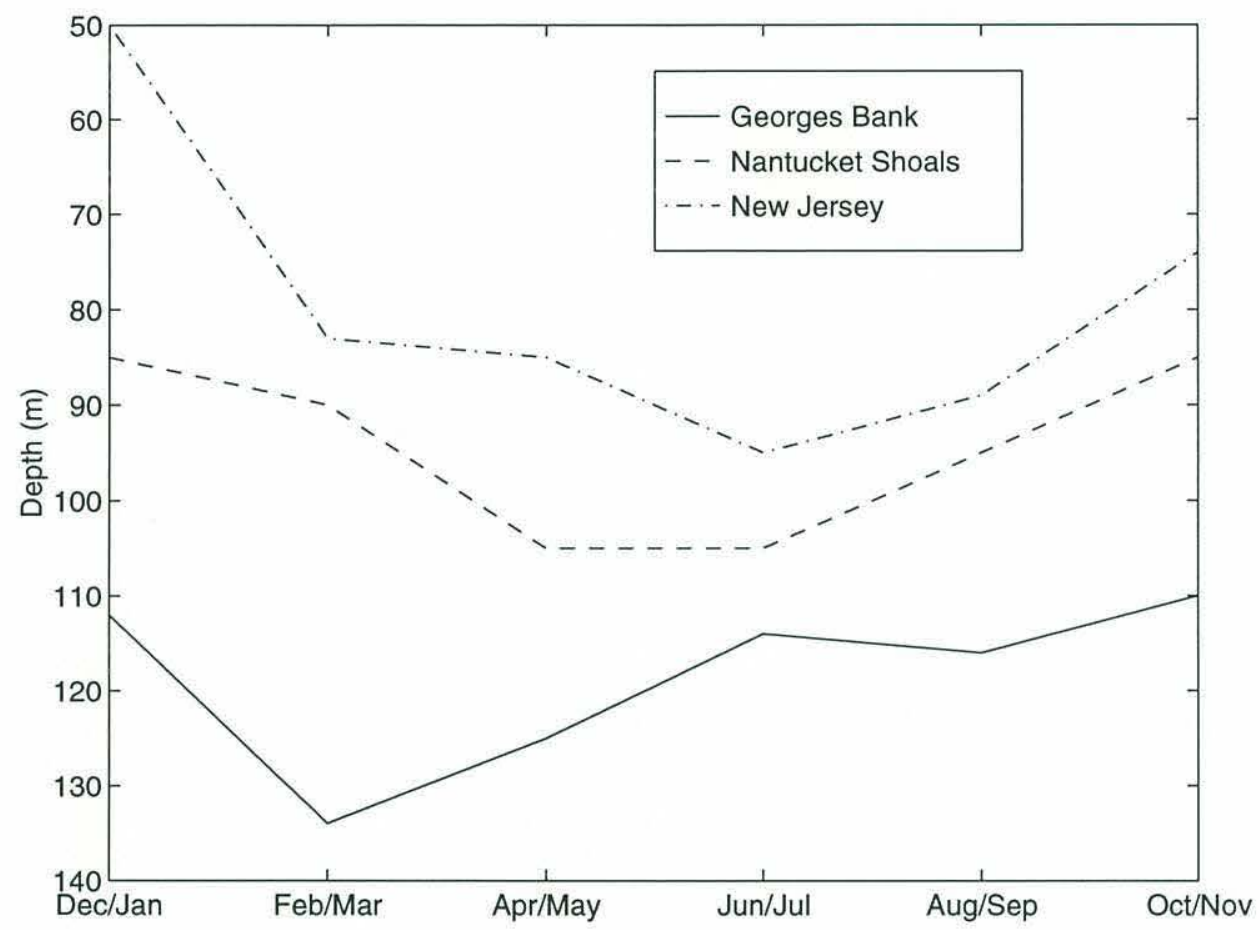

Figure 3.11: Inter-regional comparison of the depth of the frontal bottom outcrop

Figure 3.11 also reveals a spatial lag in the frontal migration. This is most readily apparent when considering the time period of extreme offshore frontal position (deepest bottom outcrop). The front is most offshore during Feb/Mar for GB, Apr/May or Jun/Jul for NS, and Jun/Jul for NJ. Despite the coarse temporal scale of the study, it appears that a freshwater pulse could be moving southward through the MAB, displacing the frontal boundary seaward. This is consistent with Chapman and Beardsley [1989], who con- 
cluded that the MAB mid and outer shelf waters were part of a southward flowing coastal current originating as far north as the Labrador Shelf.

\subsection{Nantucket shoals salinity variability}

The seasonal salinity on the shelf and slope has been studied using the raw (unbinned) NODC salinity measurements for NS. First, the stations with no echosounder depths were removed. Then, the stations were segregated based on echosounder depths into shelf (depths $<80 \mathrm{~m}$ ), frontal (depths 80-300 m), and slope (depths $>300 \mathrm{~m}$ ) regimes. Figure 3.12 shows the raw NS shelf regime salinity values, plotted by Julian day, for 5-15 $\mathrm{m}$ depth (a) and 45-55 $\mathrm{m}$ depth (b). Below these plots is the monthly mean salinity for each month and the standard error. Note the change in salinity scale between the upper and lower plots. The raw salinity plots for both depth levels show a marked increase in the variability during the late summer through winter months. A seasonal trend is evident in both the upper layer (a) and intermediate layer (b) monthly mean salinities. The highest mean shelf salinity, 33.1 PSS, occurs in January in the near surface layer. The peak salinity for the intermediate layer is nearly 0.5 PSS greater than the surface value, and occurs in October. The lowest monthly mean salinities occur in July for the surface $(\sim 32.4$ PSS) and June for the intermediate ( 32.8 PSS) depth bands.

Figure 3.13 repeats the analysis for the frontal (echosounder depths $80-300 \mathrm{~m}$ ) regime. The most striking difference from the shelf regime is the large increase in salinity variability. This is expected due to the movement of the frontal boundary through this region. The monthly mean salinities are both greater than the shelf waters by about 0.5 PSS. The vertical range in mean near surface salinity (from 32.9 PSS in July to 34.2 PSS in October) is more than double the range observed for the shelf regime. The annual mean 
a)
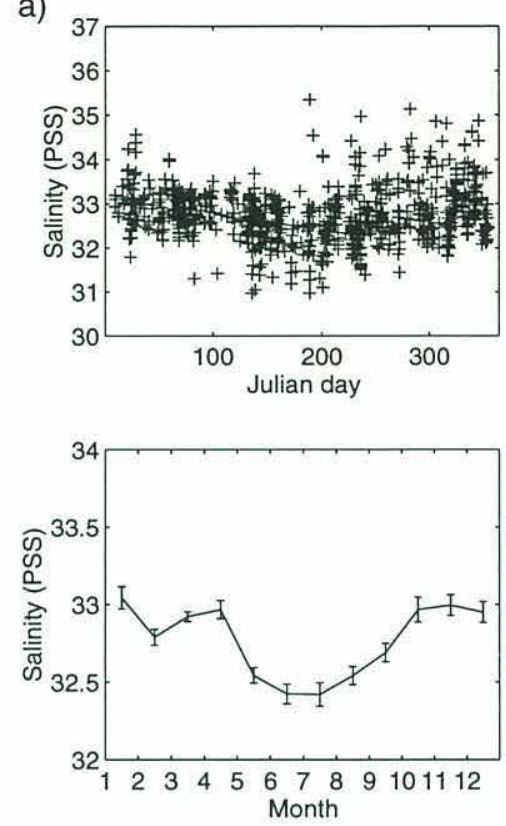

b)
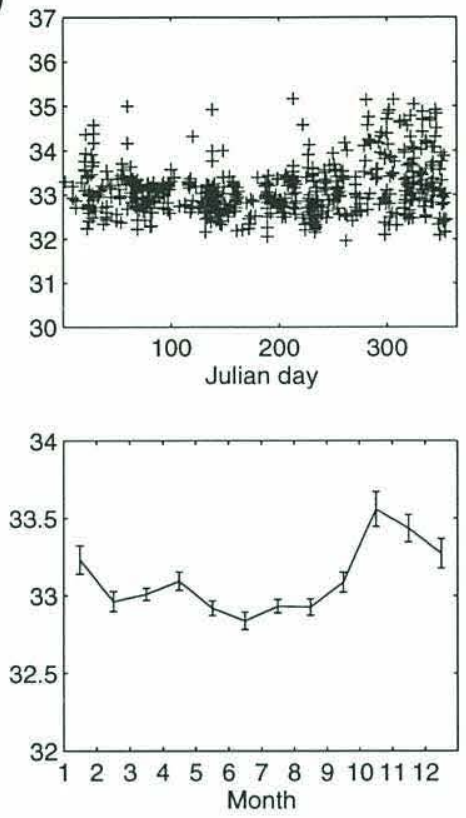

Figure 3.12: (a) Near surface (5-15 m) (b) Intermediate layer (45-55 m) NS shelf water salinity (stations within $0-80 \mathrm{~m}$ isobaths)

standard errors for the upper and intermediate layers are larger than the shelf water values by $59 \%$ and $62 \%$, respectively.

Surprisingly, the slope water (echosounder depths $>300 \mathrm{~m}$ ) regime, shown in Figure 3.14, exhibits even more variability than the frontal regime. Salinities from 32-36 PSS can be found in the near surface (a, upper) plot. The monthly mean near surface salinity shows no clear seasonal trend, due mainly to the relatively few data points contributing to the mean. This is shown by the large standard error bars. The intermediate layer monthly mean is much more coherent, and reveals a similar seasonal trend to the other regimes. A sharp drop in the salinity occurs in June, when the monthly mean was a remarkably fresh 33.7 PSS. The salinity was $\sim 34.5$ PSS for the rest of the year. 


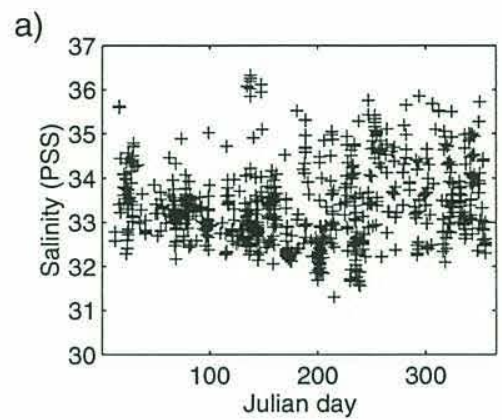

b)
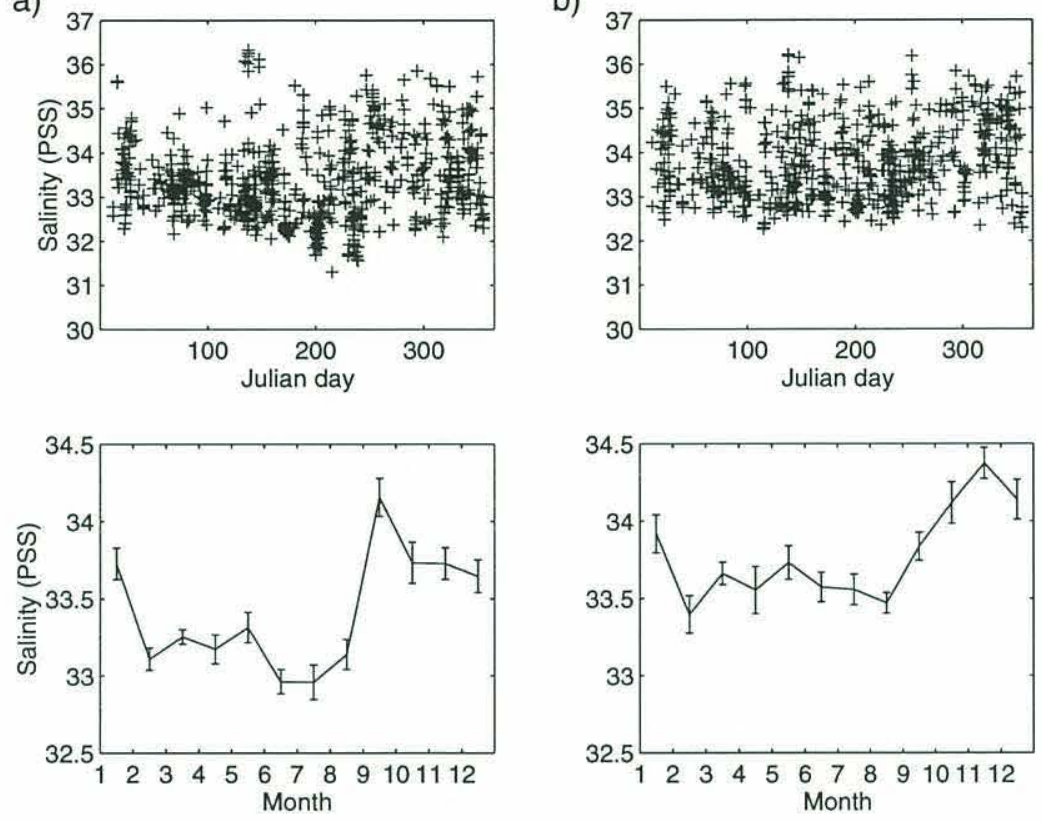

Figure 3.13: (a) Near surface (5-15 m) (b) Intermediate layer (45-55 m) NS frontal water salinity (stations within $80-300 \mathrm{~m}$ isobaths)

These plots have shown the clear seasonal cycle in the near surface and intermediate depth salinities for all three regimes. A lack of data is evident in the large standard errors in the slope regime. The seasonal trend of the mean shelf salinity supports the observations of frontal movement made in the previous section. The mean monthly averaged 45-55 m shelf salinity (Figure 3.12 (b), lower panel) closely follows a similar curve computed by Manning [1991], which shows a clear salinity peak in January and a minimum in June.

To better illustrate the cross-shelf distribution of salinity in the upper surface layer, the raw salinities have been plotted in the 5-15 $\mathrm{m}$ depth range for NS as a function of cross-shelf distance from the $100 \mathrm{~m}$ isobath. The cross-shelf distances were computed from the latitudes of each station, assuming the average latitude of the $100 \mathrm{~m}$ isobath to be 
a)
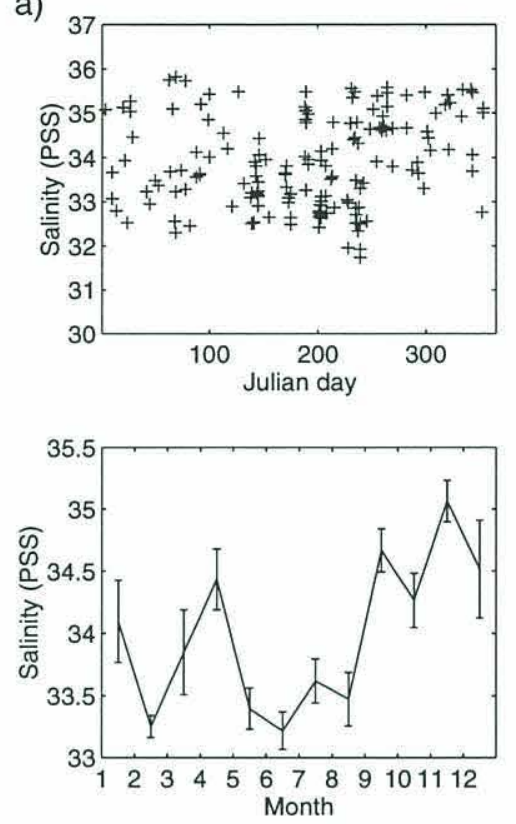

b)
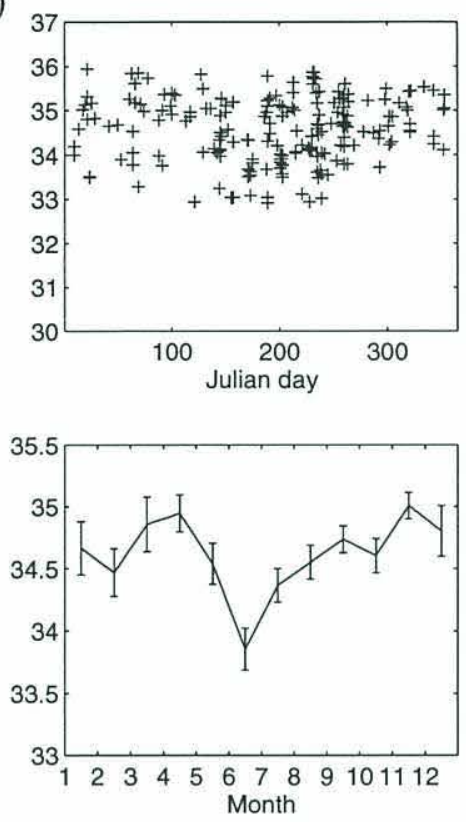

Figure 3.14: (a) Near surface (5-15 m) (b) Intermediate layer (45-55 m) NS slope water salinity (stations within $300-2500 \mathrm{~m}$ isobaths)

$40^{\circ} 7.66^{\prime}$ N. Every station could thus be used, regardless of echosounder depth.

Figure 3.15 shows the result of this analysis for Dec/Jan, Feb/Mar, and Apr/May.

The 34 and 35 PSS values have been added to delineate shelf waters ( $<34$ PSS), frontal waters (34-35 PSS), and slope waters (> 35 PSS), following Manning [1991]. The surface expression of the shelfbreak front can also thus be delineated in these plots as the point where the "frontal water" is concentrated. During Dec/Jan, the frontal water appears to be centered at about the $100 \mathrm{~m}$ isobath. "Shelf" water penetrates up to $70 \mathrm{~km}$ seaward of the shelfbreak. "Slope" water rarely (one instance) penetrates shoreward of the shelfbreak. During Feb/Mar, an increased freshening of the surface layer is evident. Almost all of the data points fall in the shelf water regime, with a seasonal minimum of observations in the frontal band. Shelf water is found nearly $100 \mathrm{~km}$ seaward of the $100 \mathrm{~m}$ isobath. Once 
again no slope water has penetrated shoreward of the shelfbreak. This freshness in the surface layer continues through Apr/May. The average location of this frontal water has moved offshore by about $20 \mathrm{~km}$ compared to Dec/Jan, indicating an increasing frontal slope, substantiating the observations made in the previous section.

Figure 3.16 continues the plots for Jun/Jul, Aug/Sep, and Oct/Nov. Jun/Jul exhibits a few marked differences from the previous "winter" plots. Firstly, the average shelf salinity has dropped considerably. During Feb/Mar and Apr/May, the shelf salinities appear to be centered between 32 and 33 PSS. Jun/Jul shelf salinities on the average are much lower, centered between 31.5 and 32.5 PSS, supporting the previous conclusion that this time of the year is the freshest for NS. It is also important to note the large horizontal extent ( $130 \mathrm{~km}$ ) in frontal water. The shelf regime water penetrates to the maximum offshore extent of the data set. A few slope water measurements can be observed up to $50 \mathrm{~km}$ onshore of the shelfbreak, most likely due to the isopycnal connection between shelf and slope waters established via the summer thermocline. The freshening trend in the shelf waters has reversed during Aug/Sep (mean 32.7 PSS). Also, the offshore extent of the shelf waters has decreased noticeably, penetrating only $60-70 \mathrm{~km}$ seaward of the shelfbreak. The cross-shelf extent of frontal water has increased, as well as the number of points in the frontal water range. Slope waters continue to penetrate shoreward of the shelfbreak, extending up to $40 \mathrm{~km}$ shoreward of the $100 \mathrm{~m}$ isobath. During Oct/Nov, no salinities in the surface layer fresher than 31.9 PSS are found, indicating the time period of possibly most saline surface waters. Fewer offshore measurements of shelf water can be found, and penetrations of slope water onto the shelf have also become more rare. 

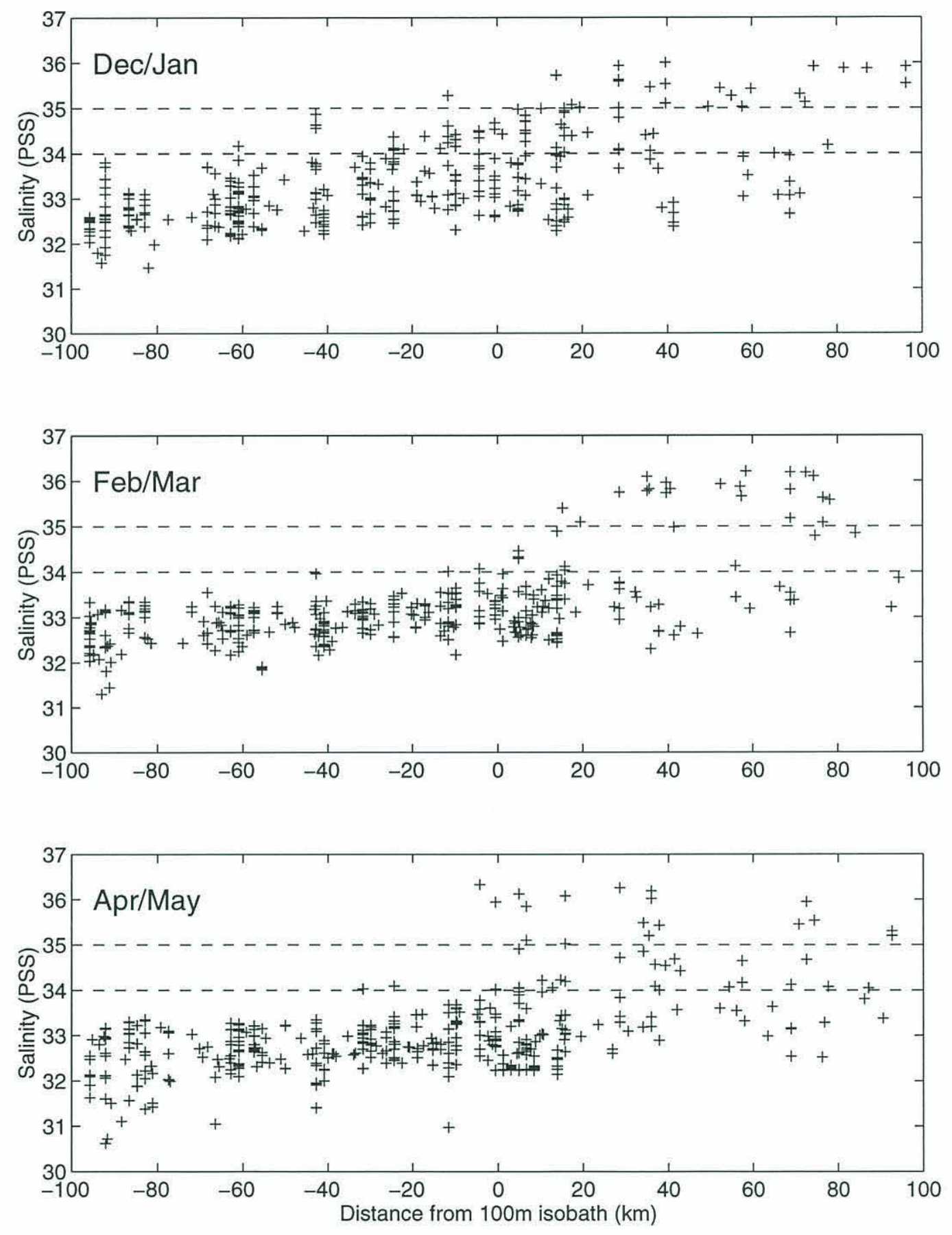

Figure 3.15: Winter/spring NS cross-shelf near surface (5-15 m) salinities 

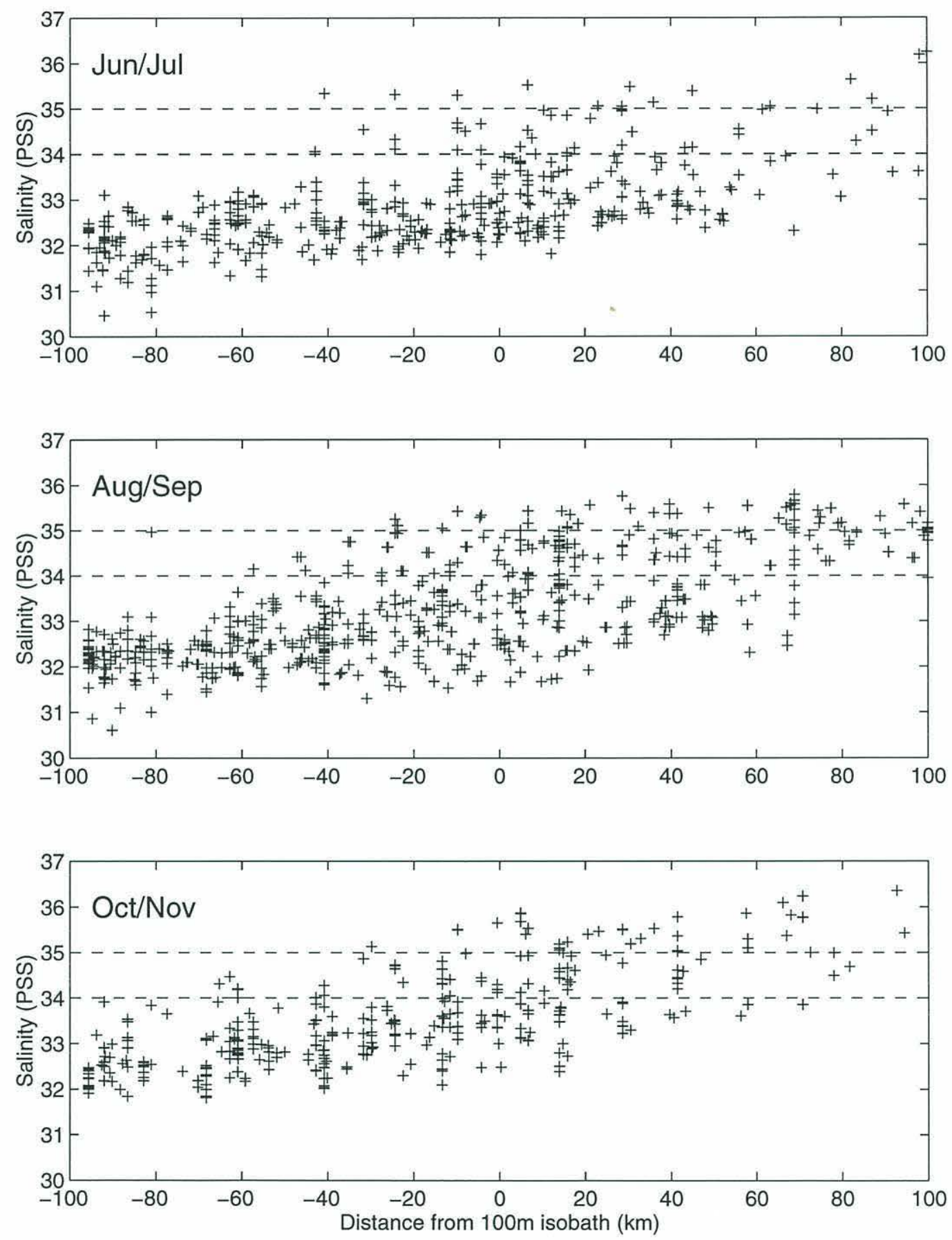

Figure 3.16: Summer/fall NS cross-shelf near surface (5-15 m) salinities 
Figures 3.15 and 3.16 have revealed a number of important results about the NS near surface $(5-15 \mathrm{~m})$ layer. The "shelf" waters $(<34$ PSS) exhibit a seasonal freshening which results in the freshest shelf water being found during Jun/Jul, and the most saline during Oct/Nov and Dec/Jan. These results are in good agreement with Manning [1991]. The shelf water extends far offshore throughout the year, and has even been observed at the maximum southern extent of the study region, $39^{\circ} \mathrm{N}$. The number of "frontal" water measurements (34-35 PSS) varies substantially by season, being a minimum during the winter and a maximum during the summer months. The large variation in frontal water cross-shelf position indicates that the slope of the shelfbreak front may be highly variable during this period.

The penetration of "slope" water ( $>35$ PSS) onto the shelf can be caused by the isopycnal connection between the shelf and slope waters [Aikman, 1984]. However, Gawarkiewicz et al. [1992] has also observed a large-scale penetration of extremely saline (> 36 PSS) Gulf Stream water off Cape Hatteras. The saline water was concentrated in the near surface layer $(10-30 \mathrm{~m})$ and reached as far onshore as the $25 \mathrm{~m}$ isobath. Figures 3.15 and 3.16 have shown that such events have not been observed in the database used for this climatology. Gawarkiewicz et al. [submitted] have recently (August, 1995 data) observed a similar summertime penetration of saline water in the New England MAB. The intrusion was also confined to the upper $25 \mathrm{~m}$ of the water column and coincided with the presence of an offshore warm core ring. The saline water penetrated up to $40 \mathrm{~km}$ shoreward of the $100 \mathrm{~m}$ isobath. These instances illustrate the extreme range of variability in the shelfbreak frontal region. They also point out that the climatology is useful mainly as a representation of the "most likely" state of the ocean, or a benchmark by which to judge the rarity of certain states or occurrences in the frontal region. 


\section{Chapter 4}

\section{Dynamics of the mean fields}

\subsection{Baroclinic jet temporal and spatial variability}

The currents over the shelf and slope were initially mapped in the mid-19th century by Findlay and Maury [Beardsley and Boicourt, 1981]. Since then, researchers have attempted to better quantify the mean flow through the MAB by measuring the currents directly and by inferring them from the density fields of geostrophic adjustment models. The driving force behind the mean flow has also been a topic of interest.

Current meter analyses by Beardsley and Flagg [1976], Voorhis et al. [1976], Beardsley et al. [1985], and Aikman et al. [1988] have revealed the structure of the mean and synoptic currents over the MAB shelf. Beardsley and Flagg [1976] and Voorhis et al. [1976] observed that the mean flow was consistently to the southwest, generally parallel to the isobaths. Due to coarse current meter spacing, the surface intensified frontal baroclinic jet could not be resolved. Aikman et al. [1988] and Burrage and Garvine [1988] observed a strengthening of the mean surface currents in the vicinity of the shelfbreak, providing strong proof of the baroclinic jet's existence. Using a high-resolution ADCP section, Gawarkiewicz et al. [in press] have shown the scale and magnitude of a typical shelfbreak front jet. They demonstrated that the jet resulted almost entirely from the horizontal density shear across the front. Modelers [Ou, 1983 and 1984, and Wang, 1984] have also contributed descriptions of the baroclinic jet feature.

Beardsley and Flagg [1976] observed that the mean westward currents persisted for the duration of their experiment despite eastward wind events. Chapman et al. [1986] 
also showed that the mean wind stress and currents were in opposition. This evidence seems to discount the possibility of wind stress being the MAB shelf flow forcing mechanism. Beardsley and Flagg [1976] postulated that either the coastal fresh water input or a momentum component from the deep ocean was responsible for the mean shelf flow. Beardsley and Boicourt [1981] provide further discussion on the possibility of the deep ocean contributing an alongshelf pressure gradient. Chapman et al. [1986] modified this argument by specifying that the alongshelf pressure gradient may be confined to the shelf itself. An $\mathrm{O}^{18}$ analysis has shown that the alongshelf flow through the MAB is part of a $5000 \mathrm{~km}$ long coastal current system originating as far away as the Denmark Straits [Chapman and Beardsley, 1989].

Figure 4.1 shows regularly gridded sections of the alongshelf geostrophic velocity, computed for winter (Feb/Mar) and summer (Aug/Sep) using the thermal wind relation described in Section 2.3.2. Barotropic currents derived from mean near bottom current meter observations [taken from Beardsley et al., 1983] have been included in the calculations. The geostrophic velocity calculations indicate a mean westward shelf flow of greater than $5 \mathrm{~cm} \mathrm{~s}^{-1}$ to the west during both seasons. Flow over the shelf is generally dominated by the barotropic component, since horizontal density gradients are weak on the shelf throughout the year. The dominant feature is the frontal baroclinic jet, which is clearly resolved by the climatology. It has a cross-shelf extent of about $15 \mathrm{~km}$ at the surface and a core velocity in excess of $15 \mathrm{~cm} \mathrm{~s}^{-1}$ during winter and $25 \mathrm{~cm} \mathrm{~s}^{-1}$ in summer. The size and location of the jet for each of the three regional subsets will be discussed later.

Figure 4.2 shows the NS depth-averaged alongshelf geostrophic velocity over a full seasonal cycle. Depth ranges correspond to those used in earlier plots: the upper plot 

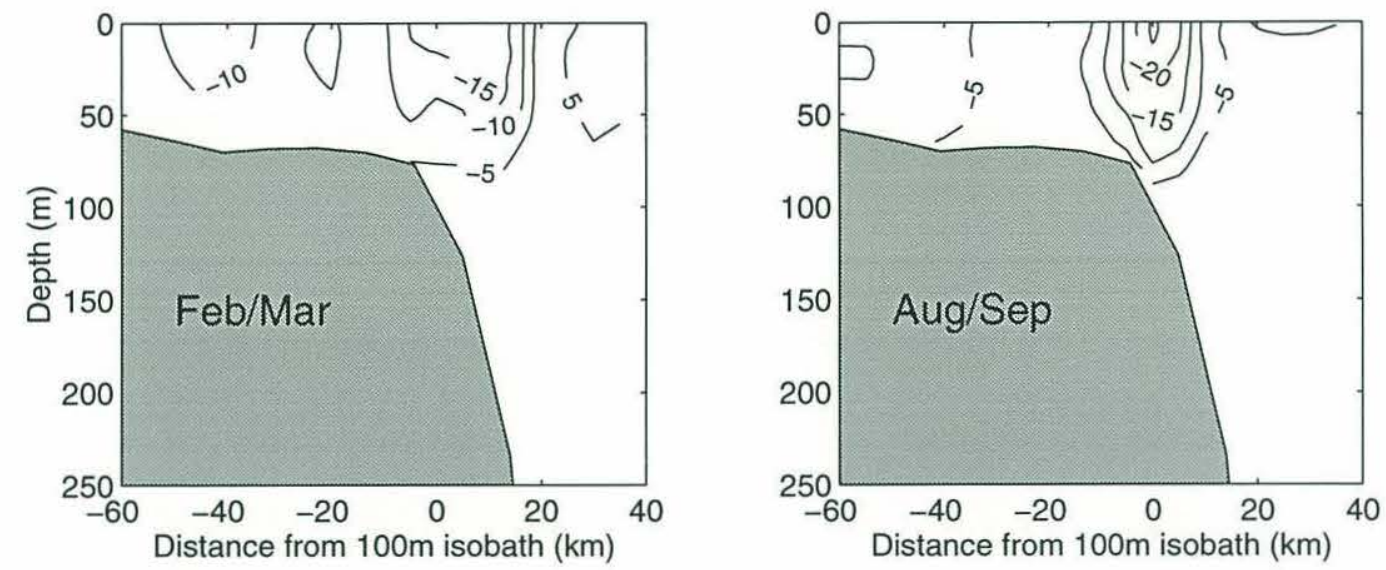

Figure 4.1: Winter and summer NS geostrophic velocity sections $\left(\mathrm{cm} \mathrm{s}^{-1}\right)$ computed using Figure 2.7 bottom reference velocities

shows the near surface (5-25 m) and the lower plot shows an intermediate layer (45-65 m). For uniformity, a level of no motion along the bottom was assumed for all time periods. The near surface plot reveals the seasonal robustness of the baroclinic jet feature. The core of the surface jet is located from $0-15 \mathrm{~km}$ offshore of the $100 \mathrm{~m}$ isobath and ranges in strength from $15-25 \mathrm{~cm} \mathrm{~s}^{-1}$ to the west throughout the year. The baroclinic current is small but generally westward over the shelf, ranging from $1-10 \mathrm{~cm} \mathrm{~s}^{-1}$ in magnitude. It is also interesting to note the presence of a second eastward-flowing baroclinic jet located just onshore of the shelfbreak. It reaches a maximum strength of over $5 \mathrm{~cm} \mathrm{~s}^{-1}$ during Dec/Jan. It appears to be a more robust feature during the winter and spring time periods (Dec/Jan and Apr/May). This feature is a likely result of the Nantucket Shoals tidal mixing front [Limeburner and Beardsley, 1982]. The baroclinic current also tends to shift eastward over the slope waters, sometimes reaching magnitudes of over $5 \mathrm{~cm} \mathrm{~s}^{-1}$.

The lower plot of Figure 4.2 shows the depth-averaged geostrophic velocity for a deeper region (45-65 m). Over the shelf, where the water depth is relatively shallow, the 

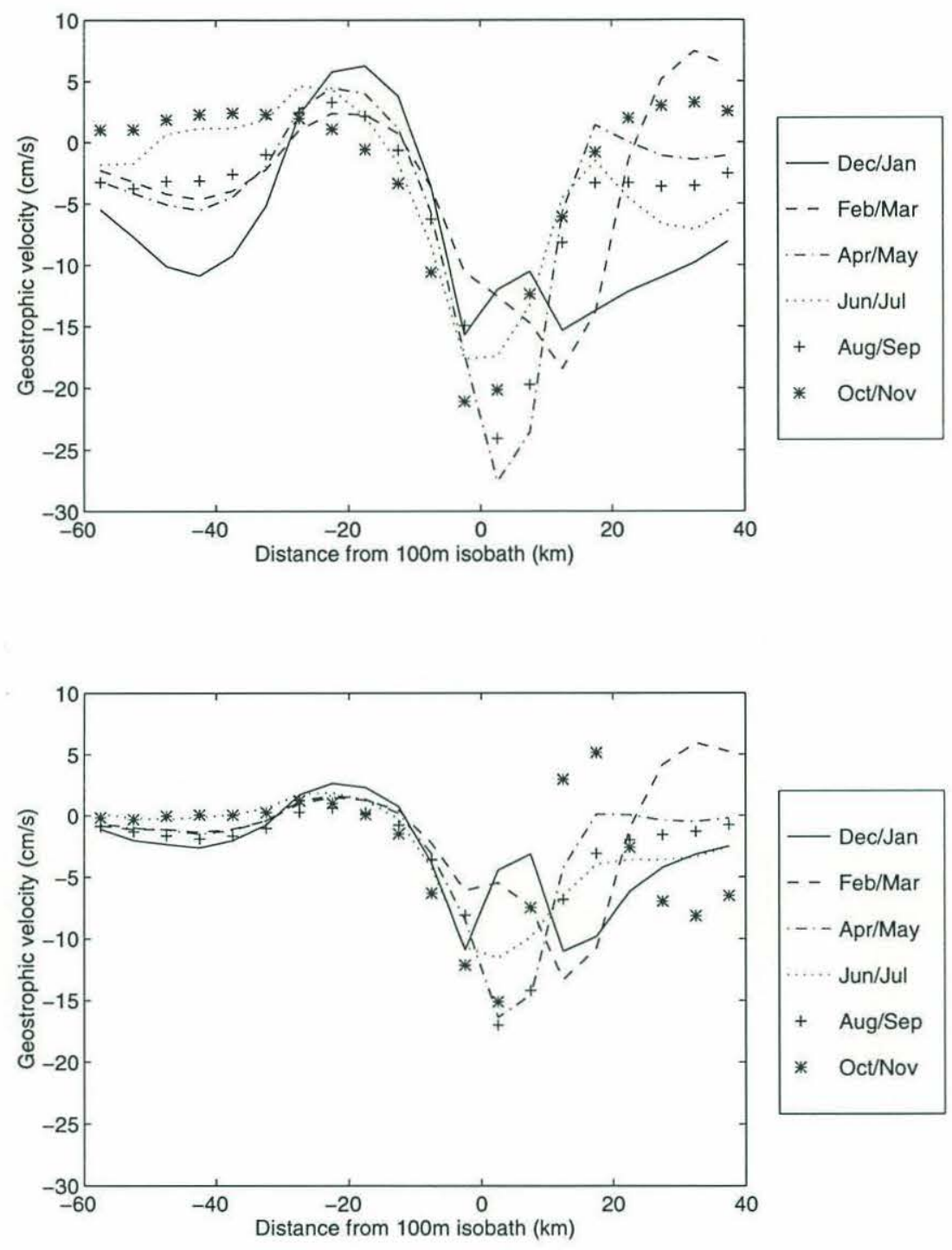

Figure 4.2: Depth averaged near surface (5-25 m, upper panel) and intermediate layer (45-65 m, lower panel) NS geostrophic velocity (level of no motion along bottom)

intermediate layer geostrophic velocity is nearly zero. Therefore, the westward baroclinic current and the small eastward jet are mainly due to density variations in the upper portion of the water column. In the shelfbreak jet region, it is expected from Section 3.2.2 that the geostrophic velocity contributions would be concentrated near the shelfbreak, especially 
in the summer. The lower plot of Figure 4.2 reveals that between $45-65 \mathrm{~m}$, the jet strength varies from $10-15 \mathrm{~cm} \mathrm{~s}^{-1}$. The jet velocities are not substantially less than the near surface velocities shown in the upper plot, showing the relative weakness of the baroclinic shear above $45 \mathrm{~m}$ depth. To better illustrate the seasonal and vertical distribution of geostrophic velocity contributions, the velocity contributions, computed with the thermal wind relation, for a horizontal distance of $2.5 \mathrm{~km}$ seaward of the shelfbreak (above $\sim 113 \mathrm{~m}$ isobath) have been plotted (Figure 4.3).

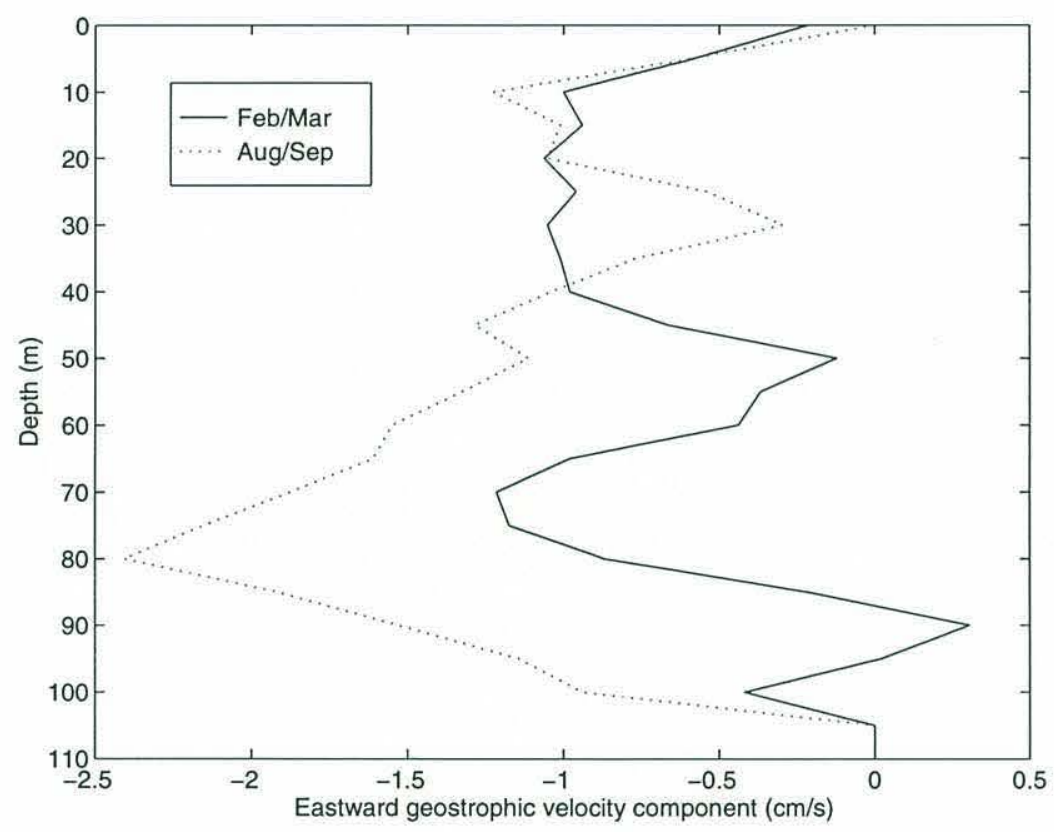

Figure 4.3: NS geostrophic velocity contributions $(\Delta v)$ above the $113 \mathrm{~m}$ isobath This plot reveals an increased summertime near bottom contribution (reaching a maximum of $\sim 2.5 \mathrm{~cm} \mathrm{~s}^{-1}$ at $80 \mathrm{~m}$ depth). The Feb/Mar vertical velocity contributions also peak near $80 \mathrm{~m}$, but seldom exceed $1 \mathrm{~cm} \mathrm{~s}^{-1}$ and are more uniformly distributed in depth. The two time periods have similar distributions near the surface. The increased near bottom contributions could be due to two factors. Firstly, this effect would be expected for the summer, when the horizontal density gradients decrease in the surface stratified layer but 
strong horizontal stratification exists at the foot of the front. This is consistent with arguments put forth by Gawarkiewicz and Chapman [1992] for the maintenance of the front. The contributions could also reflect a bias within the climatology. Since the surface expression of the front tends to be much more variable than the bottom outcrop [Wright, 1976], one would expect increased data smearing of horizontal density gradients in the upper water column. This would explain the relatively high contribution to the geostrophic velocity at depth shown in Figure 4.3 for Feb/Mar and Aug/Sep.

Figure 4.4 shows the maximum surface jet velocity (upper panel) and horizontal location relative to the $100 \mathrm{~m}$ isobath (lower panel). These calculations all assume a level of no motion along the bottom. The strength of the NS surface jet is a minimum, $\sim 17 \mathrm{~cm}$ $\mathrm{s}^{-1}$, during Dec/Jan. The velocity increased to $\sim 30 \mathrm{~cm} \mathrm{~s}^{-1}$ during Apr/May. The strength of the jet fell to between 17 and $23 \mathrm{~cm} \mathrm{~s}^{-1}$ for the rest of the year. The annual mean maximum jet velocity is $\sim 22 \mathrm{~cm} \mathrm{~s}^{-1}$ to the west. The GB jet is generally weaker by $5-15 \mathrm{~cm} \mathrm{~s}^{-1}$ (annual mean velocity of $\sim 15 \mathrm{~cm} \mathrm{~s}^{-1}$ to the west). During Dec/Jan, the jet is at its peak strength of $23 \mathrm{~cm} \mathrm{~s}^{-1}$. The jet strength then decreased, until reaching a minimum of $\sim 7 \mathrm{~cm}$ $\mathrm{s}^{-1}$ during Aug/Sep. Although the NJ and GB surface baroclinic maximum velocities have similar annual means, they have opposite seasonal trends. The $\mathrm{NJ}$ jet is weakest during the winter $\left(\sim 8 \mathrm{~cm} \mathrm{~s}^{-1}\right)$ and increases in strength during the summer, reaching a maximum of $\sim$ $20 \mathrm{~cm} \mathrm{~s}^{-1}$ during Jun/Jul. It is important to note that the jet maximum velocities, while slightly higher for NS, are all significant for each region throughout the year.

The movement of the surface jet core is shown in the lower plot of Figure 4.4. All of the regional subsets seem to migrate onshore through the spring and summer, and make a large offshore movement between late fall and winter. The NS jet core ranges from 

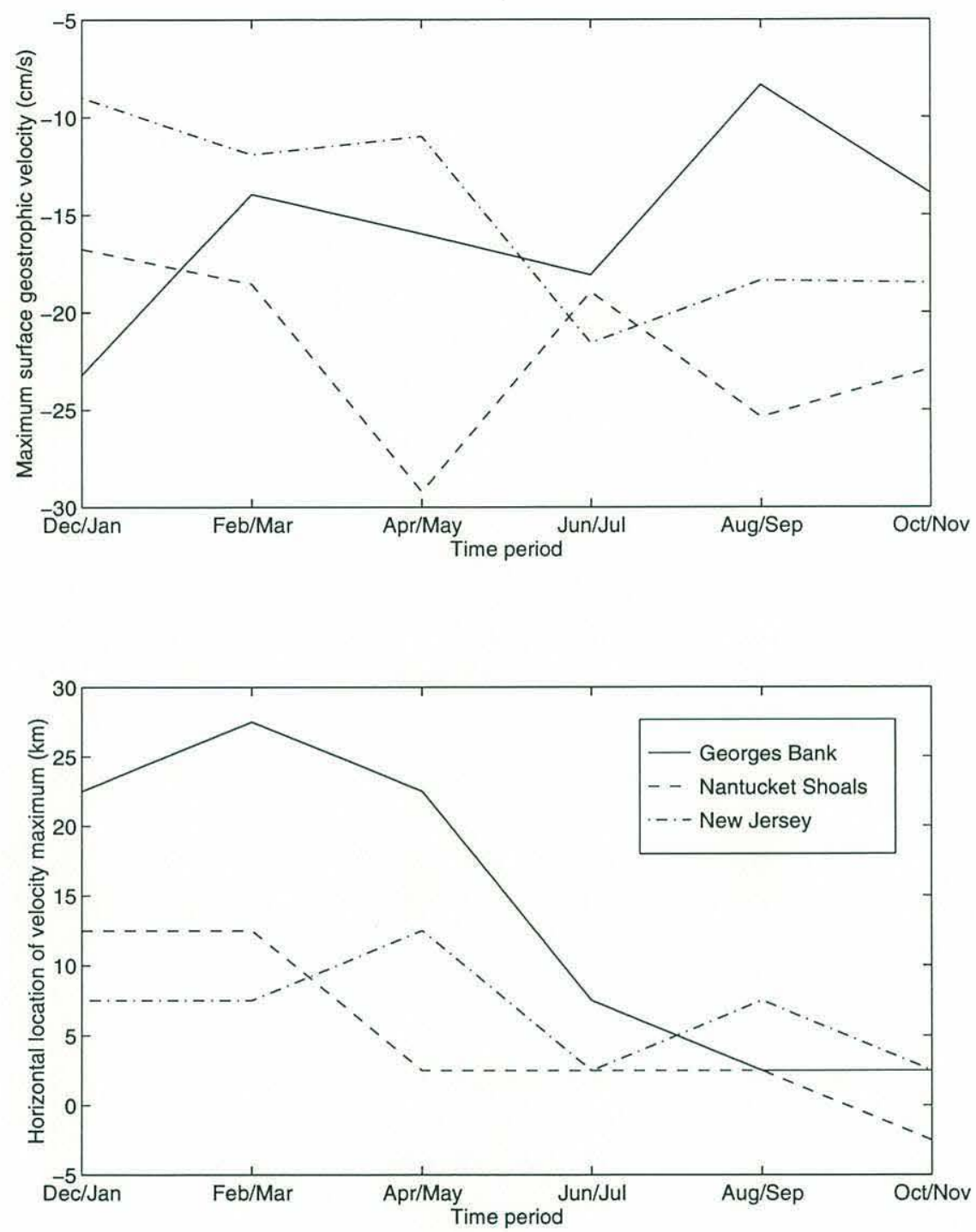

Figure 4.4: Peak surface velocity (positive eastward) and location of shelfbreak jet core between $12.5 \mathrm{~km}$ offshore (Dec/Jan) to $2.5 \mathrm{~km}$ onshore (Oct/Nov) of the $100 \mathrm{~m}$ isobath. The annual mean position of the NS jet core is $\sim 5 \mathrm{~km}$ offshore of the $100 \mathrm{~m}$ isobath, or above the $125 \mathrm{~m}$ isobath. In previous Sections (3.2 and 3.3) the front was shown to be at its most offshore point during Jun/Jul, then migrating back onshore through the fall and 
winter. Figure 4.4 shows that the jet continues its onshore migration through the late summer and fall despite an apparent offshore frontal migration occurring in spring. The GB and $\mathrm{NJ}$ jet cores have similar seasonal trends. The annual mean location of the GB jet is $14 \mathrm{~km}$ offshore of the $100 \mathrm{~m}$ isobath or above the $200 \mathrm{~m}$ isobath, while the annual mean location of the $\mathrm{NJ}$ jet is $\sim 7 \mathrm{~km}$ offshore of the $100 \mathrm{~m}$ isobath or above the $150 \mathrm{~m}$ isobath.

The upper panel of Figure 4.5 shows the surface width of the baroclinic jet, computed based on the width of the contour of half of the maximum surface velocity. The results showed very little seasonal variability for any region. The NS jet is approximately $15-20 \mathrm{~km}$ wide except for Dec/Jan, when it is roughly $40 \mathrm{~km}$ wide. The annual mean width of the NS jet is $\sim 21 \mathrm{~km}$. The NJ jet is consistently $10-20 \mathrm{~km}$ wide (with the exception of Apr/May), with an annual mean of $\sim 19 \mathrm{~km}$. The GB jet was the most horizontally diffuse (annual mean width of $\sim 47 \mathrm{~km}$ ), corresponding perhaps to increased smearing of the frontal data or an increased frequency of warm core ring-induced streamers [Garfield and Evans, 1987]. It was often $>2$ times as wide as NS or NJ, and experienced a greater range of variability, being a minimum in Feb/Mar of $32 \mathrm{~km}$, and reaching a maximum in Aug/Sep of $80 \mathrm{~km}$. This plot clearly illustrates why previous direct observations of the baroclinic jet have been rare. Due to the smoothing effect resulting from averaging over 90 years of data, one would expect a typical "synoptic" jet to be smaller and have a larger peak velocity than shown in this work. In Section 3.2.2 it was shown that the climatological cross-shelf density difference is less than observed by a factor of 2-3. In general, then, one would expect a typical NS frontal jet to be about half as wide as the climatology ( 10 $\mathrm{km})$ and have twice the core velocity magnitude $\left(>40 \mathrm{~cm} \mathrm{~s}^{-1}\right)$. It would most likely be found between the 110-130 m isobaths. A detailed ADCP section off New Jersey [Gawarkiewicz et al., in press] supports the scales derived from the climatology. Gawark- 
iewicz et al. [in press] observed a $\sim 10 \mathrm{~km}$ wide jet feature with a maximum core velocity of $51 \mathrm{~cm} \mathrm{~s}^{-1}$. Pickart [pers. comm., 1996], in a preliminary analysis of high resolution ADCP data collected on the New England shelf during the winter, has noted an extremely intense jet feature with core velocities exceeding $80 \mathrm{~cm} \mathrm{~s}^{-1}$.
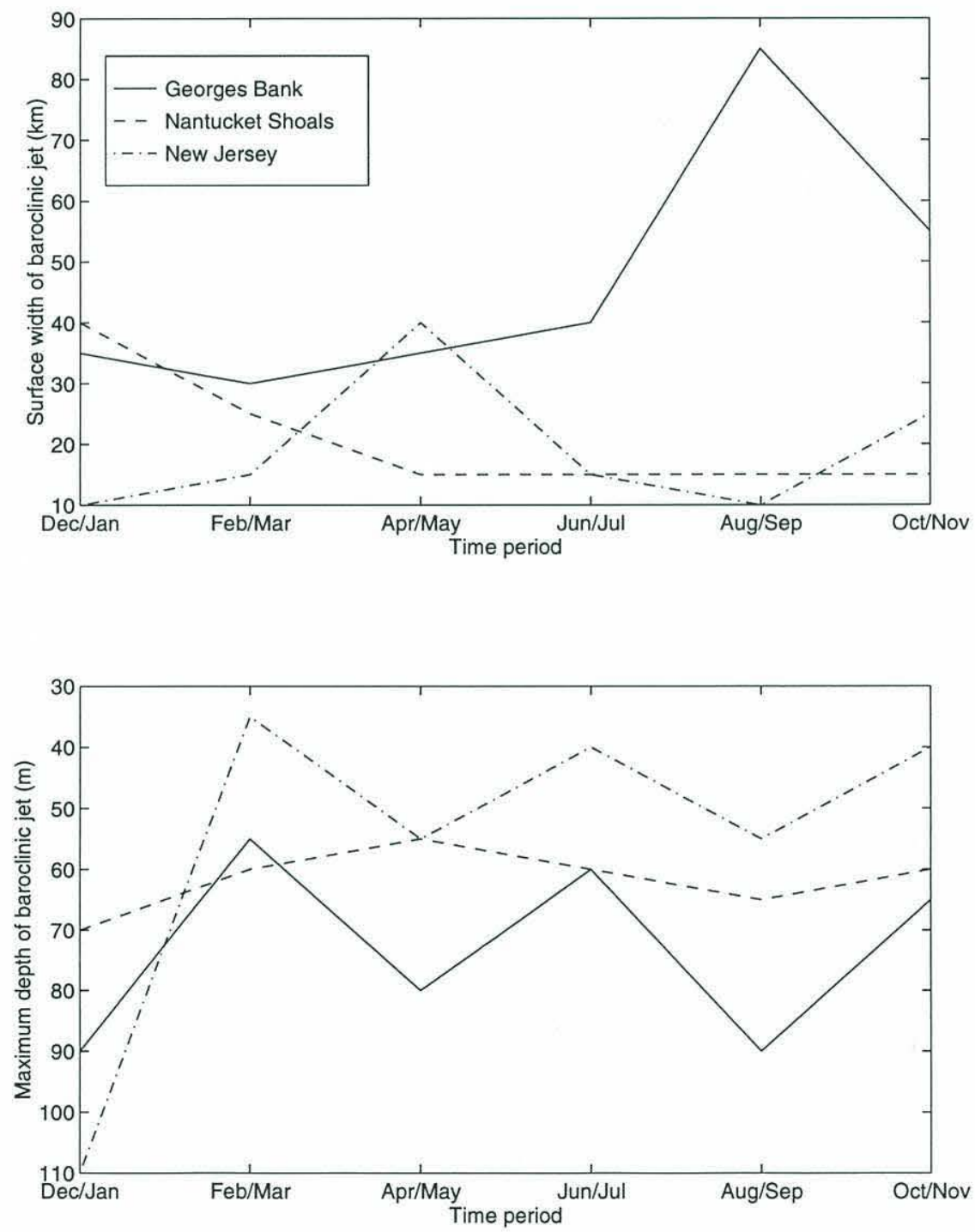

Figure 4.5: Shelfbreak jet width and depth, defined by $V_{\max } / 2$ contour 
The depth of the baroclinic jet, shown in the lower panel of Figure 4.5, is also defined by the $\mathrm{V}_{\max } / 2$ contour. The jet depth changed little seasonally for NS, being roughly $60 \mathrm{~m}$ throughout the year. On average, the GB jet extended an extra $15 \mathrm{~m}$ deeper than NS, also with little seasonal variation. The NJ jet depth is a maximum in Dec/Jan (over $110 \mathrm{~m}$ deep), and a minimum in Feb/Mar and Jun/Jul ( $35 \mathrm{~m})$. The average depth of the NJ jet is $55 \mathrm{~m}$. The three regions' baroclinic jets reach their peak depths during Dec/ Jan, corresponding to the period of weakest horizontal density gradients. The jet which Gawarkiewicz et al. [in press] observed extended to roughly $50 \mathrm{~m}$ based on the $\mathrm{V}_{\max } / 2$ contour, showing good agreement with the climatology.

The transport within the baroclinic jet has been calculated, defining the horizontal extents by the points at which the surface velocity decreases to $5 \mathrm{~cm} \mathrm{~s}^{-1}$ to the west. This corresponds to roughly $15 \mathrm{~km}$ cross-shelf for NS. Should this criteria not be satisfied, a maximum extent of $30 \mathrm{~km}$ in either direction from the core of the surface jet is used. Once the horizontal extents have been established, the transport is integrated over the entire water column between those two points. The results are shown in Figure 4.6. For NS, the jet transport remained between 0.20 to $0.32 \mathrm{~Sv}$ to the west, peaking in Dec/Jan and Aug/ Sep. The NS annual mean jet transport is $\sim 0.24$ Sv. Transport within the NJ jet was slightly smaller in magnitude (annual mean of $\sim 0.16 \mathrm{~Sv}$ ). A slight seasonal trend may be observed. The jet transport is a minimum during Dec/Jan, but increases steadily until peaking in Jun/Jul at $\sim 0.22 \mathrm{~Sv}$. In the fall the jet transport once again decreases. The GB jet transport is about twice the NS transport due primarily to the larger jet size, and peaked in Dec/Jan at $0.65 \mathrm{~Sv}$. The rest of the year it remained fairly constant at $0.42 \mathrm{~Sv}$ to the west, however. The GB annual mean westward transport is $\sim 0.45 \mathrm{~Sv}$. It is important to note that the definition of the jet used for transport calculations changes for each individ- 


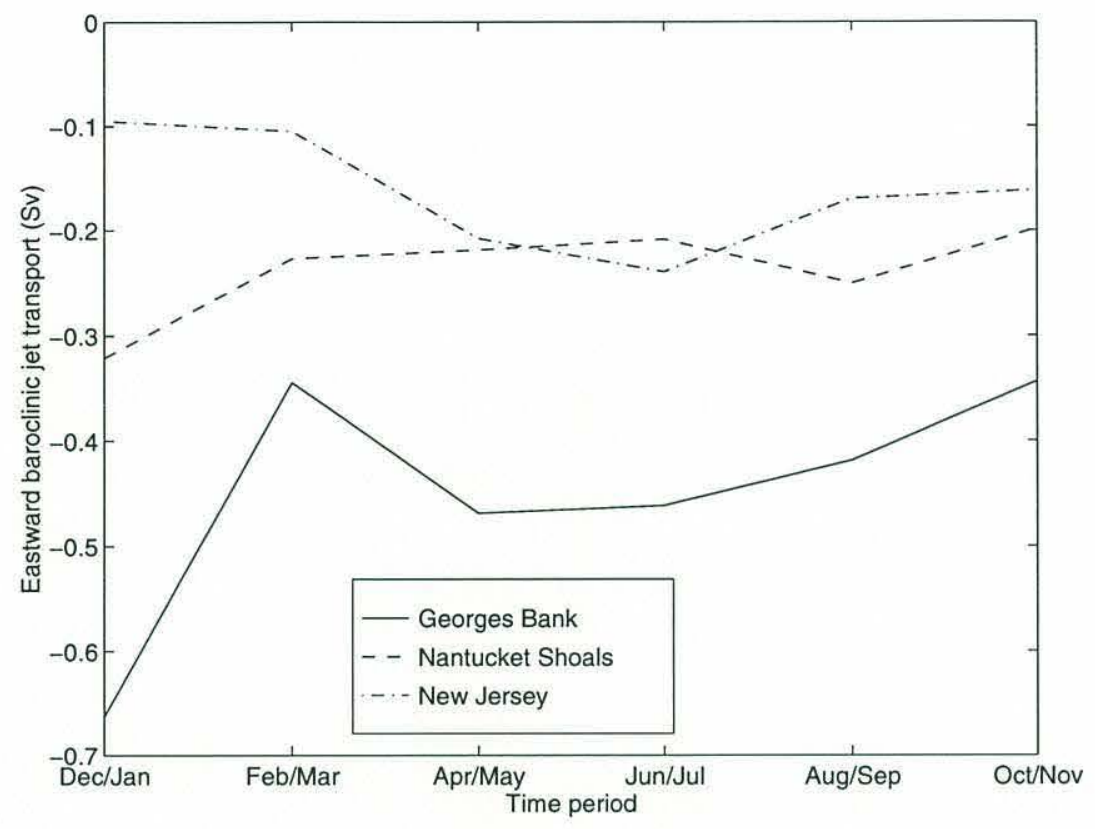

Figure 4.6: Baroclinic jet transport

ual case. Thus, the difference in transport between the regional subsets should not be used to infer onshore or offshore flows between the regions.

The shelf transport (defined from the $40 \mathrm{~m}$ isobath to the onshore edge of the jet) and jet transport (defined previously) have been calculated for the Feb/Mar and Aug/Sep NS cases, with the NSFE [Beardsley et al., 1983] bottom values included (see Figure 2.7). This revealed a westward shelf transport of $0.29 \mathrm{~Sv}$ for Feb/Mar and $0.18 \mathrm{~Sv}$ for Aug/Sep. Beardsley et al. [1985] observed a slightly higher annual mean shelf transport of $0.383 \mathrm{~Sv}$, likely corresponding to a greater cross-shelf integration range. The associated westward jet transports were $0.30 \mathrm{~Sv}$ (Feb/Mar) and $0.28 \mathrm{~Sv}$ (Aug/Sep). These values agree well with Gawarkiewicz et al. [in press], who computed a jet transport of $0.38 \mathrm{~Sv}$ from their synoptic ADCP section. The total shelf and jet transports are $0.59 \mathrm{~Sv}$ (Feb/Mar) and 0.46 
$\mathrm{Sv}$ (Aug/Sep). The percentage of the shelf plus jet transport that was due only to the jet is $51 \%$ for Feb/Mar and $61 \%$ for Aug/Sep. It is clear that the transport within the jet is of roughly the same order as the transport over the entire shelf. This observation shows the great impact the jet has on the total coastal alongshelf transport. Voorhis et al. [1976], in a study of the New England shelf current structure, postulated that the transport within the frontal region was highly baroclinic. Two geostrophic velocity sections were computed from density sections (relative to a level of no motion along the bottom) and revealed jet transports of 0.6 and $0.7 \mathrm{~Sv}$. These values are about twice the transport computed from the climatology, as expected. Voorhis et al. [1976] concluded that the baroclinic jet was responsible for $>70 \%$ of the shelf plus jet transport.

\subsection{Relative and potential vorticity}

Figure 4.7 shows the relative vorticity (upper panels), and shallow water potential vorticity (lower panels), computed from the regularly gridded geostrophic velocity sections shown in Figure 4.1. The relative vorticity field is dominated by the anticyclonic and cyclonic shears on the onshore and offshore sides of the shelfbreak jet, respectively. During Feb/Mar, the offshore relative vorticity core exceeds the onshore vorticity core by a factor of about 2, indicating a tighter offshore horizontal jet structure. Conversely, the onshore edge of the jet appears to be more horizontally diffuse. The shallow water potential vorticity undergoes abrupt seasonal changes relating directly to the thermohaline structure. During the winter, the potential vorticity is nearly uniform over the shelf and slope waters. However, during the summer, the vertical stratification term dominates and the potential vorticity structure mimics the temperature field, being highly stratified in the vertical. 

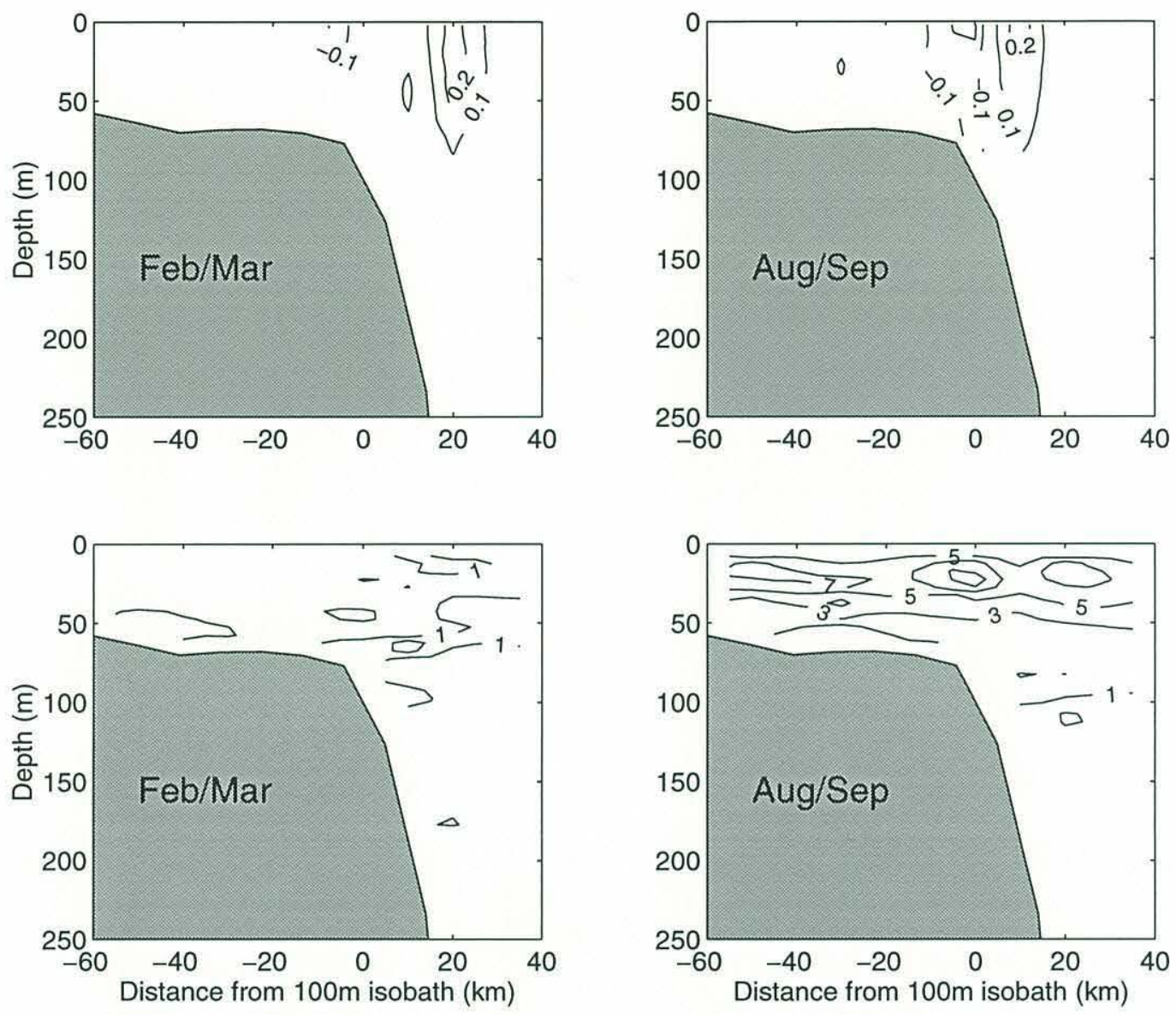

Figure 4.7: NS relative vorticity (upper, normalized by f) and potential vorticity (lower, units of $\mathrm{m}^{-1} \mathrm{~s}^{-1} \times 10^{-9}$ ) structure

Figure 4.8 shows the depth-averaged (5-25 m, upper and 45-65 m, lower) relative vorticity, normalized by $\mathrm{f}$. A local maximum in relative vorticity, reaching $0.08-0.09 * \mathrm{f}$ on average, is found on the shelf, corresponding to the secondary baroclinic jet observed in the previous section. The dominant feature in both the near surface and intermediate layers is the transition from the onshore anti-cyclonic shear to the offshore, cyclonic shear. Anticyclonic shears typically approach $-0.2 * \mathrm{f}$, while cyclonic shears vary from 0.2 to $0.4 * \mathrm{f}$. 

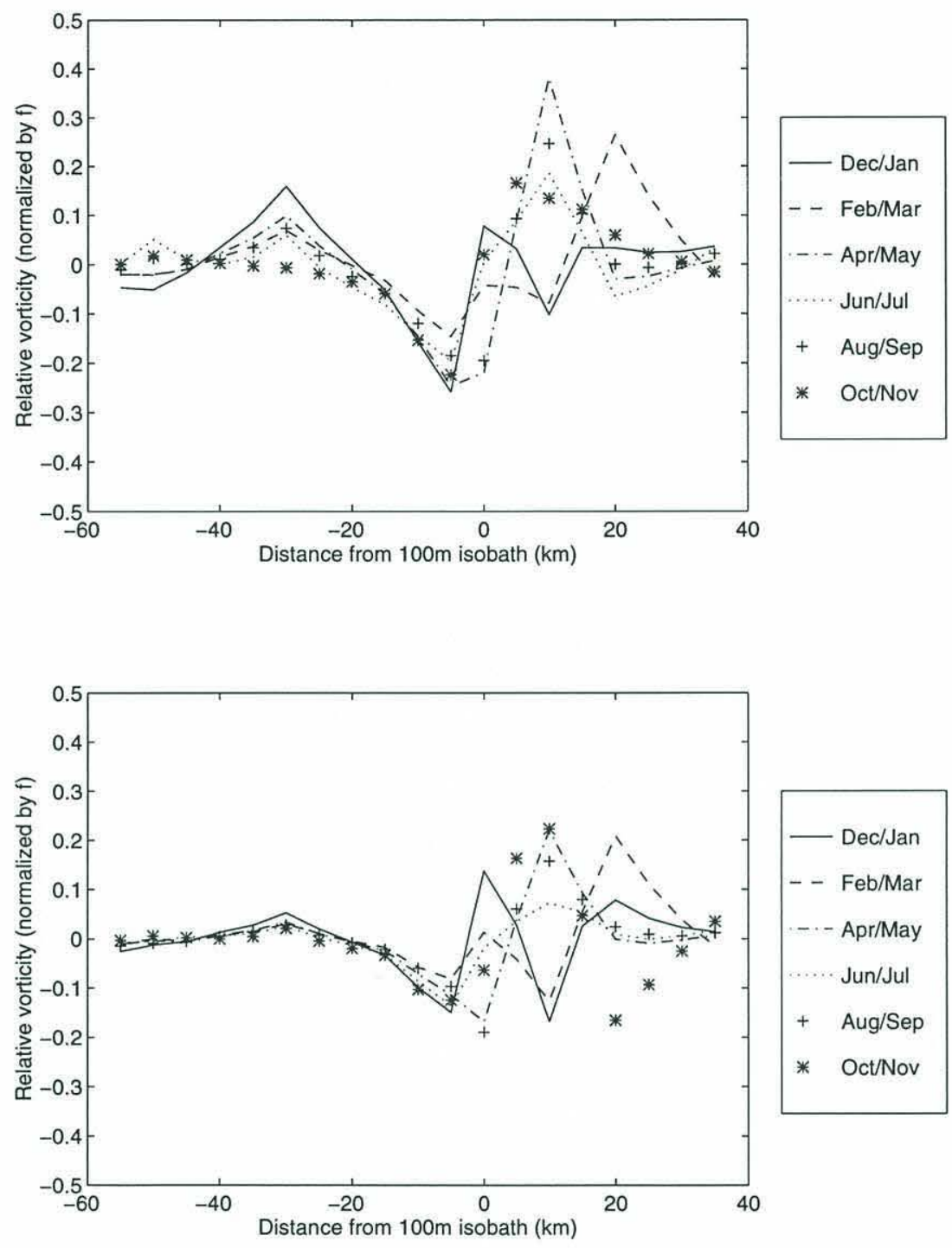

Figure 4.8: Depth averaged near surface (5-25 m, upper panel) and intermediate layer (45-65 m, lower panel) NS relative vorticity

In certain time periods (Apr/May, Aug/Sep, Feb/Mar), the offshore shear greatly exceeds the onshore shear. This situation, indicating that the onshore edge of the jet is more horizontally diffuse, has also been observed by Gawarkiewicz et al. [in press]. From an ADCP section, they estimated anti-cyclonic, or onshore relative vorticity to be roughly $-0.33 * \mathrm{f}$ 
and the cyclonic, offshore relative vorticity to be much greater, $0.96 * \mathrm{f}$. This is consistent with other comparisons with the climatology, which have shown that the climatology tends to smooth the dynamic results by a factor of 2-3. In all other climatological time periods, the onshore and offshore shears are relatively similar, indicating a uniform horizontal jet distribution. The intermediate layer plot shows that the frontal jet maintains its tight spatial distribution. Possible reasons for this were discussed in the previous section.

The depth-averaged shallow water potential vorticity is shown in Figure 4.9 (5-25 $\mathrm{m}$, upper and 45-65 m, lower). The near surface plot shows a clear dichotomy between the summer time periods (Jun/Jul and Aug/Sep) and the rest of the year. The strong vertical stratification dominates the potential vorticity, causing the summer periods to have a 3-4 times greater total potential vorticity than the winter, spring, and fall time periods. The contribution of the lateral velocity shear is also more apparent in the summer cases. The lower plot reveals a nearly uniform cross-shelf potential vorticity distribution. Seasonal variations are also small. Thus, while the vertical distribution of the shallow water potential vorticity is approximately constant in depth and cross-shelf distance for some time periods, during the summer the potential vorticity undergoes a rapid structural change. The potential vorticity becomes highly vertically stratified, mirroring the summertime density or thermal structure. These results have important implications for modelers. Condie [1993] has assumed uniform potential vorticity distributions over the shelf and slope, which may only be reasonable during winter conditions. 

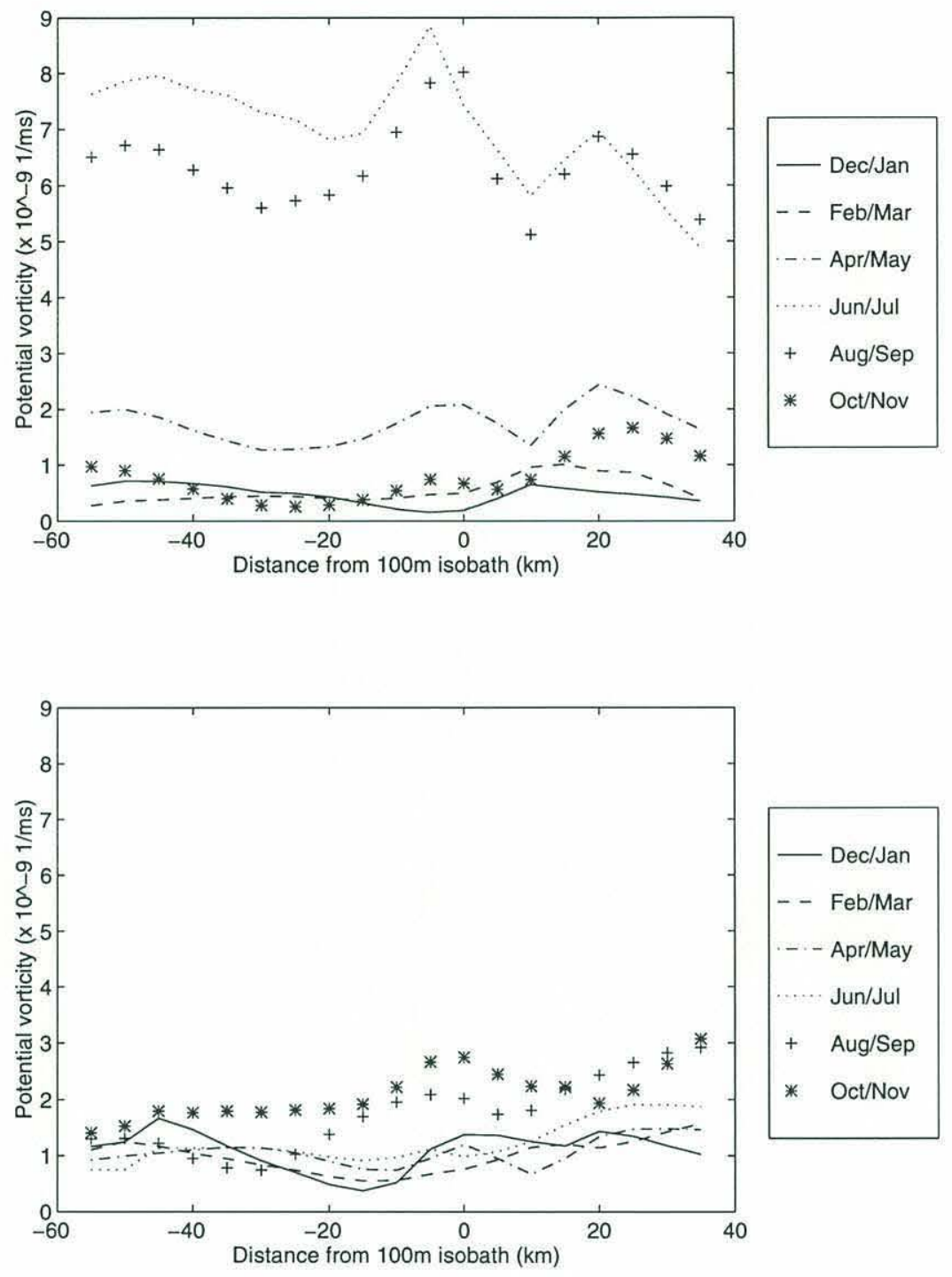

Figure 4.9: Depth averaged near surface (5-25 m, upper panel) and intermediate layer (45-65 m, lower panel) NS potential vorticity 


\section{Chapter 5}

\section{Conclusions}

\subsection{Comparisons with established results}

\subsubsection{TEMPEST surface temperature}

Using Northeast Fisheries Center Marine Resources Monitoring, Assessment, and Prediction (MARMAP) data from 1977-1987, Mountain [1989] has created a program which estimates the surface or bottom temperature at any location from Cape Hatteras to the Gulf of Maine for any day of the year. The program fits an annual curve to the observed data using a multiple regression model with three harmonic sine components.

Five MARMAP stations within the Nantucket shoals study region (39-41 ${ }^{\circ} \mathrm{N}, 69$ $72^{\circ} \mathrm{W}$ ) in a cross-isobath transect have been selected to evaluate the climatology. The station spacing is $\sim 30 \mathrm{~km}$ on average. For these five stations, the midpoint date of each bimonthly period (e.g. Jan 1 for Dec/Jan, Mar 1 for Feb/Mar, etc.) was used to compare to the climatological fields. Figure 5.1 shows the cross-shelf temperature and standard deviation for the NS 5-15 m vertical depth bins. Overplotted is the surface temperature predicted by Mountain's [1989] program. In every case the curves appear very similar qualitatively, and the standard deviations consistently overlap. Standard deviations are notably higher in summer. This is caused by two effects: alongshelf advection of alongshelf gradients [Burrage and Garvine, 1988] and also simply the large natural variation in near surface temperature between early June and late July, or early August and late September. In the winter months, when the water column is vertically well-mixed, the agreement is very good and the standard deviations relatively small, with the temperature 
difference between the climatology and TEMPEST being a maximum of $\pm 1{ }^{\circ} \mathrm{C}$. In the summer months, when the surface thermocline is prevalent, Mountain's [1989] temperatures (computed for the surface) were on the average $2-3^{\circ} \mathrm{C}$ higher than the climatological values taken at a mean depth of $10 \mathrm{~m}$ ), which is a reasonable and expected difference. The good agreement lends further credibility to the climatological fields.

\subsection{2 "Synoptic" SEEP thermohaline fields}

Winter and summer SEEP II [Houghton et al., 1988] sections have also been used to assess the climatology. The near surface $(\sim 10 \mathrm{~m}$ depth $)$ and intermediate layer $(\sim 50 \mathrm{~m}$ depth) points from both March and July cruises have been extracted to compare the mean and standard deviation of the Feb/Mar and Jun/Jul climatological fields, respectively. Figure 5.2 shows a comparison of the near surface (upper panels) and intermediate layer (lower panels) for the winter case. The plots show an extremely good correlation in temperature but poorer agreement in salinity for both depths. One possible explanation of this relative freshness in the SEEP II data is that it is a result of an interannual variation in the salinity. Manning [1991] observed that, although the temperature experienced relatively few interannual deviations, the salinity underwent large changes based primarily on local meteorological effects. Gawarkiewicz et al. [submitted] have observed a large scale penetration of extremely saline water on the New England shelf. They postulated that this intrusion may have been due to recent local drought conditions. Figure 5.3 shows the same analysis repeated for a 1 July 1988 cruise. Here the temperature and salinity show remarkably close correlation, especially in the intermediate depth band. 

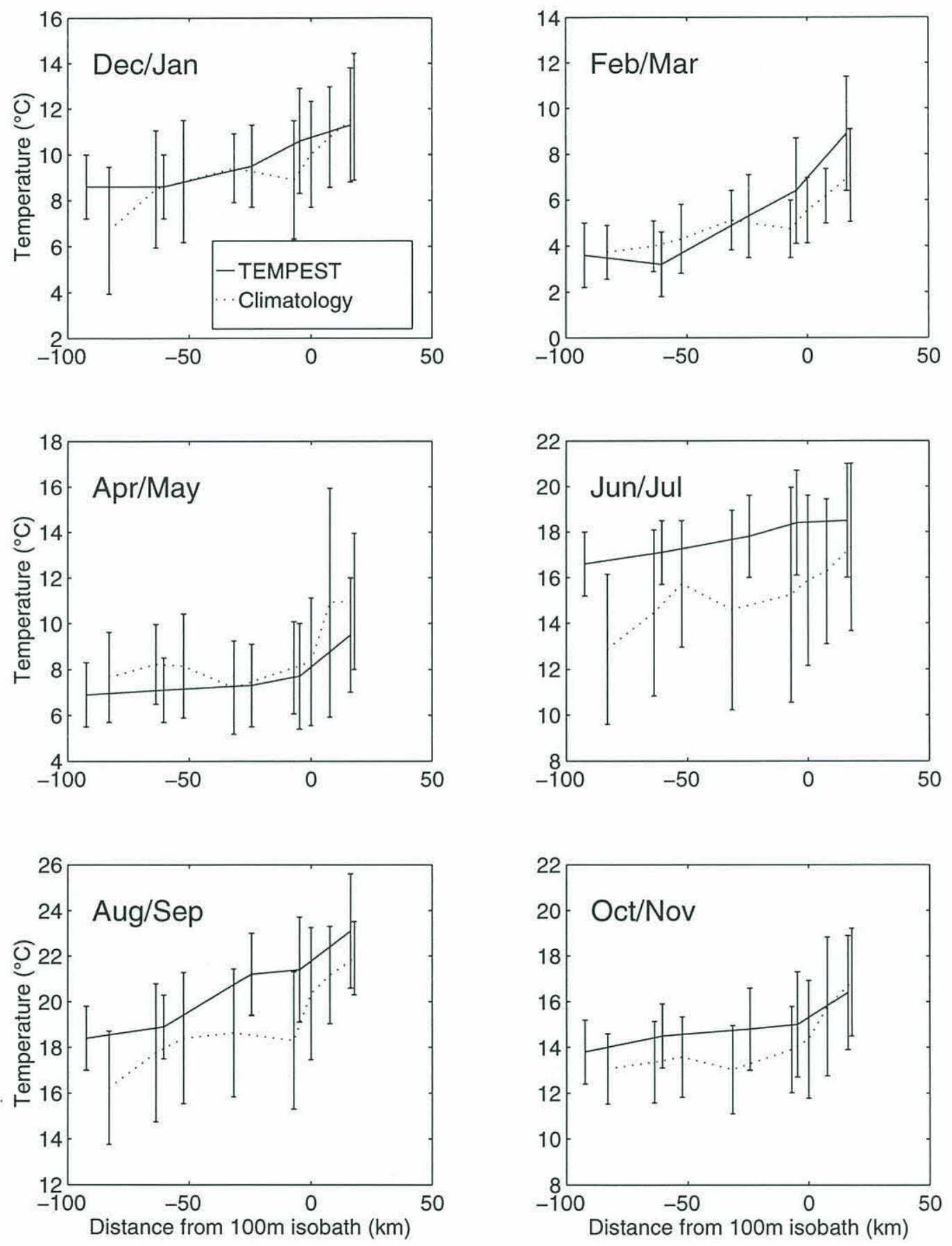

Figure 5.1: Comparison of NS climatology near surface temperature (5-15 m) and TEMPEST [Mountain, 1989] surface temperature 

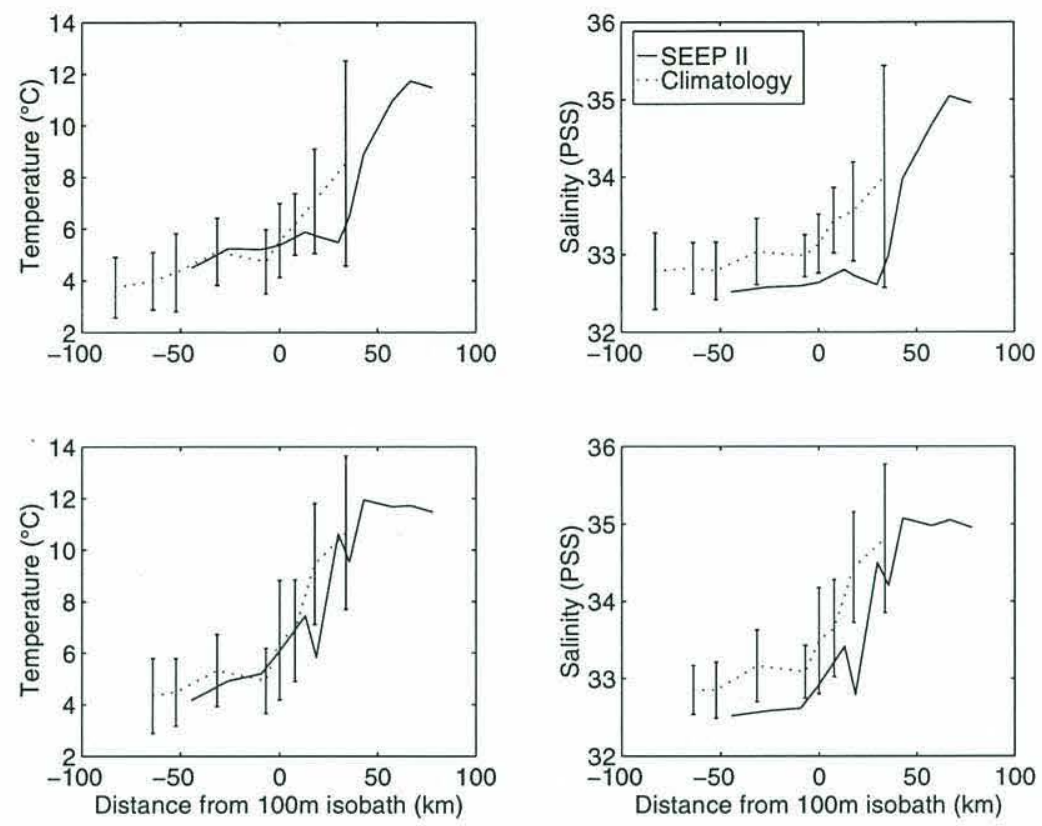

Figure 5.2: Comparison of NS climatology and SEEP II winter near surface (upper plots, 5-15 m) and intermediate layer (lower plots, 45-55 m) temperature and salinity
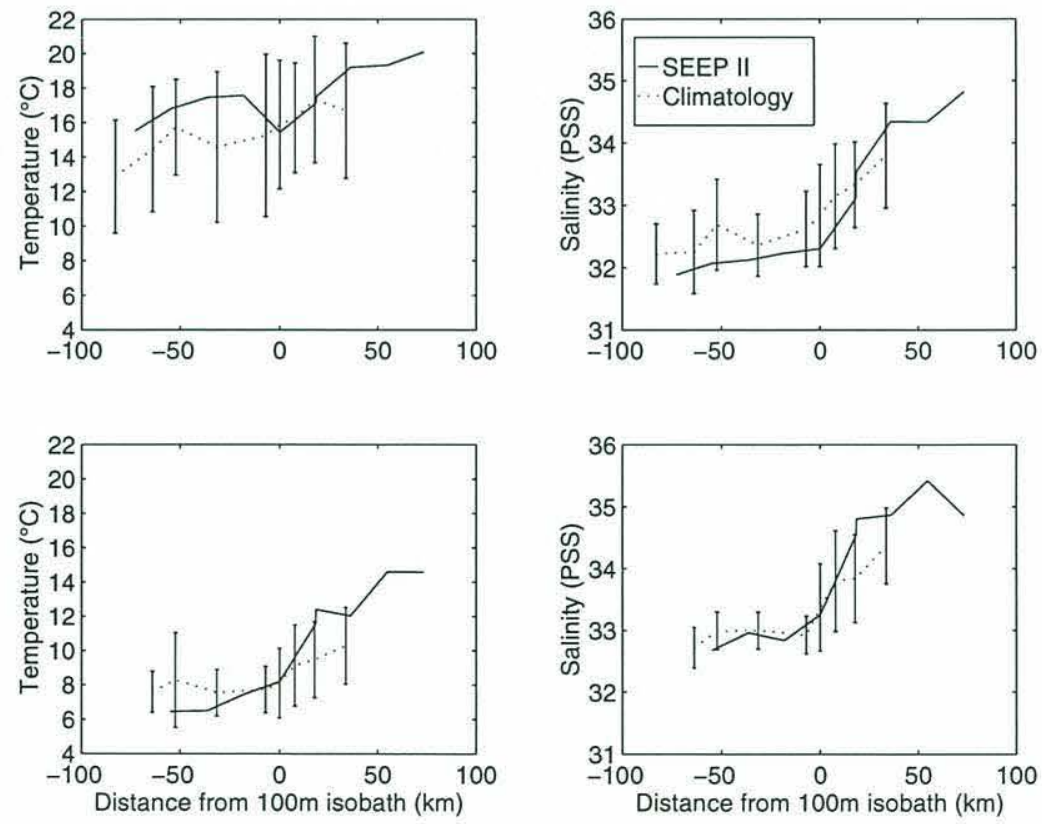

Figure 5.3: Comparison of NS climatology and SEEP II summer near surface (upper plots, 5-15 m) and intermediate layer (lower plots, 45-55 m) temperature and salinity 


\subsection{Limitations and implications}

This climatology has synthesized of over 90 years of hydrographic measurements in the Middle Atlantic Bight using a depth bin averaging method. The products of this climatology have shown close agreement with previously published climatologies, modeling efforts, and synoptic observations. However, this climatology suffers from several limitations. Firstly, an assumption inherent to any climatology is that interannual variability is minimal compared to the seasonal cycle. Although the temperature follows a well regulated seasonal cycle, Manning [1991] showed that for the MAB salinity, large interannual fluctuations are superimposed on the seasonal cycle. He attributed $70 \%$ of this interannual variation to local river runoff and precipitation. Secondly, slope water averaging results should also be interpreted with caution. This region experiences large temperature and salinity fluctuations associated with the interaction of slope water, warm core rings, and the Gulf Stream. A combination of warm core ring water data and slope water data could produce a water mass which never exists. Ideally, several climatologies should be produced to show the varied states of the shelfbreak front. However, the limited amount of data points, which is accentuated beyond the $500 \mathrm{~m}$ isobath, prohibits a study of this nature at this time. Thirdly, this study was limited by its two dimensional nature. Chapman and Beardsley's [1989] $\mathrm{O}^{18}$ analysis has shown how the mean flow through the MAB is part of a large coastal current system. Thus, any changes to an upstream portion of the current system would eventually be advected far downstream. The inclusion of the two other study regions, GB and NJ, has attempted to provide a more accurate, three dimensional, representation of the MAB. The lag in frontal migration found between NS and NJ lends further support to this three dimensional argument. 
Despite its limitations, the climatology is useful in showing the first order features of the two dimensional frontal hydrography and dynamics. In that respect, this work has quantitatively and qualitatively shown the dramatic seasonal shift in cross-frontal hydrography. The cross-frontal gradients in temperature and salinity are at least a factor of 2 times weaker than those observed in synoptic sections, reflecting some data smearing. The surface layer gradients are noticeably less than deeper layers, possibly indicating increased smearing due to increased cross-shelf movement of the surface frontal outcrop. The climatology has shown the seasonal migration of the front through plots of the crossshelf salinity structure. The Nantucket Shoals region front is observed to progress offshore during the spring and summer, reaching a maximum offshore distance during Jun/Jul before migrating onshelf again.

The foot of the front was shown to be the region of strongest horizontal density gradients and thus an important component to the vertical velocity shear. A modeling analysis by Gawarkiewicz and Chapman [1992] of the frontogenesis mechanism also addressed the strengthening of horizontal gradients at the foot of the front. Using a primitive equation model, Gawarkiewicz and Chapman [1992] studied the downstream evolution of a horizontally sheared flow. The model fluid was initially vertically stratified, with no horizontal density gradients present. They found that an offshore flow initiated in the bottom boundary layer, advecting light water under heavier water near the shelfbreak. Convective overturning acted to homogenize the shelf water mass, establishing a horizontal density gradient, or front, which was concentrated near the shelfbreak. The strong gradients the climatology has revealed near the foot of the front lend greater support to this frontogenesis mechanism. 
The climatology has quantified the seasonal and spatial structure of the baroclinic jet. Very small ( $20 \mathrm{~km}$ for NS) mean horizontal jet scales have been found in the climatology, explaining why previous direct observations have been limited. The climatology has also brought to light interesting questions about the role of the shelfbreak frontal jet in the transport of water along the shelf. Rough calculations have shown the jet to be of equal importance as the shelf to the alongshore transport. This large jet transport could also be responsible for the large volumes of water Garfield and Evans [1987] have observed being entrained by Gulf Stream warm core rings. It is hoped that this work will be used as a reference point by which the extreme variability of synoptic sections can be compared in a quantitative sense. 


\section{References}

Aikman, F. III, Pycnocline development and its consequences in the Middle Atlantic Bight, Journal of Geophysical Research, 89(C1), 685-694, 1984.

Aikman, F. III, H. W. Ou, and R. W. Houghton, Current variability across the New England continental shelf-break and slope, Continental Shelf Research, 8, 625-651, 1988.

Beardsley, R. C. and W. C. Boicourt, On estuarine and continental -shelf circulation in the Middle Atlantic Bight, in Evolution of Physical Oceanography, B. Warren and C. Wunsch, Eds., MIT Press, Cambridge, Massachusetts, Chapter 7, 1981.

Beardsley, R. C., D. C. Chapman, K. H. Brink, S. R. Ramp, and R. Schlitz, The Nantucket Shoals Flux Experiment (NSFE79) Part I: A basic description of the current and temperature variability, Journal of Physical Oceanography, 15(6), 713-748, 1985.

Beardsley, R. C., and C. N. Flagg, The water structure, mean currents, and shelf/slope water front on the New England continental shelf. Mémoires de la Société Royale des Sciences de Liège, ser. 6(X), 209-225, 1976.

Beardsley, R. C., C. A. Mills, J. A. Jermersch, Jr., W. S. Brown, N. Pettigrew, J. Irish, S. Ramp, R. Schlitz, and B. Butman, Nantucket Shoals Flux Experiment (NSFE79) Part 2: Moored Array Data Report. WHOI Technical Report No. WHOI-83-13, 140 pp., 1983.

Bigelow, H. B., Studies of the waters on the continental shelf, Cape Cod to Chesapeake Bay: I, The cycle of temperature, Papers in Physical Oceanography and Meteorology, 2, 1-135, 1933.

Bue, C. D., Stream flow from the United States into the Atlantic Ocean during 1931-60, U.S. Geological Survey Water-Supply Paper 1899-1, Washington, D.C., 36 pp., 1970.

Burrage, D. M. and R. W. Garvine, Summertime hydrography at the shelfbreak front in the Middle Atlantic Bight, Journal of Physical Oceanography, 18, 1309-1319, 1988.

Chapman, D. C., J. A. Barth, R. C. Beardsley, and R. G. Fairbanks, On the continuity of the mean flow between the Scotian Shelf and the Middle Atlantic Bight, Journal of Physical Oceanography, 16(4), 758-772, 1986.

Chapman, D. C. and R. C. Beardsley, On the origin of shelf water in the Middle Atlantic Bight, Journal of Physical Oceanography, 19(3), 384-391, 1989.

Condie, S. A., Formation and stability of shelf break fronts, Journal of Geophysical Research, 98(C7), 12,405-12,416, 1993.

Curry, R. G., Hydrobase: A Database of Hydrographic Stations and Tools for Climatological Analysis. WHOI Technical Report No. WHOI-96-01, 50 pp., 1996.

Drinkwater, K. F., R. A. Meyers, R. G. Pettipas, and T. L. Wright, Climatic Data for the 
Northwest Atlantic: The Position of the Shelf/Slope Front and the Northern Boundary of the Gulf Stream Between 50 W and 75 W, 1973-1992, Canadian Data Report of Fisheries and Ocean Sciences 125, 103 pp., 1994.

Flagg, C. N., Hydrographic structure and variability, in Georges Bank, R. Backus, Ed., MIT Press, 108-124, 1987.

Flagg, C. N., B. A. Magnell, D. Frye, J. J. Cura, S. E. McDowell, and R. I. Scarlet, Interpretation of the physical oceanography of Georges Bank, final report, vol. I. Prepared for the New York OCS Office, Bureau of Land Management, by EG\&G Environmental Consultants, Waltham, Massachusetts, 1982.

Fofonoff, P., and R. C. Millard, Jr., Algorithms for computation of fundamental properties of seawater, Unesco Technical Papers in Marine Science, 44, 53 pp., 1983.

Garfield, N. III, and D. L. Evans, Shelf water entrainment by Gulf Stream warm-core rings, Journal of Geophysical Research, 92(C12), 13,003-13,0012, 1987.

Gawarkiewicz, G. G., and D. C. Chapman, The role of stratification in the formation and maintenance of shelf-break fronts, Journal of Physical Oceanography, 22(7), 753$772,1992$.

Gawarkiewicz, G. G., T. M. Church, G. W. Luther III, T. G. Ferdelman, and M. Caruso, Large-scale penetration of Gulf Stream water onto the continental shelf north of Cape Hatteras, Geophysical Research Letters, 19(4), 373-376, 1992.

Gawarkiewicz, G. G., T. G. Ferdelman, T. M. Church, and G. W. Luther III, Shelfbreak frontal structure on the continental shelf north of Cape Hatteras, submitted to Geophysical Research Letters.

Gawarkiewicz, G. G., C. A. Linder, J. F. Lynch, A. Newhall, and J. J. Bisagni, A surfacetrapped intrusion of slope water onto the continental shelf in the Middle Atlantic Bight, submitted to Geophysical Research Letters.

Halliwell, G., and C. Mooers, The space-time structure and variability of the shelf-slope water and Gulf Stream surface temperature fronts and associated warm-core eddies, Journal of Geophysical Research, 84(C12), 7707-7725, 1979.

Houghton, R. W., F. Aikman III, and H. W. Ou, Shelf-slope frontal structure and crossshelf exchange at the New England shelf-break, Continental Shelf Research, 8, 687$710,1988$.

Houghton, R. W., R. Schlitz, R. C. Beardsley, B. Butman, and J. L. Chamberlin, The Middle Atlantic Bight cold pool: evolution of the temperature structure during summer 1979, Journal of Physical Oceanography, 12, 1019-1029, 1982.

Limeburner, R., and R. C. Beardsley, The seasonal hydrography and circulation over Nantucket Shoals, Journal of Marine Research, 40, 371-406, 1982.

Lozier, M. S., M. McCartney, and W. B. Owens, Anomalous anomalies in averaged hydrographic data, Journal of Physical Oceanography, 24(12), 2624-2638, 1994. 
Manning, J., Middle Atlantic Bight salinity: interannual variability, Continental Shelf Research, 11(2), 123-137, 1991.

Marra, J., R. W. Houghton, and C. Garside, Phytoplankton growth at the shelf-break front in the Middle Atlantic Bight, Journal of Marine Research, 48, 851-868, 1990.

Mountain, D. G., TEMPEST: A Computer Program for Estimating Temperature on the Northeast Continental Shelf. Northeast Fisheries Center Reference Document 89-02, 8 pp., 1989.

$\mathrm{Ou}, \mathrm{H}$. W., Some two-layer models of the shelf-slope front: geostrophic adjustment and its maintenance, Journal of Physical Oceanography, 13, 1798-1808, 1983.

Ou, H. W., Geostrophic adjustment: a mechanism for frontogenesis, Journal of Physical Oceanography, 14, 994-1000, 1984.

Pickart, R. S., Space-time variability of the deep western boundary current oxygen core, Journal of Physical Oceanography, 22(9), 1047-1061, 1992.

Voorhis, A. D., D. C. Webb, and R. C. Millard, Current structure and mixing in the shelf/ slope water front south of New England, Journal of Geophysical Research, 81, 36953708, 1976.

Wang, D-P., Mutual intrusion of a gravity current and density front formation, Journal of Physical Oceanography, 14, 1191-1199, 1984.

Wessel, P. and W. H. F. Smith, Free software helps map and display data, Eos Tranactions $A G U, 72,441,445-446,1991$.

Wright, W. R., The limits of shelf water south of Cape Cod, 1941 to 1972, Journal of Marine Research, 34(1), 1-14, 1976.

Wright, W. R. and C. E. Parker, A volumetric temperature/salinity census for the Middle Atlantic Bight, Limnology and Oceanography, 21, 563-571, 1976. 
